\title{
Small-Scale Testing of Plutonium(IV) Oxalate Precipitation and Calcination to Plutonium Oxide to Support the MOX Feed Mission
}

M. L. Crowder

R. A. Pierce

J. H. Scogin

W. E. Daniel

W. D. King

June 2012

Savannah River National Laboratory

Savannah River Nuclear Solutions, LLC

Aiken, SC 29808

Prepared for the U.S. Department of Energy under contract number DE-AC09-08SR22470. 
SRNL-STI-2012-00338

Revision 0

\section{DISCLAIMER}

This work was prepared under an agreement with and funded by the U.S. Government. Neither the U.S. Government or its employees, nor any of its contractors, subcontractors or their employees, makes any express or implied:

1. warranty or assumes any legal liability for the accuracy, completeness, or for the use or results of such use of any information, product, or process disclosed; or

2. representation that such use or results of such use would not infringe privately owned rights; or

3. endorsement or recommendation of any specifically identified commercial product, process, or service.

Any views and opinions of authors expressed in this work do not necessarily state or reflect those of the United States Government, or its contractors, or subcontractors.

\section{Printed in the United States of America}

Prepared for

U.S. Department of Energy 


\section{Small-Scale Testing of Plutonium(IV) Oxalate Precipitation and Calcination to Plutonium Oxide to Support the MOX Feed Mission}

M. L. Crowder

R. A. Pierce

J. H. Scogin

W. E. Daniel

W. D. King

June 2012

Savannah River National Laboratory

Savannah River Nuclear Solutions, LLC

Aiken, SC 29808

Prepared for the U.S. Department of Energy under contract number DE-AC09-08SR22470. 
SRNL-STI-2012-00338

Revision 0

\section{REVIEWS AND APPROVALS}

AUTHORS:

M. L. Crowder, Separation \& Actinide Science Programs

Date

R. A. Pierce, Separation \& Actinide Science Programs

Date

J. H. Scogin, Separation \& Actinide Science Programs

Date

W. E. Daniel, Engineering Process Development

Date

W. D. King, Advanced Characterization \& Processing

Date

TECHNICAL REVIEW:

K. M. L. Taylor-Pashow, Reviewer, Separation \& Actinide Science Programs Date

J. E. Therrell, Reviewer, HB-Line Engineering

Date

\section{APPROVAL:}

S. D. Fink, Manager

Date

Separation \& Actinide Science Programs

Date

S. L. Marra, Manager

Environmental \& Chemical Process Technology Research Programs

K. P. Burrows, Manager

Date

HB-Line Engineering 


\section{ACKNOWLEDGEMENTS}

The authors acknowledge excellent analytical support from David Missimer for particle size analysis, David DiPrete, Cecilia DiPrete and Mira Malek for radiochemical analysis, Mark Jones for ICPMS analysis, Boyd Wiedenman for ICPES analysis, Tom White for ion chromatograpy analysis, and Amy Ekechukwu for acid analysis.

As lead author, I thank my co-authors for their key contributions, but recognize that I bear responsibility for inadequacies in this report.

In addition, I acknowledge the helpfulness of Jon Duffey and Eddie Kyser in technical discussions and experimental planning and Sam Fink in recruiting great teammates and providing wise technical and project guidance. 
SRNL-STI-2012-00338

Revision 0

\section{EXECUTIVE SUMMARY}

The H-Canyon facility will be used to dissolve $\mathrm{Pu}$ metal for subsequent purification and conversion to plutonium dioxide $\left(\mathrm{PuO}_{2}\right)$ using Phase II of HB-Line. To support the new mission, SRNL conducted a series of experiments to produce calcined plutonium (Pu) oxide and measure the physical properties and water adsorption of that material. This data will help define the process operating conditions and material handling steps for HB-Line.

An anion exchange column experiment produced $1.4 \mathrm{~L}$ of a purified $52.6 \mathrm{~g} / \mathrm{L}$ Pu solution. Over the next nine weeks, seven $\mathrm{Pu}(\mathrm{IV})$ oxalate precipitations were performed using the same stock $\mathrm{Pu}$ solution, with precipitator feed acidities ranging from $0.77 \mathrm{M}$ to $3.0 \mathrm{M}$ nitric acid and digestion times ranging from 5 to 30 minutes. Analysis of precipitator filtrate solutions showed Pu losses below $1 \%$ for all precipitations. The four larger precipitation batches matched the target oxalic acid addition time of 44 minutes within 4 minutes. The three smaller precipitation batches focused on evaluation of digestion time and the oxalic acid addition step ranged from 25-34 minutes because of pump limitations in the low flow range.

Following the precipitations, 22 calcinations were performed in the range of $610-690{ }^{\circ} \mathrm{C}$, with the largest number of samples calcined at either 650 or $635^{\circ} \mathrm{C}$. Characterization of the resulting $\mathrm{PuO}_{2}$ batches showed specific surface areas in the range of 5-14 m²/g, with 16 of the 22 samples in the range of $5-10 \mathrm{~m}^{2} / \mathrm{g}$. For samples analyzed with typical handling (exposed to ambient air for 15-45 minutes with relative humidities of $20-55 \%$ ), the moisture content as measured by Mass Spectrometry ranged from 0.15 to $0.45 \mathrm{wt} \%$ and the total mass loss at $1000{ }^{\circ} \mathrm{C}$, as measured by TGA, ranged from 0.21 to 0.58 wt \%. For the samples calcined between 635 and $650{ }^{\circ} \mathrm{C}$, the moisture content without extended exposure ranged from 0.20 to $0.38 \mathrm{wt} \%$, and the TGA mass loss ranged from 0.26 to $0.46 \mathrm{wt} \%$. Of these latter samples, the samples calcined at $650{ }^{\circ} \mathrm{C}$ generally had lower specific surface areas and lower moisture contents than the samples calcined at $635^{\circ} \mathrm{C}$, which matches expectations from the literature.

Taken together, the TGA-MS results for samples handled at nominally 20-50\% RH, without extended exposure, indicate that the $\mathrm{Pu}(\mathrm{IV})$ oxalate precipitation process followed by calcination at $635-650{ }^{\circ} \mathrm{C}$ appears capable of producing $\mathrm{PuO}_{2}$ with moisture content $<0.5 \mathrm{wt} \%$ as required by the 3013 Standard.

Exposures of $\mathrm{PuO}_{2}$ samples to ambient air for 3 or more hours generally showed modest mass gains that were primarily gains in moisture content. These results point to the need for a better understanding of the moisture absorption of $\mathrm{PuO}_{2}$ and serve as a warning that extended exposure times, particularly above the $50 \% \mathrm{RH}$ level observed in this study will make the production of $\mathrm{PuO}_{2}$ with less than 0.5 wt \% moisture more challenging. Samples analyzed in this study generally contained approximately 2 monolayer equivalents of moisture.

In this study, the bulk of the moisture released from samples below $300{ }^{\circ} \mathrm{C}$, as did a significant portion of the $\mathrm{CO}_{2}$. Samples in this study consistently released a minor amount of NO in the 40$300{ }^{\circ} \mathrm{C}$ range, but no samples released $\mathrm{CO}$ or $\mathrm{SO}_{2}$. TGA-MS results also showed that MS moisture content accounted for $80 \pm 8 \%$ of the total mass loss at $1000{ }^{\circ} \mathrm{C}$ measured by the TGA.

The $\mathrm{PuO}_{2}$ samples produced had particles sizes that typically ranged from $0.2-88 \mu \mathrm{m}$, with the mean particle size ranging from $6.4-9.3 \mu \mathrm{m}$. The carbon content of ten different calcination batches ranged from 190-480 $\mu \mathrm{g} \mathrm{C/g} \mathrm{Pu,} \mathrm{with} \mathrm{an} \mathrm{average} \mathrm{value} \mathrm{of} 290 \mu \mathrm{g} \mathrm{C/g} \mathrm{Pu.}$ 
A statistical review of the calcination conditions and resulting SSA values showed that in both cases tested, calcination temperature had a significant effect on SSA, as expected from literature data. The statistical review also showed that batch size had a significant effect on SSA, but the narrow range of batch sizes tested is a compelling reason to set aside that result until tests with larger batch sizes are completed. When feed acidity was not included as a variable, calcination time had a significant effect on SSA. However, including feed acidity as a variable showed that neither feed acidity nor calcination time had a significant effect on SSA in this study. Also, for both cases the statistical review also indicated that digestion time did not have a significant effect on SSA. 


\section{TABLE OF CONTENTS}

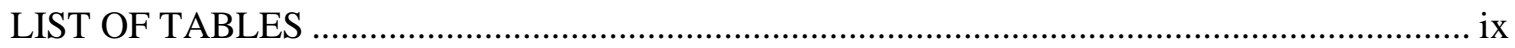

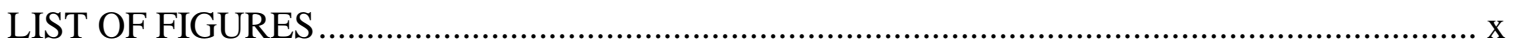

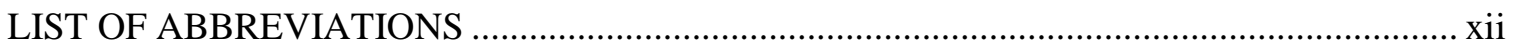

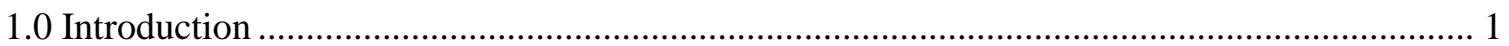

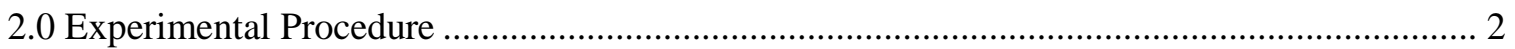

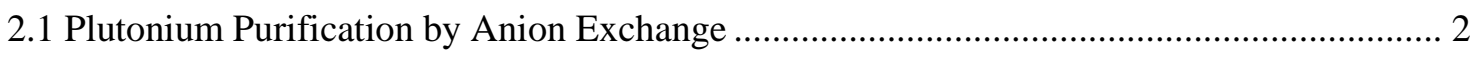

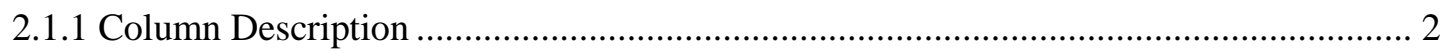

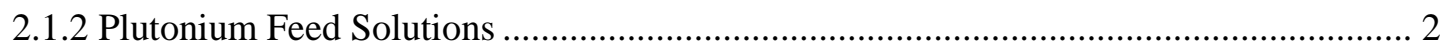

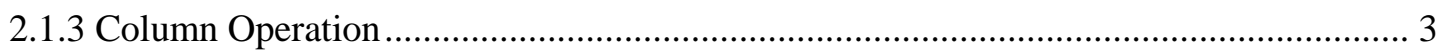

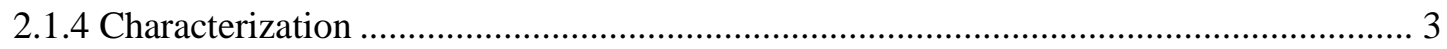

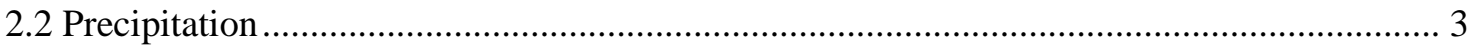

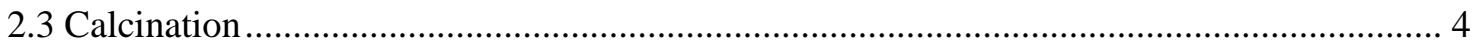

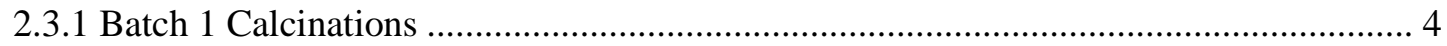

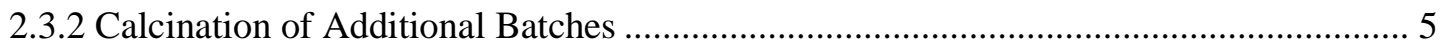

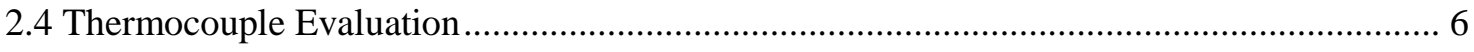

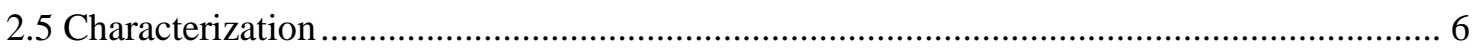

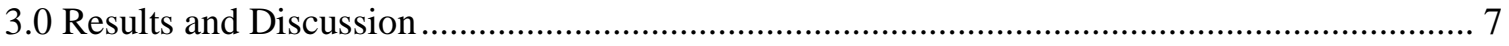

3.1 Plutonium Purification by Anion Exchange ........................................................................ 7

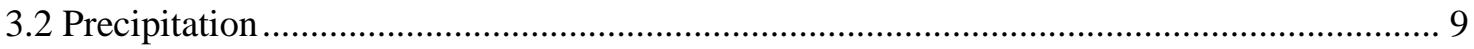

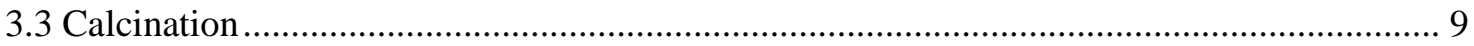

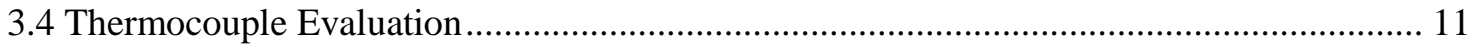

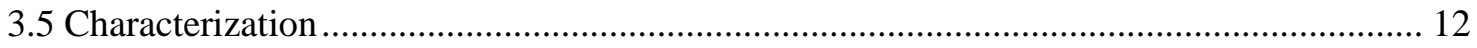

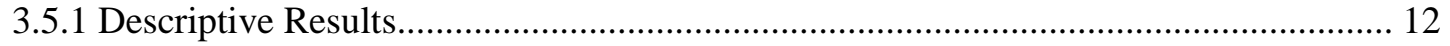

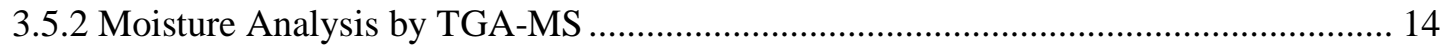

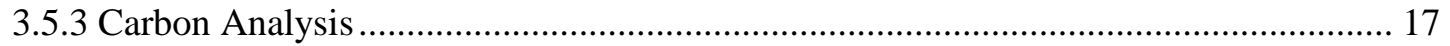

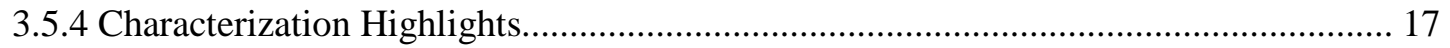

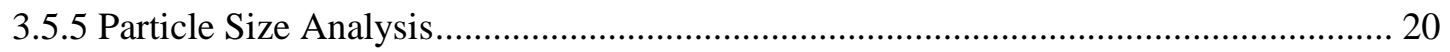

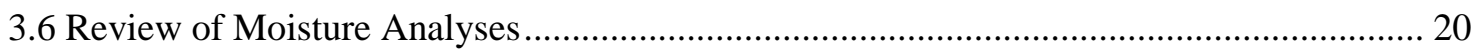

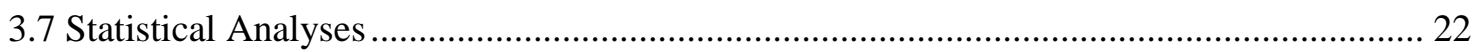

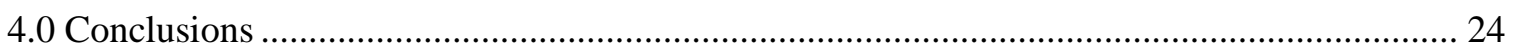

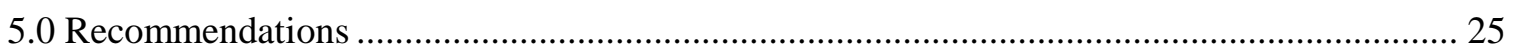

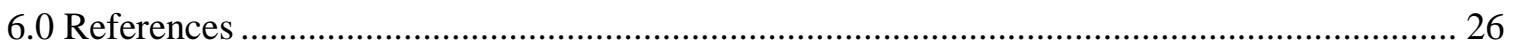




\section{LIST OF TABLES}

Table 2-1. BET Specific Surface Area for $\mathrm{NpO}_{2}$. .................................................................... 4

Table 2-2. Target Calcination Conditions for Pu Oxalate Batches. .............................................. 5

Table 3-1. Impurity Contents of Pu Product Solution ................................................................ 8

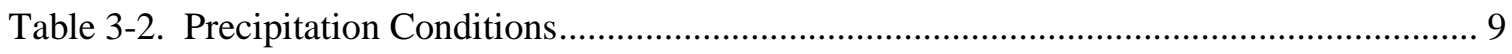

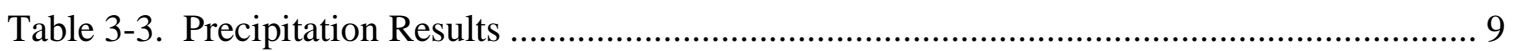

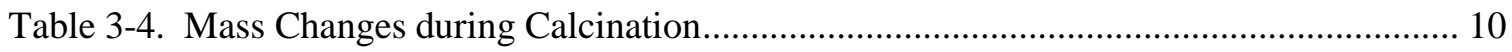

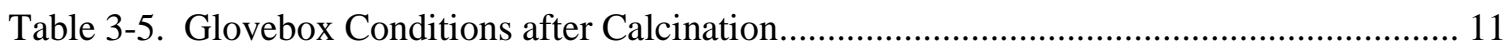

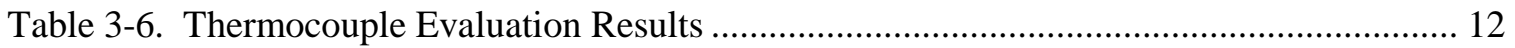

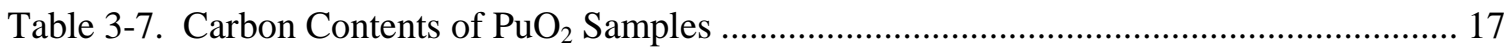

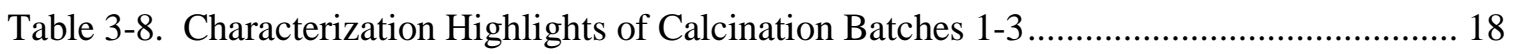

Table 3-9. Characterization Highlights of Additional Calcination Batches ................................. 19

Table 3-10. Particle Size Analyses of $\mathrm{PuO}_{2}$ Samples............................................................... 20

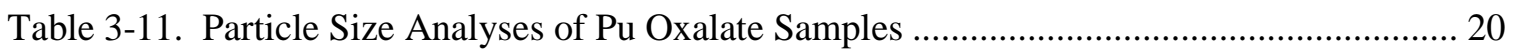

Table 3-12. Relations Between MS Moisture, TGA, and SSA ................................................. 21

Table 3-13. Summary of Data for Statistical Analysis .............................................................. 22

Table 3-14. Statistical Summary of Fit - Case 1: All Data, 4 Parameters ................................. 23

Table 3-15. Statistical Parameter Estimate - Case 1: All Data, 4 Parameters............................... 23

Table 3-16. Statistical Summary of Fit - Case 2: Omit Batch 1 Data, 5 Parameters ................... 23

Table 3-17. Statistical Parameter Estimate - Case 2: Omit Batch 1 Data, 5 Parameters ............ 23

Table A-1. Anion Exchange Results for Pu and Am............................................................ A-2

Table A-2. Impurity Contents in Anion Exchange Feed by ICPES ....................................... A-2

Table A-3. Uncertainties in MS Moisture Contents................................................................ A-4

Table A-4. Specific Surface Area Measurements with Uncertainties. ..................................... A-5 


\section{LIST OF FIGURES}

Figure 2-1. Crucible Holder Used for Calcinations..................................................................... 5

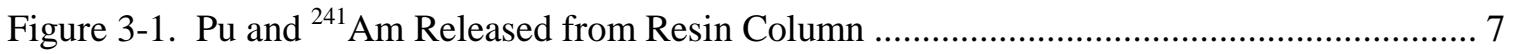

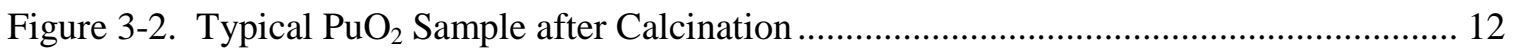

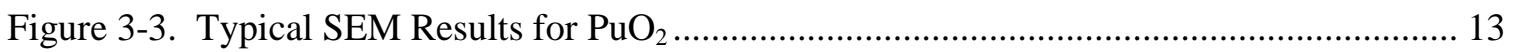

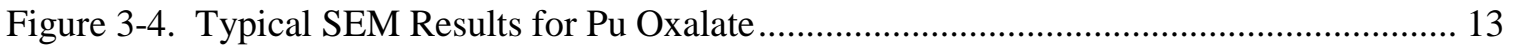

Figure 3-5. TGA Mass Measurements for Sample B3-1a ....................................................... 14

Figure 3-6. MS Signals (linear scale) from TGA-MS Analysis of Sample B3-1a ....................... 14

Figure 3-7. MS Signals (logarithmic scale) from TGA-MS Analysis of Sample B3-1a.............. 15

Figure 3-8. MS Signals (linear scale) from TGA-MS Analysis of Sample B4-1b...................... 16

Figure 3-9. MS Signals (logarithmic scale) from TGA-MS Analysis of Sample B4-1b.............. 16

Figure A-1. MS Signals (linear scale) from TGA-MS Analysis of Sample D30-A................... A-3

Figure A-2. MS Signals (logarithmic scale) from TGA-MS Analysis of Sample D30-A.......... A-3

Figure B-1. Temperature Profiles for Batch 1 Calcinations .................................................... A-7

Figure B-2. Temperature Profiles for Batch 2a Calcinations ............................................... A-7

Figure B-3. Temperature Profiles for Batch 2b Calcinations ................................................. A-8

Figure B-4. Temperature Profiles for Batch 3-1 Calcinations................................................ A-8

Figure B-5. Temperature Profiles for Batch 3-2 Calcinations................................................. A-9

Figure B-6. Temperature Profiles for Batch 3-3 Calcinations................................................. A-9

Figure B-7. Temperature Profiles for Batch 3-4 Calcinations.............................................. A-10

Figure B-8. Temperature Profiles for Batch 3-5 Calcinations............................................. A-10

Figure B-9. Temperature Profiles for Batch 4 Calcinations .................................................. A-11

Figure B-10. Temperature Profiles for Batch D5 Calcinations ............................................ A-11

Figure B-11. Temperature Profiles for Batch D30-A Calcinations ........................................ A-12

Figure B-12. Temperature Profiles for Batch D30-B Calcinations ........................................ A-12

Figure B-13. Temperature Profiles for Batch D15-A Calcinations ........................................ A-13

Figure B-14. Temperature Profiles for Batch D15-B Calcinations ……............................... A-13 


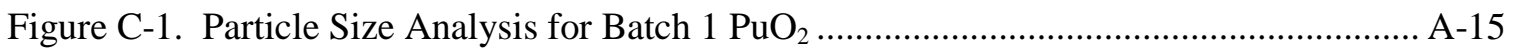

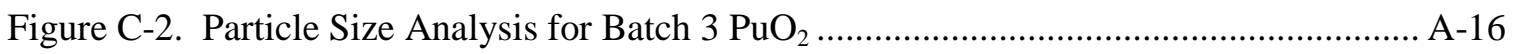

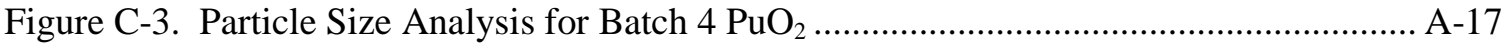

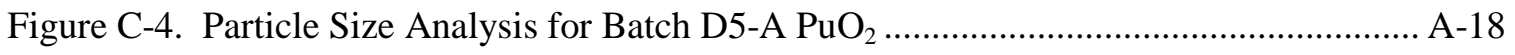

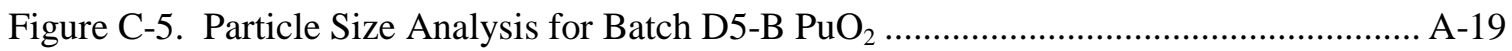

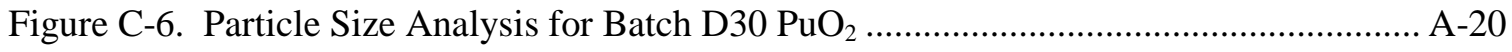

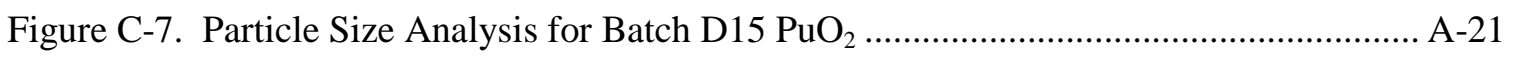

Figure C-8. Particle Size Analysis for Batch 2 Pu Oxalate ................................................... A-22

Figure C-9. Particle Size Analysis for Batch 4 Pu Oxalate .................................................. A-23

Figure C-10. Particle Size Analysis for Batch D5 Pu Oxalate ............................................. A-24

Figure C-11. Particle Size Analysis for Batch D30 Pu Oxalate ........................................... A-25

Figure C-12. Particle Size Analysis for Batch D15 Pu Oxalate ........................................... A-26 


\section{LIST OF ABBREVIATIONS}

$\begin{array}{ll}\text { ANN } & \text { aluminum nitrate nonahydrate } \\ \text { BET } & \text { Brunaer-Emmett-Teller } \\ \text { BV } & \text { bed volume } \\ \text { DI } & \text { deionized water } \\ \text { IC } & \text { ion chromatography } \\ \text { ICP-ES } & \text { inductively coupled plasma emission spectroscopy } \\ \text { ICP-MS } & \text { inductively coupled plasma mass spectroscopy } \\ \text { MOX } & \text { Mixed Oxide } \\ \text { PHA } & \text { pulse height analysis } \\ \text { PSA } & \text { particle size analysis } \\ \text { RH } & \text { relative humidity } \\ \text { SEM } & \text { scanning electron microscopy } \\ \text { SRNL } & \text { Savannah River National Laboratory } \\ \text { SSA } & \text { specific surface area } \\ \text { TGA-MS } & \text { thermogravimetric analysis-mass spectrometry }\end{array}$




\subsection{Introduction}

$\mathrm{H}$-Canyon and $\mathrm{HB}$-Line are tasked with the production of plutonium oxide $\left(\mathrm{PuO}_{2}\right)$ from a feed of plutonium metal. The $\mathrm{PuO}_{2}$ will provide feed material for the Mixed Oxide (MOX) Fuel Fabrication Facility. After dissolution of the Pu metal in H-Canyon, plans are to transfer the solution to HB-Line for purification by anion exchange, followed by plutonium(IV) oxalate precipitation, filtration and calcination to form $\mathrm{PuO}_{2}$. This report details the results from SRNL precipitation, filtration, calcination and characterization tests, as requested by HB-Line ${ }^{1}$ and described in the task plan².

$\mathrm{H}$-Area Engineering selected direct strike $\mathrm{Pu}(\mathrm{IV})$ oxalate precipitation ${ }^{3}$ mainly because it yields a denser $\mathrm{PuO}_{2}$ product than $\mathrm{Pu}(\mathrm{III})$ oxalate precipitation. The term "direct strike" indicates that the oxalic acid is added to a tank already containing $\mathrm{Pu}$ solution. The $\mathrm{Pu}(\mathrm{IV})$ approach also eliminates the need for reduction by ascorbic acid. The proposed HB-Line precipitation process $^{1,2}$ involves a digestion time of 5 minutes after the time required for oxalic acid addition, as was used during HB-line production of neptunium oxide $\left(\mathrm{NpO}_{2}\right)$. Therefore, in this study, researchers targeted an oxalic acid addition time of 44 minutes to match expected HB-Line conditions. In addition, a series of small $\mathrm{Pu}(\mathrm{IV})$ oxalate precipitation tests with different digestion times were conducted to better understand the effect of digestion time on particle size, filtration efficiency and other factors.

After production in HB-Line, plans are to ultimately store the purified $\mathrm{PuO}_{2}$ in containers suitable for compliance with the DOE-STD-3013 (i.e., the 3013 Standard). ${ }^{4}$ Originally, the Standard required heating of plutonium materials to $950{ }^{\circ} \mathrm{C}$ for 2 hours in air, with a resulting moisture content of less than $0.5 \mathrm{wt} \%$. Later, the 3013 Standard allowed stabilization at $750{ }^{\circ} \mathrm{C}$ for 2 hours in air for materials with high chloride salt content, thus reducing the volatilization of chloride salts during stabilization. It is expected that the results of this study will be included as part of a technical basis requesting that the 3013 Standard be modified to allow certain purified $\mathrm{PuO}_{2}$ materials to be calcined at low temperature conditions, such as $640-650{ }^{\circ} \mathrm{C}$ for 3-4 hours. Though the available technical literature helps understand the effects of calcination temperature and time on specific surface area (SSA) for $\mathrm{PuO}_{2}$, most of these studies have calcined $\mathrm{PuO}_{2}$ at different temperatures than expected in current HB-Line furnaces. One helpful publication from Los Alamos National Laboratory ${ }^{5}$ showed that production of $\mathrm{PuO}_{2}$ by $\mathrm{Pu}(\mathrm{IV})$ oxalate precipitation and subsequent calcination at $650{ }^{\circ} \mathrm{C}$ for 4 hours consistently produced $\mathrm{PuO}_{2}$ with a specific surface area of $9.77 \pm 1.79 \mathrm{~m}^{2} / \mathrm{g}$ and moisture content of $0.22 \pm 0.08 \mathrm{wt} \%$. However, a literature review ${ }^{6}$ of $\mathrm{PuO}_{2}$ calcination studies showed a need for additional data in the temperature range of interest, $600-650{ }^{\circ} \mathrm{C}$. In addition, the review showed that the SSA of $\mathrm{PuO}_{2}$ changes significantly with calcination temperature in the temperature range of interest, and the lower the SSA, the less likely the $\mathrm{PuO}_{2}$ is to absorb moisture.

In light of the need for more data pertinent to the expected process conditions, researchers performed a set of calcination tests at different times and temperatures that are achievable in current HB-Line equipment. The calcined batches of $\mathrm{PuO}_{2}$ were characterized for moisture and SSA, since moisture is already a requirement in the 3013 Standard, and SSA provides an indication of how much water would be re-adsorbed onto $\mathrm{PuO}_{2}$ when exposed to humid air.

In addition, since the 3013 Standard requires that the calcination (or stabilization) process eliminate organics, characterization of $\mathrm{PuO}_{2}$ batches monitored the presence of oxalate, by thermogravimetric analysis-mass spectrometry (TGA-MS). To use the TGA-MS for carbon or oxalate content, some method development will be required. However, the TGA-MS is already used for moisture measurements. Therefore, SRNL initiated method development for the TGAMS to allow quantification of oxalate or total carbon. That work continues at this time and is not 
yet ready for use in this study although the collected test data can be reviewed later as those analysis tools are available. In the current report, the TGA-MS provides a "less than" quantity for oxalate, since total mass loss and moisture loss is readily quantified.

\subsection{Experimental Procedure}

\subsection{Plutonium Purification by Anion Exchange}

\subsubsection{Column Description}

To perform $\mathrm{Pu}(\mathrm{IV})$ oxalate precipitation tests, researchers prepared a purified $\mathrm{Pu}$ solution by anion exchange. The ion exchange column was fabricated from $90-\mathrm{mm}$ borosilicate glass tubing (1.5-mm wall thickness) by the SRNL Glass Shop. A coarse frit was sealed into the bottom of the column to hold the resin. Approximately $1.6 \mathrm{~L}$ of Reillex ${ }^{\mathrm{TM}} \mathrm{HPQ}$ anion exchange resin were loaded into the column for a bed height of $\sim 27 \mathrm{~cm}$. Solutions were fed to the column from the top and effluent was withdrawn from the bottom. Solutions were fed to the column using a FMI QV-50 piston pump. Polyethylene tubing (6.35 mm outside diameter) linked feed bottles, effluent collection bottles, and the pump to the column.

\subsubsection{Plutonium Feed Solutions}

Feed solutions came from two source materials. The first feed source was $\delta$-phase Pu metal dissolved using 8-10 $\mathrm{M}$ nitric acid $\left(\mathrm{HNO}_{3}\right)$, potassium fluoride (KF), and either gadolinium (Gd) or boron (B). ${ }^{7}$ The second feed source was a mixed $\mathrm{PuO}_{2}$ batch (termed HBL-11-OX8 or 3013 DE Feed) that was fused with sodium peroxide and dissolved in $8 \mathrm{M} \mathrm{HNO}_{3}$. The $3013 \mathrm{DE}$ Feed contained impurities that are listed in Appendix A. The material from the two feed sources was further divided into separate feed solutions, as listed below.

1) 4.4 L of dissolved HBL-11-OX8 material (3013 DE Feed). The solution contained $\sim 42.1$ $\mathrm{g}$ of $\mathrm{Pu}$. The total $\mathrm{NO}_{3}{ }^{-}$concentration was $\sim 8 \mathrm{M}$ and the $\mathrm{HNO}_{3}$ concentration was $\sim 6.7 \mathrm{M}$. The solution was filtered through a 5-micron filter.

2) $1.0 \mathrm{~L}$ of dissolved $\delta$-phase metal. The solution contained $\sim 7.6 \mathrm{~g}$ of Pu. The solution concentrations were $10 \mathrm{M} \mathrm{HNO}_{3}, \sim 0.075 \mathrm{M} \mathrm{KF}$, and $1.0 \mathrm{~g} / \mathrm{L} \mathrm{B}$. To this solution were added $84 \mathrm{~mL}$ of $2.0 \mathrm{M}$ aluminum nitrate nonahydrate (ANN) solution to complex fluoride at a 2:1 Al:F molar ratio and $190 \mathrm{~mL}$ deionized (DI) water to reduce the total $\mathrm{NO}_{3}{ }^{-}$ concentration. The solution was not filtered after the addition of ANN and $\mathrm{DI}_{2} \mathrm{O}$.

3) $1.6 \mathrm{~L}$ of dissolved $\delta$-phase metal. The solution contained $\sim 7.5 \mathrm{~g}$ of Pu. The solution concentrations were $9.5 \mathrm{M} \mathrm{HNO}_{3}, \sim 0.16 \mathrm{M} \mathrm{KF}$, and $1.5 \mathrm{~g} / \mathrm{L} \mathrm{B}$. To this solution were added $260 \mathrm{~mL}$ of $2.0 \mathrm{M}$ ANN solution to complex fluoride at a 2:1 Al:F molar ratio and $190 \mathrm{~mL}$ DI water to reduce the total $\mathrm{NO}_{3}{ }^{-}$concentration. The solution was not filtered after the addition of ANN and $\mathrm{DI} \mathrm{H}_{2} \mathrm{O}$.

4) $1.6 \mathrm{~L}$ of dissolved $\delta$-phase metal. The solution contained $\sim 11.5 \mathrm{~g}$ of Pu. The solution concentrations were $10.3 \mathrm{M} \mathrm{HNO}_{3}, \sim 0.05 \mathrm{M} \mathrm{KF}$, and $0.63 \mathrm{~g} / \mathrm{L} \mathrm{Gd}$. To this solution were added $77 \mathrm{~mL}$ of $2.0 \mathrm{M}$ ANN solution to complex fluoride at a 2:1 Al:F molar ratio and $250 \mathrm{~mL}$ de-ionized (DI) water to reduce the total $\mathrm{NO}_{3}{ }^{-}$concentration. The solution was not filtered after the addition of ANN and DI $\mathrm{H}_{2} \mathrm{O}$.

5) $1.7 \mathrm{~L}$ of dissolved $\delta$-phase metal. The solution contained $\sim 8.6 \mathrm{~g}$ of $\mathrm{Pu}$. The solution concentrations were $9.3 \mathrm{M} \mathrm{HNO}_{3}, \sim 0.044 \mathrm{M} \mathrm{KF}$, and $0.67 \mathrm{~g} / \mathrm{L} \mathrm{Gd}$. To this solution were added $80 \mathrm{~mL}$ of $2.0 \mathrm{M}$ ANN solution to complex fluoride at a 2:1 Al:F molar ratio and $120 \mathrm{~mL}$ DI water to reduce the total $\mathrm{NO}_{3}{ }^{-}$concentration. The solution was not filtered after the addition of ANN and $\mathrm{DI} \mathrm{H}_{2} \mathrm{O}$. 


\subsubsection{Column Operation}

The ion exchange resin was conditioned, loaded, washed, and eluted with downward flow. Prior to loading Pu onto the resin, the column was conditioned with $4 \mathrm{~L}$ of $8 \mathrm{M} \mathrm{HNO}_{3}$ at $90 \mathrm{~mL} / \mathrm{min}$. Feed \#1 was fed at $60 \mathrm{~mL} / \mathrm{min}$. The column was then washed with $1.6 \mathrm{~L}$ of $8 \mathrm{M} \mathrm{HNO}_{3}$ to harvest some of the ${ }^{241} \mathrm{Am}$. Feeding of Pu continued with Feeds \#2, \#3, and \#4 being processed at $60 \mathrm{~mL} / \mathrm{min}$.

During the loading of Feed \#5, greatly reduced flow rates through the column were observed, most likely due to the presence of a precipitate. Parts of the unprocessed feed were mixed with $8 \mathrm{M} \mathrm{HNO}_{3}$ wash solution and passed through the column. The solids causing the reduced processing rate dissolved and improved flow was re-established. However, due to time constraints, only half of Feed \#5 was loaded onto the column.

After feeding was complete, the $\mathrm{Pu}$ on the column was washed with $7 \mathrm{~L}$ of $8 \mathrm{M} \mathrm{HNO}_{3}$ at $60-90 \mathrm{~mL} / \mathrm{min}$. The Pu was eluted with $0.35 \mathrm{M} \mathrm{HNO}_{3}$. The heads cut $(1.2 \mathrm{~L})$ was collected at a flow rate of $30 \mathrm{~mL} / \mathrm{min}$. The hearts cut $(1.4 \mathrm{~L})$ was obtained at $20 \mathrm{~mL} / \mathrm{min}$ with a targeted $\mathrm{Pu}$ concentration of $50 \mathrm{~g} / \mathrm{L}$.

\subsubsection{Characterization}

The feed, product and other effluent solutions from the anion exchange column experiment were characterized by some or all of these methods: gamma pulse height analysis (PHA), inductively coupled plasma-mass spectroscopy (ICP-MS), inductively coupled plasma-emission spectroscopy (ICP-ES), ion chromatograpy (IC) for anions, and free acid. In addition, to attain lower detection limits and to reduce interferences for some impurities in the Pu product solution, the Pu product solution was analyzed by ICP-MS and ICP-ES after Pu removal. The details of that method development effort are documented elsewhere. ${ }^{8}$

\subsection{Precipitation}

The Pu product solution described above was stored and used for seven precipitation batches. No valence adjustments were performed before any of the precipitations. Precipitation tests began before acid analysis of the Pu product solution completed. For precipitations involving acid adjustments, researchers added the volume of $7 \mathrm{M} \mathrm{HNO}_{3}$ needed to raise the solution to a target concentration of $2.5 \mathrm{M} \mathrm{HNO}_{3}$ for Batch 4 or a target concentration of $1.5 \mathrm{M} \mathrm{HNO}_{3}$ for Batches D-5, D-30 and D-15. Typically, precipitations began within about $2 \mathrm{~h}$ after acid adjustments. Free acid analyses occurred after precipitations completed. Prior to each precipitation batch, researchers calculated the volume of $0.9 \mathrm{M}$ oxalic acid needed to achieve $0.1 \mathrm{M}$ excess oxalic acid after Pu precipitation, and that volume of $0.9 \mathrm{M}$ oxalic acid was transferred into a $250-\mathrm{mL}$ bottle. For each precipitation, purified Pu solution was heated in a glass beaker to $50 \pm 3{ }^{\circ} \mathrm{C}$. Researchers used a 2-L glass beaker for the first three batches (nominally $18.5 \mathrm{~g}$ Pu each) and a 600 -mL glass beaker for the smaller remaining batches (4-6 g Pu each). Once the Pu solution reached nominally $50{ }^{\circ} \mathrm{C}, 0.9 \mathrm{M}$ oxalic acid was added at a flow rate that targeted a total oxalic acid addition time of 44 minutes, to correspond to expected HB-Line precipitation conditions. ${ }^{3} \mathrm{~A}$ summary of the precipitation conditions is provided in the Results section.

For the first three precipitation batches, the digestion time, or time between end of oxalic addition and start of filtration, was nominally 15 minutes. The fourth precipitation batch involved a digestion time of 6 minutes. Then, for the last three precipitations, the digestion times were 5, 30 and 15 minutes, so those batches are designated D-5, D-30 and D-15. Attempts were made to make all other experimental conditions consistent for these last three precipitations to determine the minimum digestion time and the effects of digestion time on oxalate and oxide properties. 
Following each precipitation, the Pu oxalate slurry was poured into a stainless steel filter housing containing a nominally $10-\mu \mathrm{m}$ stainless steel filter screen material provided by HB-Line. Prior to testing, the SRNL Glass Shop cut appropriately-sized circular sections of the filter screen, and prior to each filtration, personnel loaded a new filter into the filter housing and performed a leak check. After the bulk of the Pu oxalate slurry was transferred to the filter housing and the liquid was vacuum filtered and collected in a 1-L beaker, the Pu oxalate solids remaining in the glass beaker were transferred using modest volumes of cake wash solution (i.e., $1.4 \mathrm{M} \mathrm{HNO}_{3} / 0.1 \mathrm{M}$ oxalic acid), but additional cake washing did not occur. Except for Batch 1, the vacuum continued to operate for 15-60 minutes after standing liquid was gone from the cake. In addition, all oxalate batches except Batch 1 remained open to the ambient conditions overnight or longer to promote drying. Volumes used for each precipitation are shown in the Results section. Filtrate solutions were characterized by gamma PHA to allow determination of Pu losses to the filtrate. Filtrate solutions were also characterized by ICP-MS, ICP-ES and IC.

\subsection{Calcination}

\subsubsection{Batch 1 Calcinations}

The first precipitation batch of $\mathrm{Pu}$ oxalate, or $\mathrm{Pu}\left(\mathrm{C}_{2} \mathrm{O}_{4}\right)_{2} \bullet x \mathrm{H}_{2} \mathrm{O}$, was transferred to a 4-ounce ( $\sim 10 \mathrm{~mL}$ ) glass jar, which was then closed. Four days later, this Batch 1 material was divided into four 30-mL quartz crucibles (B1-2 through B1-5). The $\mathrm{Pu}\left(\mathrm{C}_{2} \mathrm{O}_{4}\right)_{2}$ material was quite wet and sticky and difficult to transfer completely. Each crucible had a bed depth of approximately $2-3 \mathrm{~cm}$. As noted in previous SRNL work ${ }^{9}$ with neptunium oxide $\left(\mathrm{NpO}_{2}\right)$ oxide calcinations, we assumed that a bed depth of $2-3 \mathrm{~cm}$ (or less for later in this study) would allow enough air to permeate the powder during calcination that the $\mathrm{PuO}_{2}$ produced would be reasonably similar to that produced in HB-Line at similar conditions. This assumption seems reasonable because in the case of $\mathrm{NpO}_{2}$, the batches of $\mathrm{NpO}_{2}$ calcined at SRNL at 600 and $650{ }^{\circ} \mathrm{C}$ for 2 hours had specific surface areas which bounded that of the $\mathrm{NpO}_{2}$ made by HB-Line early in the production campaign as shown in Table 2-1. ${ }^{10}$

Table 2-1. BET Specific Surface Area ${ }^{10}$ for $\mathrm{NpO}_{2}$

\begin{tabular}{||c|c||}
\hline $\mathbf{N p O}_{\mathbf{2}}$ Material & $\begin{array}{c}\text { BET Specific } \\
\text { Surface Area, } \\
\mathbf{m}^{2} / \mathbf{g}\end{array}$ \\
\hline SRNL $600{ }^{\circ} \mathrm{C}$ & 5.34 \\
\hline SRNL $650{ }^{\circ} \mathrm{C}$ & 3.67 \\
\hline HB-Line & 4.03 \\
\hline
\end{tabular}

The HB-Line design, which passes air through the filter cake (or powder bed) during calcination, effectively removes moisture and oxalate decomposition products from the filter cake, and may have additional advantages for the properties of the $\mathrm{PuO}_{2}$.

Having assumed that a shallow bed depth without an air purge was reasonable, a thermocouple with a $0.5-\mathrm{mm}$ diameter probe was inserted into each of the four cakes and the four crucibles were loaded into a Barnstead Thermolyne 1300 muffle furnace capable of heating to $1100{ }^{\circ} \mathrm{C}$. Unfortunately, moving two of the crucibles to the back of the furnace caused the affected thermocouple probes to bend enough that the thermocouple tips were no longer in contact with the $\mathrm{Pu}\left(\mathrm{C}_{2} \mathrm{O}_{4}\right)_{2}$ material. The thermocouples in the front two crucibles, however, were verified to be in contact with the cake at the start of calcination. After calcination above $600{ }^{\circ} \mathrm{C}$ for $2 \mathrm{~h}$, the furnace door was opened to remove the first crucible. At that time, personnel observed that the thermocouples in the front two crucibles were no longer touching the cakes, but were positioned 
just above the cakes. It appeared that the mass loss from drying and calcination of the oxalate to oxide caused the cake to subside enough that contact with the thermocouples was lost.

\subsubsection{Calcination of Additional Batches}

Batch 2 calcinations were performed with two crucibles in the furnace at a time with a target cake temperature of $625{ }^{\circ} \mathrm{C}$. While calcining the first pair of samples, the cake temperatures were $625{ }^{\circ} \mathrm{C}(\mathrm{B} 2-4)$ and $628{ }^{\circ} \mathrm{C}(\mathrm{B} 2-5)$, and the samples were calcined for 4 and $5 \mathrm{~h}$, respectively. Next, an additional pair of oxalate samples was calcined. In this case, however, the cake temperatures were $625{ }^{\circ} \mathrm{C}(\mathrm{B} 2-3)$ and $610{ }^{\circ} \mathrm{C}(\mathrm{B} 2-2)$ and the calcination times were 3 and $2 \mathrm{~h}$, respectively. Because of the temperature variation observed within the furnace, the first four Batch 3 samples (B3-1 through B3-4) were calcined individually to ensure the desired cake temperature of $650^{\circ} \mathrm{C}$ was attained. A summary of the calcination conditions is shown in Table 2-2. Thereafter, a firebrick crucible holder (shown in Figure 2-1) was used, along with smaller $(15-\mathrm{mL})$ quartz crucibles. The expectation was that the crucible holder would reduce temperature variation within the furnace, and would also prevent the crucibles from tipping over.

Table 2-2. Target Calcination Conditions for Pu Oxalate Batches.

\begin{tabular}{|c|c|c|c|c||}
\hline Batch & $\begin{array}{c}\text { Target } \\
\text { Pu } \\
\mathbf{g}\end{array}$ & Portions & $\begin{array}{c}\text { Target } \\
\text { Temp. } \\
{ }^{\circ} \mathbf{C}\end{array}$ & $\begin{array}{c}\text { Crucible } \\
\text { Holder } \\
\text { Y or N }\end{array}$ \\
\hline 1 & 17.5 & 4 & 650 & $\mathrm{~N}$ \\
\hline 2 & 17.5 & 4 & 625 & $\mathrm{~N}$ \\
\hline 3 & \multirow{2}{*}{17.5} & 4 & 650 & $\mathrm{~N}$ \\
\cline { 3 - 5 } & & 2 & 635 & $\mathrm{Y}$ \\
\hline 3 & 6.36 & 2 & 635,650 & $\mathrm{Y}$ \\
\hline 4 & 4.21 & 2 & 635,650 & $\mathrm{Y}$ \\
\hline $\mathrm{D}-5$ & 4.21 & 2 & 635,650 & $\mathrm{Y}$ \\
\hline $\mathrm{D}-30$ & 4.86 & 2 & 635,650 & $\mathrm{Y}$ \\
\hline D-15 & \multicolumn{3}{|l}{} \\
\hline
\end{tabular}

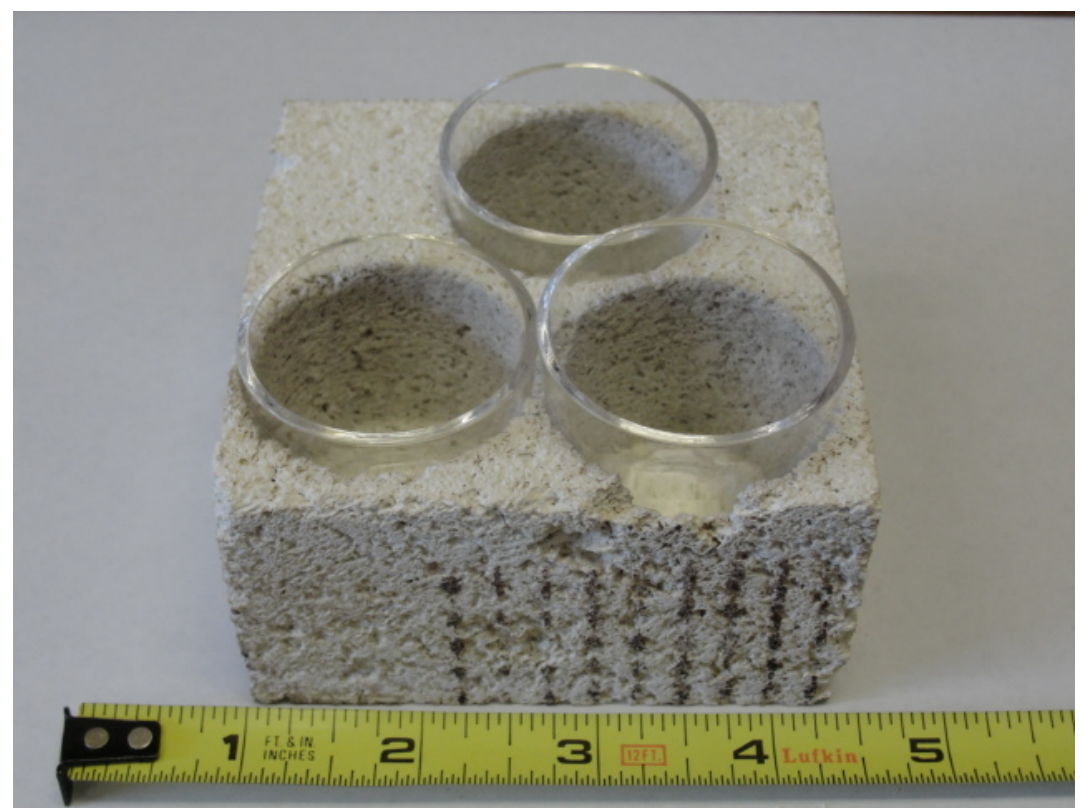

Figure 2-1. Crucible Holder Used for Calcinations. 


\subsection{Thermocouple Evaluation}

In the Task Technical and Quality Assurance Plan set forth at the beginning of this study, personnel accepted the manufacturer's calibration of the thermocouples to be used. However, after significant temperature variations within the furnace were observed during Batch 1 calcinations, evaluations were made of the precision and accuracy of the four thermocouples used in this study. Prior to Batch 2 and the subsequent calcinations, the precision of the thermocouples near $650{ }^{\circ} \mathrm{C}$ was tested by placing all four thermocouples into an empty quartz crucible and heating the furnace. In addition, the four thermocouples were checked for precision at room temperature and were checked for precision and accuracy by measuring the temperature of boiling water. After the calcinations for this study were complete, the four thermocouples were again tested for precision by heating in the furnace to nominally $650{ }^{\circ} \mathrm{C}$. However, in this case, the thermocouple probes were twisted together to ensure they were in essentially the same position. After that, a test for thermocouple accuracy was made by inserting one thermocouple into a thin hole drilled into a small aluminum cylindrical block. The cylinder was turned upside down and placed inside a quartz crucible, so that the thermocouple tip would remain inside the aluminum block. The other three thermocouples were left in the furnace and stationed in the same place but not in contact with the crucible. Then, the furnace was heated to above $700{ }^{\circ} \mathrm{C}$ to ensure melting of the aluminum, as pure aluminum melts at $660.6^{\circ} \mathrm{C}$. Throughout heating, the temperatures of the four thermocouples and the furnace thermocouple were recorded. Then the furnace was allowed to cool to $\sim 600{ }^{\circ} \mathrm{C}$ and temperatures continued to be recorded. The furnace was heated above $700{ }^{\circ} \mathrm{C}$, cooled below $600{ }^{\circ} \mathrm{C}$ then heated above $700{ }^{\circ} \mathrm{C}$ a third time in attempt to determine a consistent melting point of the aluminum block. The expectation was that during melting, the thermocouple in contact with the aluminum would have a slower rate of temperature change than it would before or after melting. Also, during cooling, the molten aluminum is expected to cool somewhat rapidly until solidification begins. However, after solidification, a higher rate of temperature decrease was expected. The aluminum alloy used was expected to be of the aluminum alloy type 6061, and it cut readily as compared to more pure aluminum alloys which are much softer. To confirm the alloy designation, a portion of the same aluminum rod was dissolved in $1 \mathrm{M}$ hydrochloric acid and submitted for analysis by ICP-ES. Aluminum 6061 contains nominally 0.6 wt \% silicon (Si), 1.0 wt \% magnesium (Mg), 0.25 wt \% copper (Cu), and 0.20 wt \% chromium (Cr). ${ }^{11}$

\section{$2.5 \underline{\text { Characterization }}$}

The plutonium oxide $\left(\mathrm{PuO}_{2}\right)$ samples from all the batches and portions generated in this study were characterized by thermogravimetric analysis-mass spectrometry (TGA-MS) for moisture content and by the Brunaer-Emmett-Teller (BET) method for specific surface area (SSA). In addition, at least one oxide sample from each of the larger batches was evaluated by either Particle Size Analysis (PSA) or by Scanning Electron Microscopy (SEM). Note that the initial Task Plan ${ }^{2}$ for this study did not include exposing $\mathrm{PuO}_{2}$ samples to humid air. Thus, though exposures to humid air were performed in this study to provide indications of moisture absorption behavior, the humidity meters were out of calibration. An end of study comparison using a calibrated humidity meter showed a bias that is noted in the affected table.

For most batches, a sample of the $\mathrm{Pu}\left(\mathrm{C}_{2} \mathrm{O}_{4}\right)_{2}$ was also evaluated for PSA and some samples were evaluated by SEM for morphology. 


\subsection{Results and Discussion}

\subsection{Plutonium Purification by Anion Exchange}

Analysis of the hearts cut by ICP-MS measured $52.7 \mathrm{~g} / \mathrm{L}$ for Masses $239-241$ and a ${ }^{239} \mathrm{Pu}$ enrichment of 94.0\%. Gamma spectroscopy analysis measured $49.4 \mathrm{~g} / \mathrm{L}{ }^{239} \mathrm{Pu}$. Factoring for the enrichment measured by ICP-MS, the total $\mathrm{Pu}$ concentration determined using gamma spectroscopy was $52.6 \mathrm{~g} / \mathrm{L}$. Free acid analysis measured $0.77 \mathrm{M} \mathrm{H}^{+}$. Ion chromatography measurement reported fluoride $<10 \mathrm{mg} / \mathrm{L}$, chloride $<10 \mathrm{mg} / \mathrm{L}$ and nitrate $=91.4 \mathrm{~g} / \mathrm{L}(1.47 \mathrm{M})$. In this case, the analyses confirm one another. The gamma analysis of $52.6 \mathrm{~g} \mathrm{Pu} / \mathrm{L}$ converts to $0.22 \mathrm{M} \mathrm{Pu}$. It is expected that the $\mathrm{Pu}$ is present as $\mathrm{Pu}(\mathrm{IV})$, which is associated with four nitrate ions per Pu ion, yielding $0.88 \mathrm{M}$ nitrate complexing the Pu. Combining the free acid (nitric acid) result of $0.77 \mathrm{M}$ with the $0.88 \mathrm{M}$ nitrate complexing the Pu yields an expected total nitrate of $1.65 \mathrm{M}$. The ion chromatography analysis of total nitrate is within $12 \%$ of this prediction, at a value of $1.47 \mathrm{M}$ nitrate.

Analytical results from the anion exchange column experiment are provided in Appendix A, and generally confirm expectations concerning resin performance. A plot of the $\mathrm{Pu}$ and ${ }^{241} \mathrm{Am}$ content of the solution exiting the resin column is shown in Figure 3-1, using average feed concentrations of $7.52 \mathrm{~g} \mathrm{Pu} / \mathrm{L}$ and $0.028 \mathrm{~g} \mathrm{Am} / \mathrm{L}$ for comparison. In Figure 3-1, the first bed volume (BV) of wash corresponds to a feed that was nominally a 50:50 mixture of feed and wash solution. Also in the figure, BV \#5 refers to the Heads Cut and BV \#6 is the Hearts Cut.

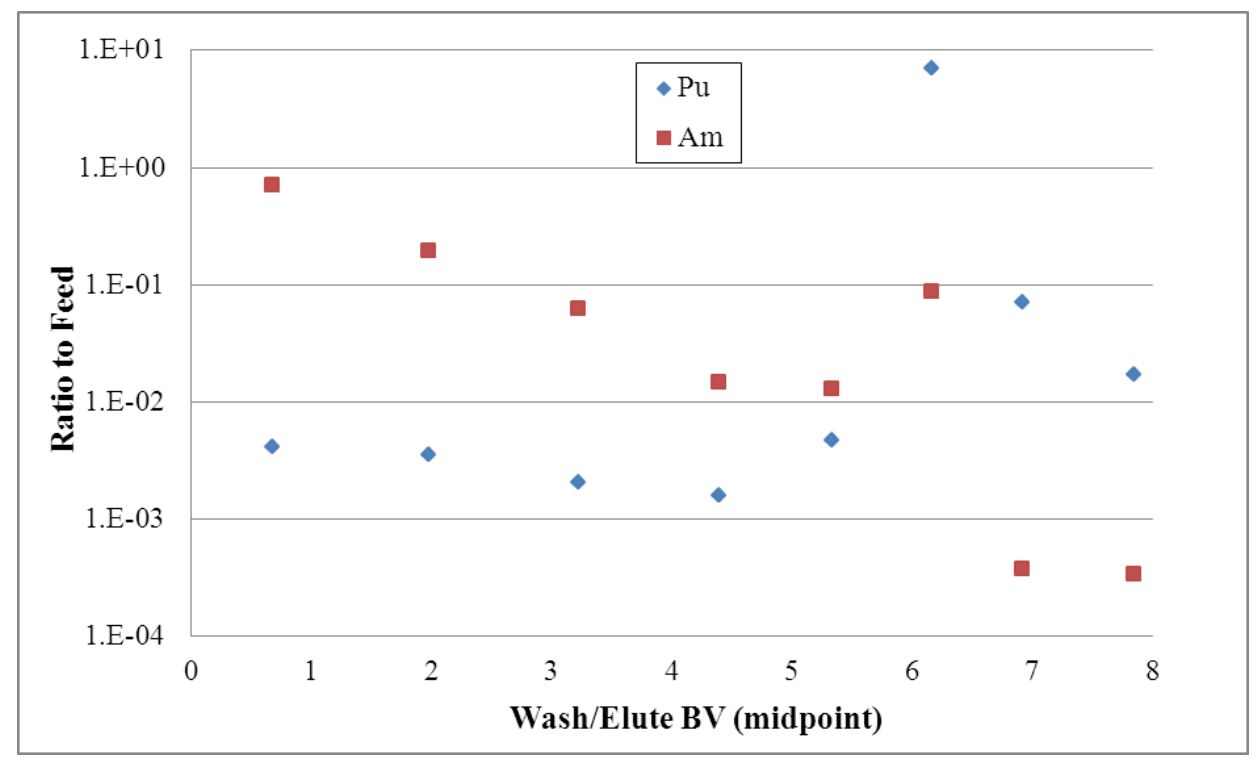

Figure 3-1. Pu and ${ }^{241}$ Am Released from Resin Column

Though this experiment included only $~ 3.6 \mathrm{BV}$ of wash, the Pu product solution was relatively pure, as shown in Table 3-1. To compare the impurity contents to the Column A Limits ${ }^{2}$, the analysis results are color-coded in Table 3-1, where red indicates the limit was not attained. For two of the "red" analytes, potassium (K) and manganese (Mn), the solution showed less than the detection limit, but the limit was above the Column A specification. For analytes in which the 
Column A limit was attained, the closeness to the limit is indicated, in order, by the colors yellow, white, and green. Yellow indicates an impurity concentration above $50 \%$ of specification. White indicates an impurity concentration between $10 \%$ and $50 \%$ of specification. Green indicates an impurity concentration below $10 \%$ of specification.

Table 3-1. Impurity Contents of Pu Product Solution

\begin{tabular}{|c|c|c|c|c|}
\hline Element & $\begin{array}{l}\text { Isotope Used } \\
\text { By ICPMS }\end{array}$ & $\begin{array}{c}\text { Column A Limit } \\
\mu \mathrm{g} / \mathrm{g} \text { Pu }\end{array}$ & $\begin{array}{l}\text { Measured } \\
\mu \mathrm{g} / \mathrm{g} \mathrm{Pu}\end{array}$ & $\begin{array}{l}\text { \% of Column A } \\
\text { Limit }\end{array}$ \\
\hline $\mathrm{Al}$ & -- & 500 & $<33.5$ & $<6.7$ \\
\hline B & -- & 100 & $<28.9$ & $<28.9$ \\
\hline $\mathrm{Be}$ & -- & 100 & $<1.14$ & $<1.1$ \\
\hline $\mathrm{Ca}$ & -- & 500 & $<106$ & $<21.3$ \\
\hline $\mathrm{Cd}$ & Cd-111 & 10 & 0.67 & 6.7 \\
\hline $\mathrm{Cd}$ & Cd-113 & 10 & 0.58 & 5.8 \\
\hline Co & Co-59 & 100 & 0.35 & 0.4 \\
\hline $\mathrm{Cr}$ & -- & 1000 & $<19.4$ & $<1.9$ \\
\hline $\mathrm{Cu}$ & -- & 100 & $<40.9$ & $<40.9$ \\
\hline Dy & Dy-163 & 1 & 0.38 & 38.3 \\
\hline $\mathrm{Eu}$ & Eu-151 & 1 & 0.073 & 7.3 \\
\hline $\mathrm{Eu}$ & Eu-153 & 1 & 0.11 & 11.3 \\
\hline $\mathrm{F}$ & -- & 250 & $<190$ & $<76.0$ \\
\hline $\mathrm{Fe}$ & -- & 2000 & $<63$ & $<3.1$ \\
\hline $\mathrm{Ga}$ & Ga-69 & 12000 & 0.88 & 0.01 \\
\hline $\mathrm{Ga}$ & Ga-71 & 12000 & 0.65 & 0.01 \\
\hline $\mathrm{Gd}$ & Gd-155 & 3 & 8.85 & 295 \\
\hline $\mathrm{Gd}$ & Gd-157 & 3 & 8.60 & 287 \\
\hline $\mathrm{K}$ & -- & 300 & $<572$ & $<191$ \\
\hline $\mathrm{Li}$ & -- & 400 & $<27.8$ & $<6.9$ \\
\hline $\mathrm{Mg}$ & -- & 500 & $<91.3$ & $<18.3$ \\
\hline $\mathrm{Mn}$ & -- & 100 & $<101$ & $<101$ \\
\hline Mo & -- & 100 & $<51.0$ & $<51.0$ \\
\hline $\mathrm{Na}$ & $\overline{--}$ & 1000 & $<303$ & $<30.3$ \\
\hline $\mathrm{Ni}$ & -- & 5000 & $<86.5$ & $<1.7$ \\
\hline $\mathrm{Pb}$ & Pb-206 & 200 & 15.6 & 7.8 \\
\hline $\mathrm{Pb}$ & Pb-207 & 200 & 14.7 & 7.4 \\
\hline $\mathrm{Pb}$ & Pb-208 & 200 & 14.9 & 7.5 \\
\hline $\mathrm{S}$ & -- & 250 & $<228$ & $<91.3$ \\
\hline $\mathrm{Si}$ & -- & 200 & $<186$ & $<92.9$ \\
\hline $\mathrm{Sm}$ & Sm-147 & 2 & 0.40 & 20.2 \\
\hline Sm & Sm-149 & 2 & 0.21 & 10.4 \\
\hline Sn & Sn-118 & 100 & 4.07 & 4.1 \\
\hline Sn & Sn-120 & 100 & 4.12 & 4.1 \\
\hline $\mathrm{Ti}$ & -- & 100 & $<3.61$ & $<3.6$ \\
\hline V & -- & 300 & $<22.2$ & $<7.4$ \\
\hline $\mathrm{Zn}$ & -- & 150 & $<17.5$ & $<11.7$ \\
\hline \multicolumn{5}{|c|}{$\begin{array}{l}\text { Note: Red background indicates impurity concentration above specification. Yellow indicates } \\
\text { impurity concentration above } 50 \% \text { of specification. White indicates impurity concentration } \\
\text { between } 10 \% \text { and } 50 \% \text { of specification. Green indicates impurity concentration below } 10 \% \text { of } \\
\text { specification. }\end{array}$} \\
\hline \multicolumn{5}{|c|}{$\begin{array}{l}\text { Note: Values from ICPMS are reported as elemental concentrations and have been corrected } \\
\text { for natural abundance. }\end{array}$} \\
\hline
\end{tabular}


SRNL-STI-2012-00338

Revision 0

\subsection{Precipitation}

A summary of precipitation conditions is shown below.

Table 3-2. Precipitation Conditions

\begin{tabular}{|c|c|c|c|c|c|c|c|c|}
\hline Batch & $\begin{array}{c}52.6 \mathrm{~g} / \mathrm{L} \\
\mathrm{Pu} \\
\mathrm{mL}\end{array}$ & $\begin{array}{c}0.9 \mathrm{M} \\
\text { Oxalic } \\
\mathrm{mL}\end{array}$ & $\begin{array}{c}7 \mathrm{M} \\
\mathrm{HNO}_{3} \\
\mathrm{~mL}\end{array}$ & $\begin{array}{c}\text { Oxalic } \\
\text { acid } \\
\text { addition } \\
\text { time, min }\end{array}$ & $\begin{array}{c}\begin{array}{c}\text { Digestion } \\
\text { Time }\end{array} \\
\text { min }\end{array}$ & $\begin{array}{c}\text { Wash } \\
\text { Solution } \\
\text { mL }\end{array}$ & $\begin{array}{c}\text { Vacuum } \\
\text { Drying } \\
\text { Time } \\
\text { min }\end{array}$ & Comments \\
\hline 1 & 351 & 239 & 0 & 43 & 17 & 118 & $<10$ & $\begin{array}{c}\text { Oxalate wet and } \\
\text { pasty }\end{array}$ \\
\hline 2 & 348 & 234 & 0 & 48 & 13 & 149 & 40 & \\
\hline 3 & 352 & 240 & 0 & 45 & 15 & 114 & $30-60$ & \\
\hline 4 & 120 & 87 & 46 & 44 & 6 & 48 & $\sim 24$ & \\
\hline D-5 & 80 & 56 & 10.4 & $34^{\dagger}$ & 5 & 65 & 15 & \\
\hline D-30 & 80 & 56 & 10.4 & $25^{\dagger}$ & 30 & 63 & 42 & $\begin{array}{c}\text { Oxalate wet and } \\
\text { pasty }\end{array}$ \\
\hline D-15 & $60+45^{*}$ & 67 & 15.8 & $34^{\dagger}$ & 15 & 73 & $\sim 30$ & \\
\hline
\end{tabular}

* $45 \mathrm{~mL}$ of $\sim 1.5 \mathrm{M} \mathrm{HNO}_{3}$ containing $\sim 1.7 \mathrm{~g}$ Pu were added.

${ }^{\dagger}$ The target addition time of 44 minutes was not attained because the low flow rate required was just below the minimum flow rate of the pump.

Note for all Batches except Batch 1, the Pu oxalate cake was kept open overnight, allowing additional drying. For Batch 3, the weights of the Pu oxalate cake were recorded before and after air drying overnight, and a $2 \%$ mass loss occurred.

Table 3-3. Precipitation Results

\begin{tabular}{||c|c|c|c|c||}
\hline Batch & $\begin{array}{c}\text { Pu } \\
\text { g }\end{array}$ & $\begin{array}{c}\text { Pu } \\
\text { Oxalate } \\
\text { g }\end{array}$ & $\begin{array}{c}\text { Pu in } \\
\text { Filtrate }^{\dagger} \\
\text { g }\end{array}$ & $\begin{array}{c}\text { \% Pu Losses } \\
\text { to Filtrate }\end{array}$ \\
\hline 1 & 18.5 & $41.58^{*}$ & 0.156 & 0.84 \\
\hline 2 & 18.3 & 48.07 & 0.105 & 0.57 \\
\hline 3 & 18.5 & 51.44 & 0.107 & 0.58 \\
\hline 4 & 6.31 & 14.26 & 0.0243 & 0.39 \\
\hline D-5 & 4.21 & 11.20 & 0.0204 & 0.48 \\
\hline D-30 & 4.21 & 12.16 & 0.0280 & 0.67 \\
\hline D-15 & 4.86 & 11.89 & 0.0213 & 0.44 \\
\hline
\end{tabular}

* Spills occurred during Batch 1 operations.

${ }^{\dagger}$ Determined by gamma PHA with isotopic ratio by ICPMS.

After the Batch 3 precipitation, personnel noted the position of the Pu oxalate cake in the filter apparatus. Following removal of the $\mathrm{Pu}$ oxalate and cleaning of the filter apparatus, the approximate volume of the filter cake was determined by filling the filter apparatus with water to the same fill level as the filter cake had been. Researchers determined the filter cake volume was $\sim 40 \mathrm{~mL}$. Since Batch 3 contained $18.5 \mathrm{~g} \mathrm{Pu}$, the density of $\mathrm{Pu}$ in the precipitate filter cake was deemed $\sim 0.4-0.5 \mathrm{~g} \mathrm{Pu} / \mathrm{mL}$ cake.

\subsection{Calcination}

Using calcination temperatures ranging from 610 to $690{ }^{\circ} \mathrm{C}$, the $\mathrm{Pu}\left(\mathrm{C}_{2} \mathrm{O}_{4}\right)_{2} \bullet x \mathrm{H}_{2} \mathrm{O}$ samples were converted to $\mathrm{PuO}_{2}$. For the nine calcinations involving Batch 1-4 materials, Appendix B provides 
furnace and sample temperature profiles. Table 3-4 shows the masses of the initial oxalate material prior to calcination and the mass of the resulting $\mathrm{PuO}_{2}$ product, along with the expected theoretical, dry amounts. Taking an average of all the batches except Batch 1, the $\mathrm{PuO}_{2}$ mass was about $41 \%$ of the initial oxalate mass, which indicates that the $\mathrm{Pu}\left(\mathrm{C}_{2} \mathrm{O}_{4}\right)_{2}$ cake was typically quite wet, having more than ten waters of hydration. Losses are attributed to minor spills during operations. Batches were precipitated from the same, purified Pu stock solution.

Table 3-4. Mass Changes during Calcination

\begin{tabular}{||c|c|c|c|c|c||}
\hline Batch & $\begin{array}{c}\text { Pu in } \\
\text { Feed } \\
\text { g }\end{array}$ & $\begin{array}{c}\text { Pu } \\
\text { Oxalate } \\
\text { (Theory) } \\
\mathbf{g}\end{array}$ & $\begin{array}{c}\text { Pu } \\
\text { Oxalate } \\
\text { (Actual) } \\
\mathbf{g}\end{array}$ & $\begin{array}{c}\mathbf{P u O}_{2} \\
\text { (Theory) }\end{array}$ & $\begin{array}{c}\text { PuO }_{2} \\
\text { (Actual) } \\
\mathbf{g}\end{array}$ \\
\hline 1 & 18.5 & 32.1 & $41.58^{*}$ & 21.0 & $14.32^{*}$ \\
\hline 2 & 18.3 & 31.8 & 48.07 & 20.8 & 19.22 \\
\hline 3 & 18.5 & 32.1 & 51.44 & 21.0 & 20.72 \\
\hline 4 & 6.31 & 11.0 & 14.26 & 7.2 & 6.61 \\
\hline D-5 & 4.21 & 7.3 & 11.20 & 4.8 & 4.55 \\
\hline D-30 & 4.21 & 7.3 & 12.16 & 4.8 & 4.64 \\
\hline D-15 & 4.86 & 8.4 & 11.89 & 5.5 & 5.22 \\
\hline
\end{tabular}

* Spills occurred during Batch 1 operations.

${ }^{\dagger}$ These values reflect total product recovered, not including SEM samples.

After calcination for the specified time, the quartz crucible was removed from the furnace at temperature and covered with a non-sealing quartz lid. After a brief cooling period, as shown in Table 3-5, the resulting $\mathrm{PuO}_{2}$ was transferred into a glass vial, which was immediately covered with a lid then placed into a secondary plastic bottle with a lid to minimize exposure to humid air. Exposure times are also provided in Table 3-5, along with ambient glovebox conditions. 
SRNL-STI-2012-00338

Revision 0

Table 3-5. Glovebox Conditions after Calcination

\begin{tabular}{|c|c|c|c|c|}
\hline \multirow[b]{2}{*}{$\begin{array}{c}\text { Calcination } \\
\text { Batch } \\
\end{array}$} & \multicolumn{2}{|c|}{$\begin{array}{c}\text { Glovebox } \\
\text { Conditions } \\
\text { during Cooling } \\
\end{array}$} & \multirow{2}{*}{$\begin{array}{c}\text { Time for Cooling and } \\
\text { Transfer into Vial } \\
\text { min } \\
\end{array}$} & \multirow[t]{2}{*}{ "Comments } \\
\hline & $\begin{array}{c}\mathbf{T} \\
{ }^{\circ} \mathbf{C} \\
\end{array}$ & $\begin{array}{c}\text { RH } \\
\%\end{array}$ & & \\
\hline B1 & NM & NM & $\sim 30 \mathrm{~min}$ & $\begin{array}{l}\text { B1-2 crucible lid not } \\
\text { used during cooling }\end{array}$ \\
\hline B2-4 & 23.1 & 20.9 & $45 \min$ & \\
\hline B2-5 & 21.6 & 24.0 & 16 hours & \\
\hline $\mathrm{B} 2-2, \mathrm{~B} 2-3$ & 20.0 & 31.3 & $\sim 30$ min & \\
\hline B3-1 & 24.0 & 43.2 & $34 \mathrm{~min}$ & \\
\hline B3-2 & 23.4 & 41.0 & $17 \mathrm{~min}$ & Crucible lid not used \\
\hline B3-3 & 24.9 & 45.7 & $19 \mathrm{~min}$ & \\
\hline B3-4 & 24.0 & 50.9 & $22 \min$ & \\
\hline B3-5B & \multirow{2}{*}{24.0} & \multirow{2}{*}{47.2} & $13 \mathrm{~min}$ & \\
\hline B3-5A & & & $18 \min$ & \\
\hline B4-1 & \multirow{2}{*}{21.7} & \multirow{2}{*}{32.0} & $15 \mathrm{~min}$ & \\
\hline B4-2 & & & $12 \mathrm{~min}$ & \\
\hline $\begin{array}{l}\text { D5-B } \\
\text { D5-A }\end{array}$ & 23.2 & 52.3 & $\begin{array}{l}10 \mathrm{~min} \\
10 \mathrm{~min}\end{array}$ & \\
\hline D30-A & 23.0 & 50.0 & $13 \mathrm{~min}$ & \\
\hline D30-B & 25.4 & 30.1 & $\sim 13$ min & \\
\hline D15-A & 21.9 & 28.9 & $\sim 25 \mathrm{~min}$ & \\
\hline D15-B & 24.0 & 26.0 & $\sim 20$ min & \\
\hline
\end{tabular}

$\mathrm{NM}=$ not measured

\subsection{Thermocouple Evaluation}

The four thermocouples used in this study were subjected to several evaluations for precision and accuracy. The thermocouple probes were all new at the beginning of the study. Two nearly identical thermocouple temperature readouts from Digi-Sense were used (one labeled DuaLogR $^{\mathrm{TM}}$ and the other Dual JTEK), each displaying the temperature of two thermocouples. The readout used for thermocouples T1 and T2 had been calibrated for the $0-200{ }^{\circ} \mathrm{C}$ range as M\&TE \# ATD1-400, with the calibration valid through 28 July 2012. Table 3-6 below shows the results of the different evaluations. As shown in the Table 3-6, the thermocouples reported temperatures with a standard deviation of $\pm 3{ }^{\circ} \mathrm{C}$ in the temperature range above $600{ }^{\circ} \mathrm{C}$ (measurements of greatest interest are in bold). Also, the test for an accurate melting temperature of an Al block showed that the start of solidification was clear because the temperature abruptly stopped decreasing for several minutes. The first "end of melting" temperature is not included because temperature readings were too variable. After that initial melting, solidification of the $\mathrm{Al}$ started at $653{ }^{\circ} \mathrm{C}$ for both cycles measured. This solidification temperature agrees well with the top of published melting range for the expected alloy, Aluminum 6061, which is 582.2 $651.7{ }^{\circ} \mathrm{C}^{12}$ Recall that Aluminum 6061 contains nominally $0.6 \mathrm{wt} \%$ silicon (Si), $1.0 \mathrm{wt} \%$ magnesium (Mg), 0.25 wt \% copper (Cu), and $0.20 \mathrm{wt} \%$ chromium (Cr). ${ }^{11}$ Analysis of impurities in a sample of dissolved Al block by ICPES showed $0.68 \mathrm{wt} \% \mathrm{Mg}, 1.0 \mathrm{wt} \% \mathrm{Si}$, which matches the nominal concentrations of Aluminum 6061. The dissolved sample also showed $0.08 \mathrm{wt} \% \mathrm{Cr}$, which is below the nominal level but clearly a component of the material. The dissolved sample also showed $0.005 \mathrm{wt} \% \mathrm{Cu}$ which is attributed to the fact that $\mathrm{CuCl}_{2}$ is sparingly soluble in water and the dissolution reaction was taken to completion, consuming chloride ion that would have been available to complex the $\mathrm{Cu}$ ions. The lead author's review of the contents of 44 common aluminum alloys ${ }^{11}$ showed that Aluminum 6061 is still the most likely 
alloy used in the furnace evaluation, and the only other common alloy with $0.6 \mathrm{wt} \% \mathrm{Mg}$ and 1.0 wt\% Si, Aluminum 6262, has the same melting range as Aluminum 6061. ${ }^{12}$ Therefore, the thermocouples used in this study showed sufficient precision $\left( \pm 3{ }^{\circ} \mathrm{C}\right.$ at 1 standard deviation) and sufficient accuracy (measuring boiling water and the melting point of an aluminum alloy) to provide reliable calcination temperatures.

Table 3-6. Thermocouple Evaluation Results

\begin{tabular}{||c|c|c|c|c|c||}
\hline Time & Condition & $\begin{array}{c}\mathbf{T}_{\mathbf{1}} \\
{ }^{\circ} \mathbf{C}\end{array}$ & $\begin{array}{c}\mathbf{T}_{\mathbf{2}} \\
{ }^{\circ} \mathbf{C}\end{array}$ & $\begin{array}{c}\mathbf{T}_{\mathbf{3}} \\
{ }^{\circ} \mathbf{C}\end{array}$ & $\begin{array}{c}\mathbf{T}_{\mathbf{4}} \\
{ }^{\circ} \mathbf{C}\end{array}$ \\
\hline Prior to Batch 2 & Ambient & 19.8 & 19.9 & 19.6 & 19.7 \\
\hline Prior to Batch 2 & In furnace @ 670 ${ }^{\circ} \mathrm{C}$ & $657.7^{*}$ & $657.4^{*}$ & $665.3^{*}$ & $664.5^{*}$ \\
\hline Prior to Batch 2 & Ambient & 20.1 & 20.2 & 19.8 & 19.9 \\
\hline Prior to Batch 2 & Boiling Water & 99.7 & 99.9 & 99.3 & 99.6 \\
\hline $\begin{array}{c}\text { After } \\
\text { Calcinations } \\
\text { Complete }\end{array}$ & Ambient & 19.5 & 19.7 & 19.3 & 19.4 \\
\cline { 2 - 6 } & In furnace @ 6999 ${ }^{\circ} \mathbf{C}^{\dagger}$ & $\mathbf{6 7 5 . 9}$ & $\mathbf{6 7 8 . 2}$ & $\mathbf{6 7 5 . 4}$ & $\mathbf{6 7 1 . 3}$ \\
\cline { 2 - 6 } & In furnace @ 777 ${ }^{\circ} \mathrm{C}^{\dagger}$ & 754.3 & 756.4 & 753.6 & 750.0 \\
\hline $\begin{array}{c}\text { After } \\
\text { Calcinations } \\
\text { Complete }\end{array}$ & $\begin{array}{c}\text { Start of } 1^{\text {st }} \\
\text { solidification of Al }\end{array}$ & 653 & $(647)$ & $(647)$ & $(645)$ \\
\cline { 2 - 6 } & End of 2 ${ }^{\text {nd }} \mathrm{Al} \mathrm{melting}$ & $\sim 654$ & $(737)$ & $(736)$ & $(729)$ \\
\cline { 2 - 6 } & $\begin{array}{c}\text { Start of 2nd } \\
\text { solidification of Al }\end{array}$ & 653 & $(651)$ & $(651)$ & $(650)$ \\
\cline { 2 - 6 } & End of 3d $\mathrm{Al}$ melting & $\sim 658$ & $(747)$ & $(746)$ & $(738)$ \\
\hline
\end{tabular}

*Post-evaluation inspection showed that $\mathrm{T}_{1}$ and $\mathrm{T}_{2}$ were nearly touching each other and were at the bottom of the crucible. The tips of thermocouples $T_{3}$ and $T_{4}$ were both about halfway up the crucible, not touching each other and $\mathrm{T}_{4}$ was not touching the crucible. All temperatures were still rising slowly.

${ }^{\dagger}$ Thermocouple temperatures still increasing slowly when temperatures recorded.

${ }^{\#}$ Only $\mathrm{T}_{1}$ was in contact with the Al block. Thermocouples $\mathrm{T}_{2}-\mathrm{T}_{4}$ were positioned together elsewhere.

\section{5 $\underline{\text { Characterization }}$}

\subsubsection{Descriptive Results}

A typical $\mathrm{PuO}_{2}$ sample from an early batch (with a 30-mL crucible) is shown in Figure 3-2.

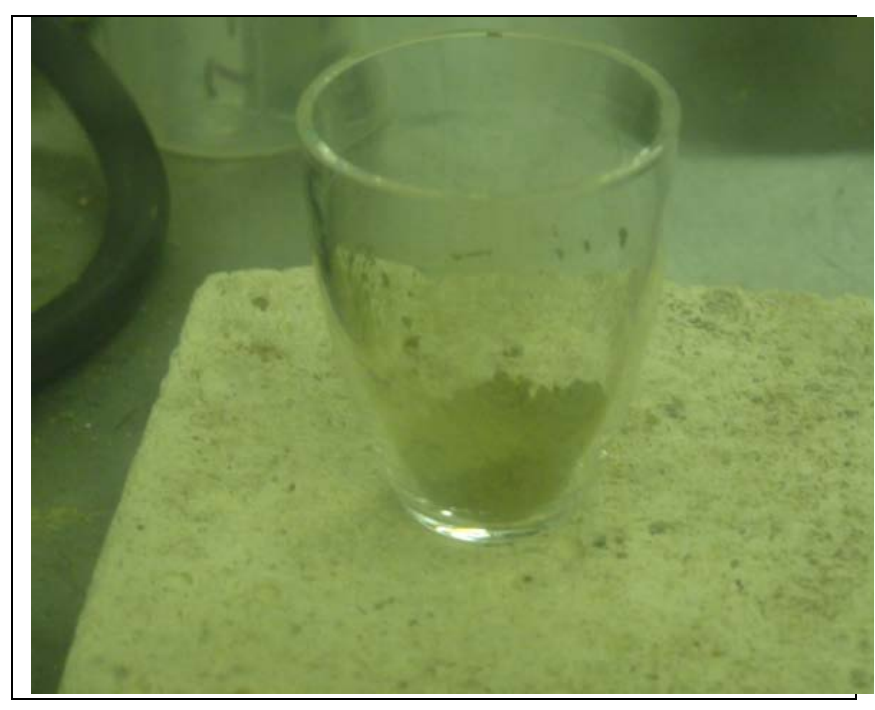

Figure 3-2. Typical $\mathrm{PuO}_{2}$ Sample after Calcination 
Samples from most batches were submitted for morphology characterization by SEM. Typical results for a $\mathrm{PuO}_{2}$ and a $\mathrm{Pu}$ oxalate sample are shown in Figures 3-3 and 3-4, respectively. Additional examples are available in the pertinent laboratory notebook. ${ }^{13}$

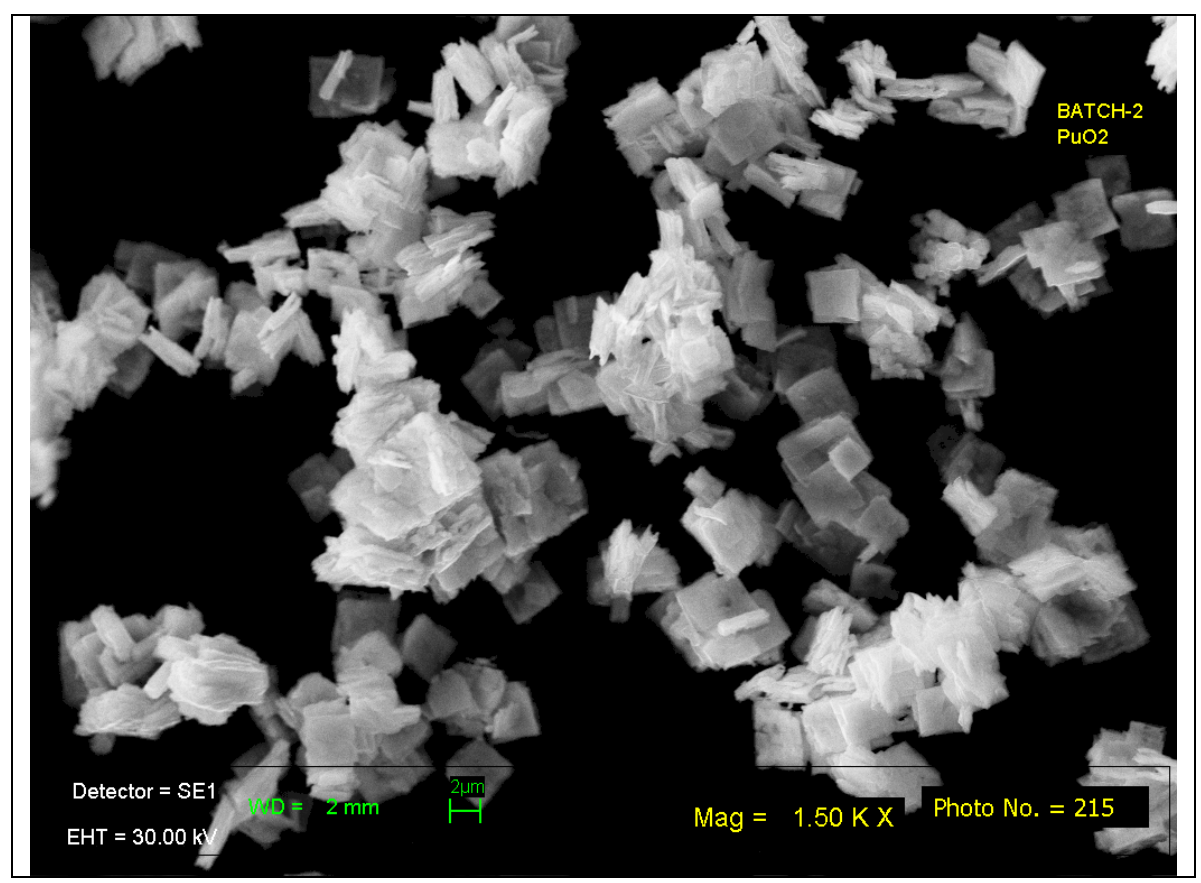

Figure 3-3. Typical SEM Results for $\mathrm{PuO}_{2}$

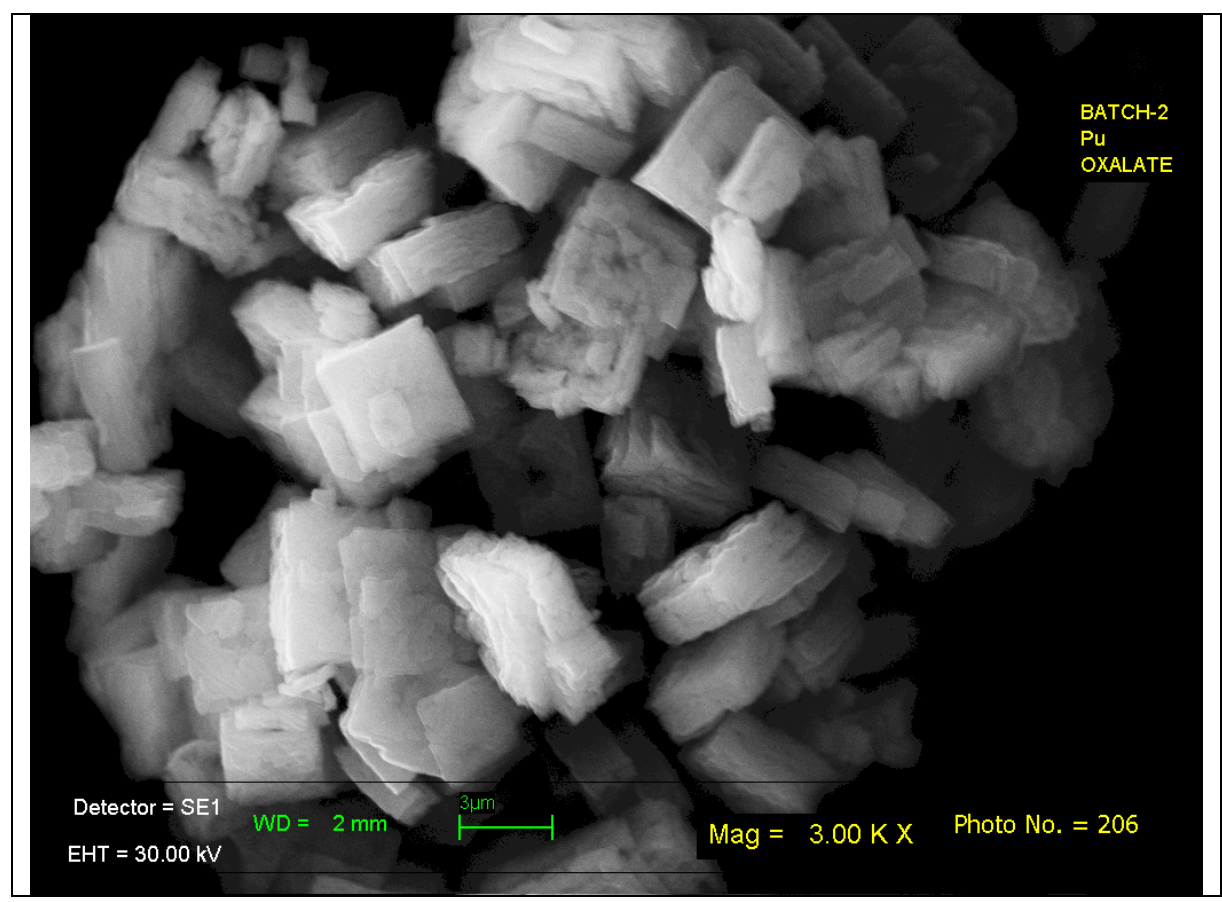

Figure 3-4. Typical SEM Results for Pu Oxalate 


\subsubsection{Moisture Analysis by TGA-MS}

Typical TGA-MS plots for $\mathrm{PuO}_{2}$ samples produced in this study are shown in Figures 3-5 through 3-7.

TGA-MS: FY2012 AFS2 (B3-1a)

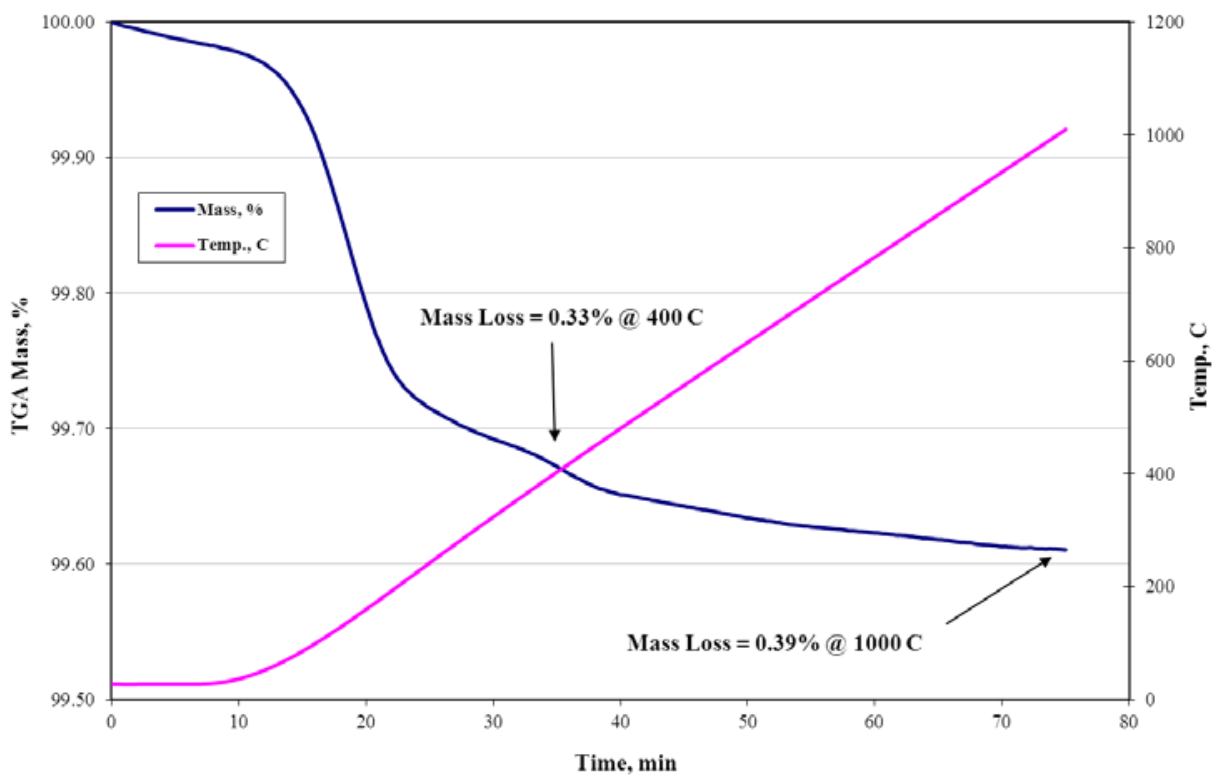

Figure 3-5. TGA Mass Measurement for Sample B3-1a

TGA-MS: FY2012 AFS2 (B3-1a)

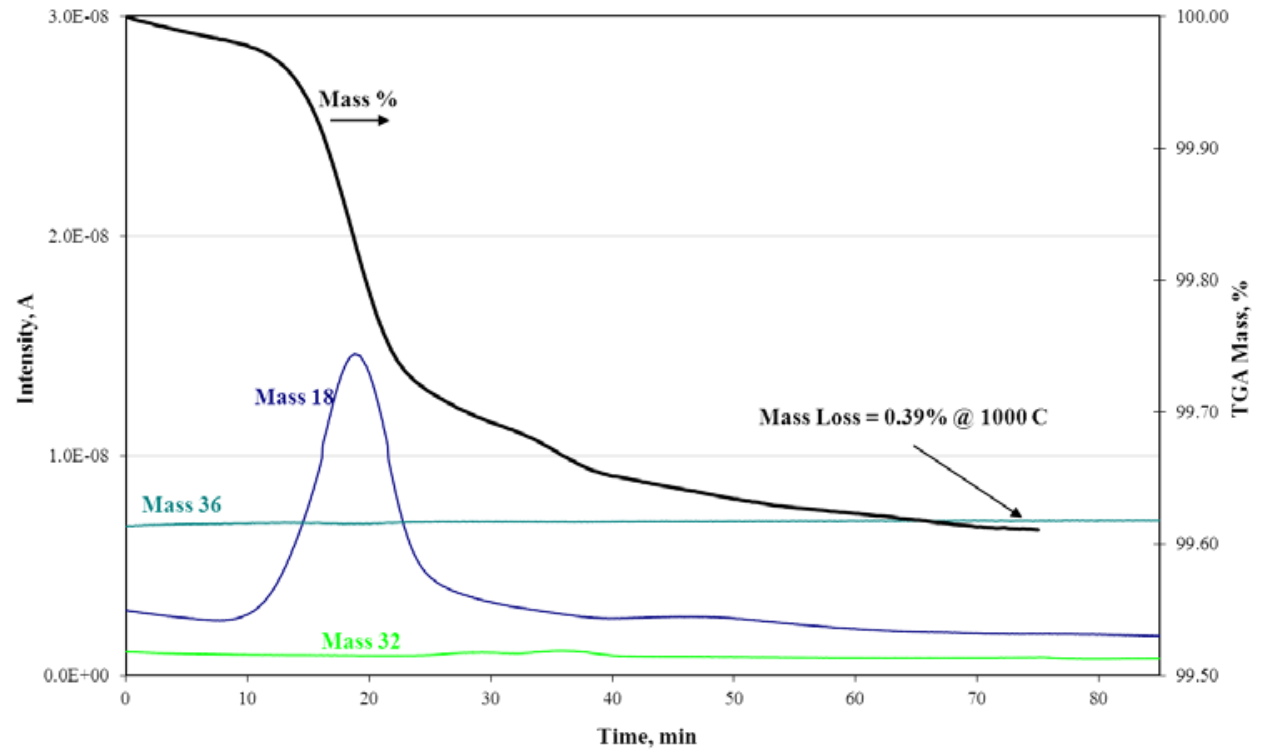

Figure 3-6. MS Signals (linear scale) from TGA-MS Analysis of Sample B3-1a 
SRNL-STI-2012-00338

Revision 0

TGA-MS: FY2012 AFS2 (B3-1a)

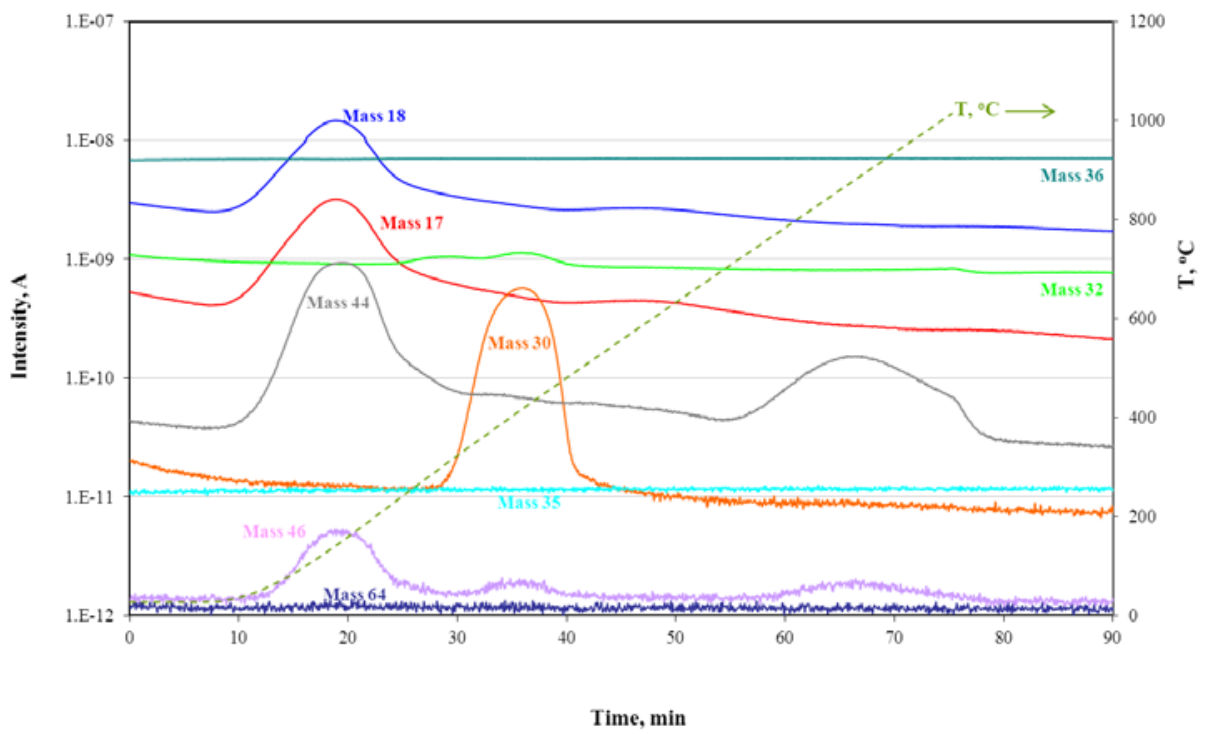

Figure 3-7. MS Signals (logarithmic scale) from TGA-MS Analysis of Sample B3-1a

As shown in Figures 3-5 through 3-7, heating to $400{ }^{\circ} \mathrm{C}$ caused release of nearly all of the moisture from Sample B3-1a. In addition, the largest portion of the carbon release, measured as Mass 44 or $\mathrm{CO}_{2}$ (carbon dioxide), occurred in the same $\sim 40-300{ }^{\circ} \mathrm{C}$ temperature range as the bulk of the moisture release. With carbon, however, the release of $\mathrm{CO}_{2}$ continued through heating, with a second, smaller release centered at $\sim 850{ }^{\circ} \mathrm{C}$. A release of Mass 30, attributed to NO (nitric oxide), occurred in the $300-500{ }^{\circ} \mathrm{C}$ range. The MS showed no other significant gas releases, including no Mass 28, which can be attributed to CO (carbon monoxide).

For samples in this study, the general shape of the TGA-MS time/temperature profile of gases released did not change. As an example, TGA-MS results from another sample are shown in Figures 3-8 and 3-9. The TGA-MS results for a third sample are provided in the Appendix, and results from all the samples in this study are in the pertinent laboratory notebook. ${ }^{13}$ Table A-3 in the Appendix also provides 95\% confidence limits for each of the MS moisture results, as calculated by JMP 5.0.1a statistical software and confirmed by Excel calculations. The confidence limits are based on the linearity of the pertinent moisture calibration curve generated by analysis of gypsum standards. Except for Batch 2 samples, the 95\% confidence limits for MS moisture contents were $\pm 10 \%$ of the reported value. Batch 2 values had higher uncertainties because one Batch 2 measurement involved a $3.7 \mathrm{~g}$ sample, which is well above typical amounts. To bound the moisture content of the larger sample, a large gypsum standard was required and thus a large crucible was required, which yields higher uncertainties. The testing of samples significantly greater than $3 \mathrm{~g}$ is not expected in future analyses.

Calibration of the TGA-MS for moisture using gypsum $\left(\mathrm{CaSO}_{4} \cdot 2 \mathrm{H}_{2} \mathrm{O}\right)$ standards yielded moisture contents for each sample, which included in the summary Tables 3-7 and 3-8. The 95\% Confidence Intervals for the MS moisture content values are provided in Appendix A. In a similar fashion, the 95\% Confidence Intervals for the SSA values in Tables 3-7 and 3-8 are provided in Appendix A. Generally, SSA samples are analyzed in duplicate and the average is 
reported. The confidence interval for a specific sample depends in part on the precision of the duplicate portions of that sample. For this study, the SSA 95\% confidence intervals correspond to percentage uncertainties ranging from \pm 1.5 to \pm 4 .

TGA-MS: FY2012 AFS2 (B4-1b)

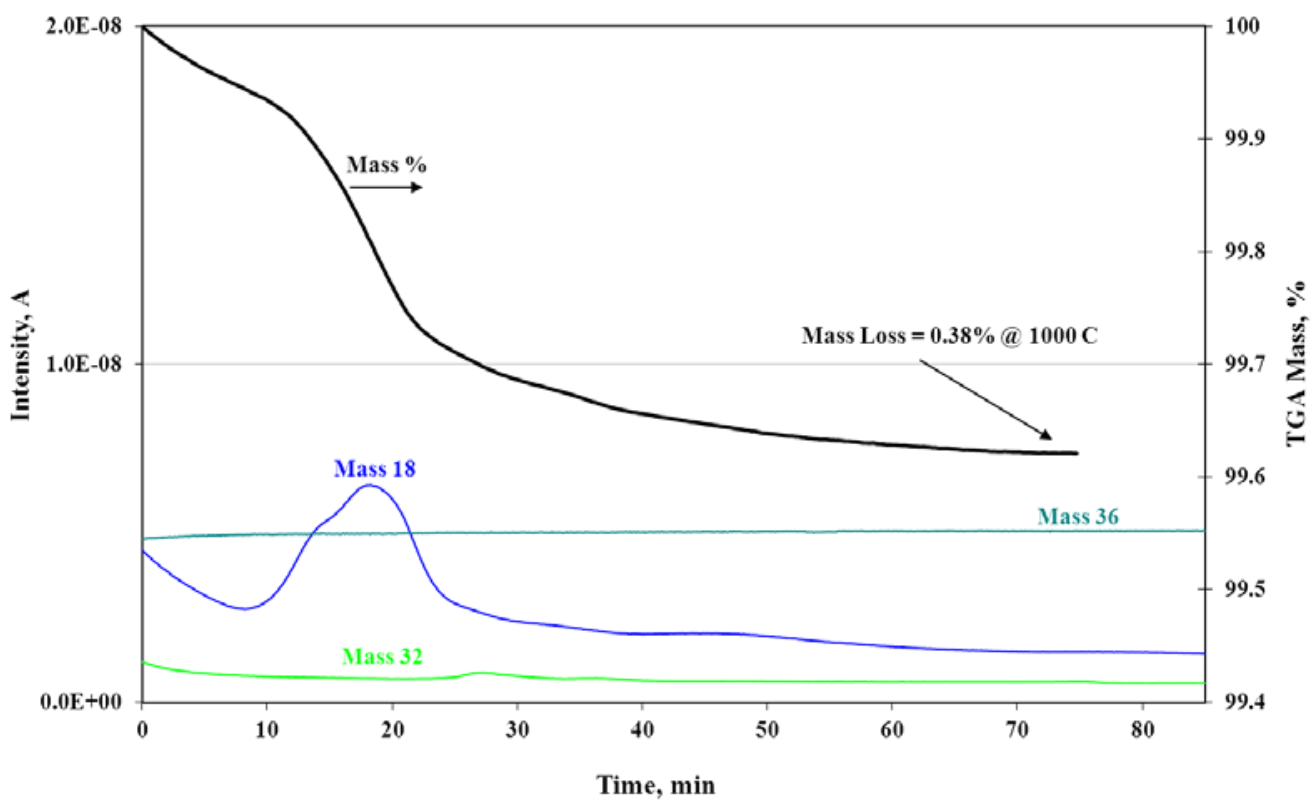

Figure 3-8. MS Signals (linear scale) from TGA-MS Analysis of Sample B4-1b

TGA-MS: FY2012 AFS2 (B4-1b)

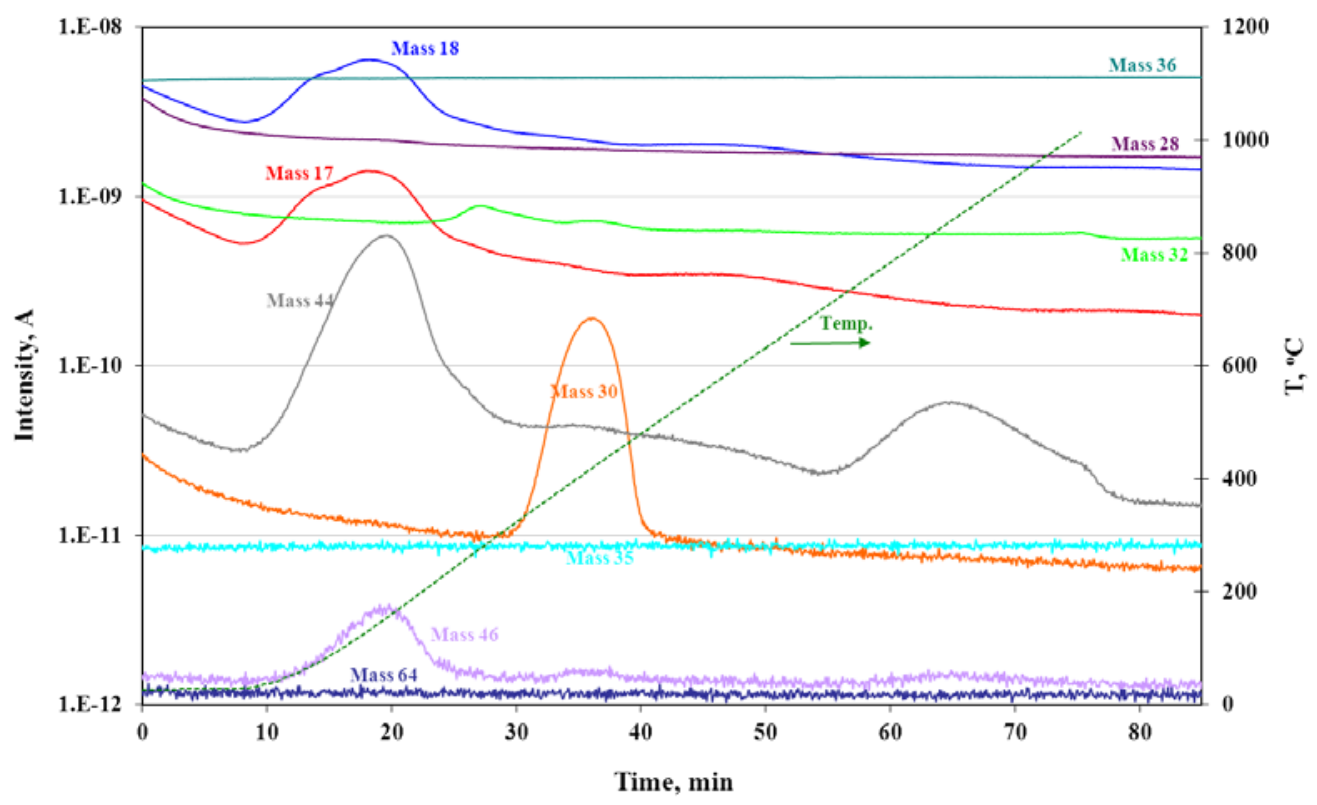

Figure 3-9. MS Signals (logarithmic scale) from TGA-MS Analysis of Sample B4-1b. 


\subsubsection{Carbon Analysis}

Results for carbon content for the samples analyzed are shown in Table 3-7. A later report will compare carbon analysis by TGA-MS to these values measured by a carbon analyzer. The values in Table 3-7 show that the carbon contents of $\mathrm{PuO}_{2}$ produced at SRNL easily met the Column A limit of $1000 \mu \mathrm{g} \mathrm{C/g} \mathrm{Pu}$, and the Column B limit of $500 \mu \mathrm{g} \mathrm{C/g} \mathrm{Pu}$, although the B4-1 sample would slightly exceed the Column B limit with the addition of $\pm 10 \%$ uncertainty. For this carbon analysis, method development is not complete, but an uncertainty of $\pm 10 \%$ is expected. The values in Table 3-7 reflect averages of duplicate analyses, and the duplicate results stayed within $\pm 10 \%$ except where noted.

Table 3-7. Carbon Contents of $\mathrm{PuO}_{2}$ Samples

\begin{tabular}{|c|c|c|c||}
\hline Batch & $\mathbf{C}$ & $\begin{array}{c}\mathbf{C} \\
\boldsymbol{\mu g} / \mathbf{g} \\
\mathbf{s a m p l e}\end{array}$ & $\boldsymbol{\mu g}^{\mathbf{w} \mathbf{g} \mathbf{P u}^{\dagger}}$ \\
\hline B3-5A & 0.034 & 340 & 390 \\
\hline B3-5B & 0.027 & 270 & 310 \\
\hline B4-1 & 0.042 & 420 & 480 \\
\hline B4-2 & 0.017 & 170 & 190 \\
\hline D5-A & 0.023 & 230 & 260 \\
\hline D5-B & 0.018 & 180 & 210 \\
\hline D30-A & $0.023^{*}$ & 230 & 260 \\
\hline D30-B & 0.020 & 200 & 220 \\
\hline D15-A & 0.024 & 240 & 270 \\
\hline D15-B & $0.029^{\#}$ & 290 & 330 \\
\hline
\end{tabular}

* Result at $\pm 35 \%$. ${ }^{*}$ Result at $\pm 20 \%$.

${ }^{\dagger}$ Based on estimated assay of $0.87 \mathrm{~g} \mathrm{Pu} / \mathrm{g} \mathrm{PuO}_{2}$ sample.

\subsubsection{Characterization Highlights}

Tables 3-8 and 3-9 summarize TGA-MS and SSA results based on the processing conditions used during precipitation and calcination. 
Table 3-8. Characterization Highlights of Calcination Batches 1-3

\begin{tabular}{|c|c|c|c|c|c|c|c|c|c|c|c|}
\hline $\begin{array}{c}\text { Sample } \\
\text { ID }\end{array}$ & $\begin{array}{c}\text { Calc. } \\
\text { Temp. } \\
{ }^{\circ} \mathrm{C}\end{array}$ & $\begin{array}{c}\text { Calc. } \\
\text { Time, } \\
\text { h }\end{array}$ & $\begin{array}{c}\text { Specific } \\
\text { Surface } \\
\text { Area, } \mathrm{m}^{2} / \mathrm{g}\end{array}$ & $\begin{array}{c}\text { Additional } \\
\text { exposure } \\
\text { time, } \mathrm{h}\end{array}$ & $\begin{array}{c}\mathrm{RH}^{\S} \text { during } \\
\text { exposure, } \\
\%\end{array}$ & $\begin{array}{c}\text { TGA Mass } \\
\text { loss to } \\
1000 \mathrm{C} \text {, wt \% }\end{array}$ & $\begin{array}{c}\text { Moisture } \\
\text { by MS } \\
\text { wt \% }\end{array}$ & $\begin{array}{l}\text { Acidity of } \\
\text { precipitator } \\
\text { feed, M }\end{array}$ & $\begin{array}{c}\text { Crucible } \\
\text { holder? } \\
\text { Y or N }\end{array}$ & $\begin{array}{l}\text { Sample } \\
\text { size, } \\
\text { mg }\end{array}$ & $\begin{array}{c}\text { Furnace } \\
\text { Temp., } \\
{ }^{\circ} \mathrm{C}\end{array}$ \\
\hline B1-2 & $\sim 620^{*}$ & 2 & 13.5 & --- & --- & 0.58 & 0.42 & 0.77 & $\mathrm{~N}$ & 1981 & \multirow{5}{*}{677} \\
\hline B1-3a & $\sim 650^{*}$ & 3 & \multirow{2}{*}{13.2} & --- & --- & 0.30 & 0.22 & 0.77 & $\mathrm{~N}$ & 1414 & \\
\hline B1-3b & $\sim 650^{*}$ & 3 & & 21 & 18.5 & 0.56 & 0.40 & 0.77 & $\mathrm{~N}$ & 1290 & \\
\hline B1-4 & $\sim 690 * \dagger$ & 3 & 9.42 & --- & --- & 0.21 & 0.15 & 0.77 & $\mathrm{~N}$ & 2021 & \\
\hline B1-5 & 685* & 3.7 & 9.09 & --- & --- & 0.24 & 0.18 & 0.77 & $\mathrm{~N}$ & 2602 & \\
\hline B2-2a & 610 & 2 & \multirow{2}{*}{14.1} & --- & --- & 0.55 & 0.45 & 0.77 & $\mathrm{~N}$ & 1530 & \multirow[t]{2}{*}{640} \\
\hline $\mathrm{B} 2-2 \mathrm{~b}$ & 610 & 2 & & 3 & 33.5 & 0.67 & 0.58 & 0.77 & $\mathrm{~N}$ & 2313 & \\
\hline B2-3a & 625 & 3 & \multirow{2}{*}{13.7} & --- & --- & 0.53 & 0.44 & 0.77 & $\mathrm{~N}$ & 2235 & \multirow{2}{*}{640} \\
\hline $\mathrm{B} 2-3 \mathrm{~b}$ & 625 & 3 & & 18 & 33.5 & 0.79 & 0.66 & 0.77 & $\mathrm{~N}$ & 2538 & \\
\hline B2-4 & 625 & 4 & 12.4 & --- & --- & Inst. error & 0.26 & 0.77 & $\mathrm{~N}$ & 3599 & 650 \\
\hline B2-5 & 628 & 5 & 11.4 & 16 & 24.0 & Inst. error & 0.49 & 0.77 & $\mathrm{~N}$ & 3654 & 650 \\
\hline B3-1a & 650 & 4 & \multirow{2}{*}{7.83} & --- & --- & 0.39 & 0.32 & 0.77 & $\mathrm{~N}$ & 1386 & \multirow{2}{*}{665} \\
\hline B3-1b & 650 & 4 & & 3 & 21.0 & 0.39 & 0.35 & 0.77 & $\mathrm{~N}$ & 1794 & \\
\hline B3-2a & 650 & 2 & \multirow{2}{*}{7.78} & --- & --- & 0.46 & 0.38 & 0.77 & $\mathrm{~N}$ & 1262 & \multirow{2}{*}{666} \\
\hline B3-2b & 650 & 2 & & 4 & 33.1 & 0.49 & 0.42 & 0.77 & $\mathrm{~N}$ & 1107 & \\
\hline B3-3a & 650 & 3 & \multirow{2}{*}{5.61} & --- & --- & 0.34 & 0.30 & 0.77 & $\mathrm{~N}$ & 1496 & \multirow[t]{2}{*}{678} \\
\hline B3-3b & 650 & 3 & & 22 & 32.5 & 0.35 & 0.35 & 0.77 & $\mathrm{~N}$ & 1069 & \\
\hline B3-4a & 650 & 4 & \multirow{2}{*}{8.72} & --- & --- & 0.43 & 0.37 & 0.77 & $\mathrm{~N}$ & 1282 & \multirow{2}{*}{656} \\
\hline B3-4b & 650 & 4 & & 3.5 & 29.4 & 0.43 & 0.36 & 0.77 & $\mathrm{~N}$ & 962 & \\
\hline В3-5Aa & 640 & 4 & \multirow{2}{*}{6.79} & --- & --- & 0.30 & 0.27 & 0.77 & $\mathrm{Y}$ & 1020 & \multirow{2}{*}{670} \\
\hline B3-5Ab & 640 & 4 & & 3 & 33.8 & 0.31 & 0.26 & 0.77 & $\mathrm{Y}$ & 881 & \\
\hline B3-5Ba & 636 & 4 & \multirow{2}{*}{7.27} & --- & --- & 0.29 & 0.26 & 0.77 & $\mathrm{Y}$ & 1091 & \multirow{2}{*}{670} \\
\hline B3-5Bb & 636 & 4 & & 3 & 35.2 & 0.35 & 0.31 & 0.77 & $\mathrm{Y}$ & 922 & \\
\hline
\end{tabular}

*Thermocouple not in contact with sample during calcination.

$\dagger$ Plus an additional 0.7 hours at $\sim 655^{\circ} \mathrm{C} *$.

${ }^{\S} \mathrm{RH}$ values may be biased low by 5-10 units based on newly calibrated humidity meter. 
Table 3-9. Characterization Highlights of Additional Calcination Batches

\begin{tabular}{|c|c|c|c|c|c|c|c|c|c|c|c|}
\hline $\begin{array}{c}\text { Sample } \\
\text { ID }\end{array}$ & $\begin{array}{l}\text { Calc. } \\
\text { Temp. } \\
{ }^{\circ} \mathrm{C}\end{array}$ & $\begin{array}{l}\text { Calc. } \\
\text { Time, } \\
\text { h }\end{array}$ & $\begin{array}{c}\text { Specific } \\
\text { Surface } \\
\text { Area, } \mathrm{m}^{2} / \mathrm{g}\end{array}$ & $\begin{array}{c}\text { Additional } \\
\text { exposure } \\
\text { time, } \mathrm{h}\end{array}$ & $\begin{array}{c}\mathrm{RH}^{\S} \text { during } \\
\text { exposure, } \\
\%\end{array}$ & $\begin{array}{c}\text { TGA Mass } \\
\text { loss to } \\
1000 \mathrm{C} \text {, wt \% }\end{array}$ & $\begin{array}{l}\text { Moisture } \\
\text { by MS } \\
\text { wt \% }\end{array}$ & $\begin{array}{l}\text { Acidity of } \\
\text { precipitator } \\
\text { feed, } \mathrm{M}\end{array}$ & $\begin{array}{l}\text { Digestion } \\
\text { time } \\
\text { min }\end{array}$ & $\begin{array}{l}\text { Sample } \\
\text { size, } \\
\text { mg }\end{array}$ & $\begin{array}{c}\text { Furnace } \\
\text { Temp., } \\
{ }^{\circ} \mathrm{C}\end{array}$ \\
\hline B4-1a & 635 & 4 & \multirow{2}{*}{6.87} & --- & --- & 0.29 & 0.26 & $2.5-3.0$ & 6 & 761 & \multirow{2}{*}{658} \\
\hline B4-1b & 635 & 4 & & 4 & 35.1 & 0.38 & 0.34 & $2.5-3.0$ & 6 & 1208 & \\
\hline B4-2a & 650 & 4 & \multirow{3}{*}{5.20} & --- & --- & 0.26 & 0.20 & $2.5-3.0$ & 6 & 538 & \multirow{3}{*}{658} \\
\hline B4-2b & 650 & 4 & & 3 & 17 & 0.30 & 0.21 & $2.5-3.0$ & 6 & 593 & \\
\hline B4-2c & 650 & 4 & & 19.5 & 21 & 0.30 & 0.22 & $2.5-3.0$ & 6 & 509 & \\
\hline D5-A & 617 & 4 & 8.13 & --- & --- & 0.49 & 0.38 & $1.23-1.5^{*}$ & 5 & 559 & $656-670$ \\
\hline D5-B & \multirow{2}{*}{650} & \multirow{2}{*}{4} & \multirow{2}{*}{7.49} & $\begin{array}{ll}-- \\
\end{array}$ & --- & 0.42 & 0.31 & \multirow{2}{*}{$1.23-1.5^{*}$} & \multirow{2}{*}{5} & 448 & \multirow{2}{*}{$656-670$} \\
\hline D5-Bb & & & & 3 & $34.0-35.8$ & 0.46 & 0.30 & & & 242 & \\
\hline D30-A & 650 & 4 & 5.33 & --- & --- & 0.32 & 0.23 & $1.23-1.5^{*}$ & 30 & 586 & 695 \\
\hline D30-B & \multirow{2}{*}{636} & \multirow{2}{*}{4} & \multirow{2}{*}{8.98} & --- & --- & 0.46 & 0.35 & \multirow{2}{*}{$1.23-1.5^{*}$} & \multirow{2}{*}{30} & 418 & \multirow{2}{*}{ 671-679 } \\
\hline D30-Bb & & & & 3 & $39.0-39.0$ & 0.55 & 0.43 & & & 508 & \\
\hline D15-A & \multirow{2}{*}{650} & \multirow{2}{*}{4} & \multirow{2}{*}{7.15} & --- & --- & 0.42 & 0.34 & \multirow{2}{*}{$1.23-1.5^{*}$} & \multirow{2}{*}{15} & 607 & \multirow{2}{*}{ 684-699 } \\
\hline D15-Ab & & & & 66 & $36.1-18.0$ & 0.44 & 0.30 & & & 455 & \\
\hline D15-B & \multirow{2}{*}{635} & \multirow{2}{*}{4} & \multirow{2}{*}{9.71} & --- & --- & 0.44 & 0.33 & \multirow{2}{*}{$1.23-1.5^{*}$} & \multirow{2}{*}{15} & 749 & \multirow{2}{*}{ 676-702 } \\
\hline D15-Bb & & & & 16 & $15.7-16.8$ & 0.53 & 0.40 & & & 632 & \\
\hline
\end{tabular}

Note: All samples on this page were calcined in a quartz crucible setting inside a firebrick crucible holder.

*Free acid analyses of a precipitator feed samples report 1.23 and $1.33 \mathrm{M}$. Volume additions indicated an acid concentration of $1.5 \mathrm{M}$.

${ }^{\S} \mathrm{RH}$ values may be biased low by 5-10 units based on newly calibrated humidity meter. 


\subsubsection{Particle Size Analysis}

Additionally, personnel performed particle size analysis on both $\mathrm{PuO}_{2}$ and $\mathrm{Pu}$ oxalate samples. The results are summarized in Tables 3-10 and 3-11 and the plots of particle size distribution are provided in Appendix C.

Table 3-10. Particle Size Analyses of $\mathrm{PuO}_{2}$ Samples

\begin{tabular}{|c|c|c|c||}
\hline $\begin{array}{c}\text { Sample } \\
\text { ID }\end{array}$ & $\begin{array}{c}\text { Particle Size } \\
\text { Range }\end{array}$ & $\begin{array}{c}\text { Mean* } \\
\text { Particle } \\
\text { Size } \\
\boldsymbol{\mu m}\end{array}$ & $\begin{array}{c}\text { Standard } \\
\text { Deviation }\end{array}$ \\
\hline Batch $1 \mathrm{PuO}_{2}$ & $0.204-62.23$ & 6.647 & $\boldsymbol{\mu m}$ \\
\hline Batch $2 \mathrm{PuO}_{2}$ & $\mathrm{NM}$ & $\mathrm{NM}$ & $\mathrm{NM}$ \\
\hline Batch $3 \mathrm{PuO}_{2}$ & $0.204-44.00$ & 6.365 & 3.981 \\
\hline Batch 4 $\mathrm{PuO}_{2}$ & $0.204-74.00$ & 9.255 & 6.168 \\
\hline Batch D-5A PuO & $0.204-88.00$ & 8.758 & 5.808 \\
\hline Batch D-5B $\mathrm{PuO}_{2}$ & $0.204-88.00$ & 9.273 & 5.976 \\
\hline Batch D-30 $\mathrm{PuO}_{2}$ & $0.204-62.23$ & 6.662 & 3.630 \\
\hline Batch D-15 $\mathrm{PuO}_{2}$ & $0.204-88.00$ & 8.295 & 5.016 \\
\hline
\end{tabular}

*Mean Particle Size determined on a volumetric basis.

NM - Not Measured

Table 3-11. Particle Size Analyses of Pu Oxalate Samples

\begin{tabular}{|c|c|c|c|c|}
\hline $\begin{array}{c}\text { Sample } \\
\text { ID }\end{array}$ & $\begin{array}{c}\begin{array}{c}\text { Particle Size } \\
\text { Range }\end{array} \\
\mu \mathrm{m}\end{array}$ & $\begin{array}{c}\text { Mean* } \\
\text { Particle } \\
\text { Size } \\
\mu \mathrm{m}\end{array}$ & $\begin{array}{c}\text { Standard } \\
\text { Deviation } \\
\mu \mathrm{m}\end{array}$ & Comments \\
\hline $\begin{array}{c}\text { Batch } 2 \\
\text { Pu Oxalate }\end{array}$ & $0.172-352.0$ & 23.91 & 17.98 & $\begin{array}{c}\text { Bi-modal } \\
\text { distribution }\end{array}$ \\
\hline $\begin{array}{c}\text { Batch } 4 \\
\text { Pu Oxalate }\end{array}$ & $0.172-124.5$ & 16.18 & 11.25 & $\begin{array}{c}\text { Bi-modal } \\
\text { distribution }\end{array}$ \\
\hline $\begin{array}{l}\text { Batch D-5 } \\
\text { Pu Oxalate }\end{array}$ & $0.344-124.5$ & 13.10 & 7.949 & --- \\
\hline $\begin{array}{l}\text { Batch D-30 } \\
\text { Pu Oxalate }\end{array}$ & $0.172-88.00$ & 10.54 & 6.349 & --- \\
\hline $\begin{array}{l}\text { Batch D-15 } \\
\text { Pu Oxalate }\end{array}$ & $0.344-124.5$ & 13.20 & 7.566 & --- \\
\hline
\end{tabular}

*Mean Particle Size determined on a volumetric basis.

\subsection{Review of Moisture Analyses}

Extracting key information from Tables 3-8 and 3-9 allows the comparisons in Table 3-12. One observation from the calculated ratio of MS moisture/TGA mass loss is that the MS moisture content averages $80 \pm 8 \%$ of the total TGA mass loss. Similarly, these samples consistently showed nominally 2 monolayer equivalents of moisture, using the accepted value of $0.22 \mathrm{mg}$ $\mathrm{H}_{2} \mathrm{O} / \mathrm{m}^{2}$ per monolayer ${ }^{14}$. 
Table 3-12. Relations Between MS Moisture, TGA, and SSA

\begin{tabular}{|c|c|c|c|c|c|}
\hline Batch & $\begin{array}{l}\text { SSA } \\
\mathrm{m}^{2} / \mathrm{g}\end{array}$ & $\begin{array}{c}\text { MS } \\
\text { wt \% } \\
\end{array}$ & $\begin{array}{l}\text { MS/ } \\
\text { TGA }\end{array}$ & $\begin{array}{c}\mathrm{H}_{2} \mathrm{O} \\
\mathrm{mg} / \mathrm{m}^{2}\end{array}$ & $\begin{array}{c}\text { Monolayer } \\
\text { equiv. }\end{array}$ \\
\hline B1-2 & 13.5 & 0.42 & 0.72 & 0.31 & 1.4 \\
\hline B1-3a & 13.2 & 0.22 & 0.73 & 0.17 & 0.8 \\
\hline B1-3b & 13.2 & 0.40 & 0.71 & 0.30 & 1.4 \\
\hline B1-4 & 9.42 & 0.15 & 0.71 & 0.16 & 0.7 \\
\hline B1-5 & 9.09 & 0.18 & 0.75 & 0.20 & 0.9 \\
\hline B2-2a & 14.1 & 0.45 & 0.82 & 0.32 & 1.5 \\
\hline B2-2b & $\begin{array}{l}14.1 \\
\end{array}$ & 0.58 & 0.87 & 0.41 & 1.9 \\
\hline B2-3a & $\begin{array}{l}13.7 \\
\end{array}$ & 0.44 & $\begin{array}{l}0.83 \\
\end{array}$ & 0.32 & 1.5 \\
\hline $\bar{B} 2-3 b$ & 13.7 & 0.66 & 0.84 & 0.48 & 2.2 \\
\hline B2-4 & 12.4 & 0.26 & NA & 0.21 & 1.0 \\
\hline B2-5 & 11.4 & 0.49 & NA & 0.43 & 2.0 \\
\hline B3-1a & 7.83 & 0.32 & 0.82 & 0.41 & 1.9 \\
\hline B3-1b & 7.83 & 0.35 & 0.90 & 0.45 & 2.0 \\
\hline B3-2a & 7.78 & 0.38 & 0.83 & 0.49 & 2.2 \\
\hline B3-2b & 7.78 & 0.42 & 0.86 & 0.54 & 2.5 \\
\hline B3-3a & 5.61 & 0.30 & 0.88 & 0.53 & 2.4 \\
\hline B3-3b & 5.61 & 0.35 & 1.00 & 0.62 & 2.8 \\
\hline B3-4a & 8.72 & 0.37 & 0.86 & 0.42 & 1.9 \\
\hline B3-4b & 8.72 & 0.36 & 0.84 & 0.41 & 1.9 \\
\hline B3-5Aa & 6.79 & 0.27 & 0.90 & 0.40 & 1.8 \\
\hline B3-5Ab & 6.79 & 0.26 & 0.84 & 0.38 & 1.7 \\
\hline B3-5Ba & 7.27 & 0.26 & 0.90 & 0.36 & 1.6 \\
\hline B3-5Bb & 7.27 & 0.31 & 0.89 & 0.43 & 1.9 \\
\hline B4-1a & 6.87 & 0.26 & 0.90 & 0.38 & 1.7 \\
\hline B4-1b & 6.87 & 0.34 & 0.89 & 0.49 & 2.2 \\
\hline B4-2a & 5.20 & 0.20 & 0.77 & 0.38 & 1.7 \\
\hline B4-2b & 5.20 & 0.21 & 0.70 & 0.40 & 1.8 \\
\hline B4-2c & 5.20 & 0.22 & 0.73 & 0.42 & 1.9 \\
\hline D5-A & 8.13 & 0.38 & 0.78 & 0.47 & 2.1 \\
\hline D5-B & 7.49 & 0.31 & 0.74 & 0.41 & 1.9 \\
\hline D5-Bb & 7.49 & 0.30 & 0.65 & 0.40 & 1.8 \\
\hline D30-A & 5.33 & 0.23 & 0.72 & 0.43 & 2.0 \\
\hline D30-B & 8.98 & 0.35 & 0.76 & 0.39 & 1.8 \\
\hline D30-Bb & 8.98 & 0.43 & 0.78 & 0.48 & 2.2 \\
\hline D15-A & 7.15 & 0.34 & 0.81 & 0.48 & 2.2 \\
\hline D15-Ab & 7.15 & 0.30 & 0.68 & 0.42 & 1.9 \\
\hline D15-B & 9.71 & 0.33 & 0.75 & 0.34 & 1.5 \\
\hline D15-Bb & 9.71 & 0.40 & 0.75 & 0.41 & 1.9 \\
\hline \multirow{2}{*}{ 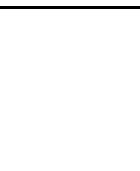 } & & Average & 0.80 & $\begin{array}{l}\text { Average } \\
\text { without } \\
\text { Batch } 1 \\
\end{array}$ & 1.8 \\
\hline & & Std. Dev. & 0.08 & Std. Dev. & 0.33 \\
\hline
\end{tabular}

NA = Not available due to TGA instrument error. 


\subsection{Statistical Analyses}

The calcination data of plutonium oxalate $\left(\mathrm{Pu}\left(\mathrm{C}_{2} \mathrm{O}_{4}\right)_{2}\right)$ into $\mathrm{PuO}_{2}$ was analyzed with JMP 5.0.1a looking at the effect of calcination temperature, calcination time, batch size, digestion time, and initial precipitation feed acidity on the SSA of the $\mathrm{PuO}_{2}$. After performing leverage analyses of the data in Table 3-13, two cases of interest are reported. For Case 1, all the data was included but Feed Acidity was not a potential factor. In Case 2, Feed Acidity was included as a potential factor. For Case 2, the software tested for effects with all of the data and with Batch 1 data excluded, since the temperatures reported for Batch 1 have higher uncertainties.

Table 3-13. Summary of Data for Statistical Analysis

\begin{tabular}{|c|c|c|c|c|c|c|c|}
\hline Batch & Sample & $\begin{array}{c}\text { SSA, } \\
\mathbf{m}^{2} / \mathbf{g}\end{array}$ & $\begin{array}{c}\text { Calc. } \\
\text { Temp. } \\
{\left[{ }^{\circ} \mathbf{C}\right]}\end{array}$ & $\begin{array}{c}\text { Calc. } \\
\text { Time } \\
{[\mathbf{h}]}\end{array}$ & $\begin{array}{c}\text { Batch } \\
\text { size }[\mathbf{g}]\end{array}$ & $\begin{array}{c}\text { Digestion } \\
\text { Time }[\mathbf{h}]\end{array}$ & $\begin{array}{c}\text { Feed } \\
\text { Acidity } \\
{[\mathbf{M}]}\end{array}$ \\
\hline 1 & B1-2 & 13.5 & 620 & 2 & 3.01 & 0.283 & 0.77 \\
\hline 1 & B1-3 & 13.2 & 650 & 3 & 4.14 & 0.283 & 0.77 \\
\hline 1 & B1-4 & 9.42 & 690 & 3 & 2.98 & 0.283 & 0.77 \\
\hline 1 & B1-5 & 9.09 & 685 & 3.7 & 3.64 & 0.283 & 0.77 \\
\hline 2 & B2-2 & 14.1 & 610 & 2 & 4.67 & 0.217 & 0.77 \\
\hline 2 & B2-3 & 13.7 & 625 & 3 & 5.65 & 0.217 & 0.77 \\
\hline 2 & B2-4 & 12.4 & 625 & 4 & 4.41 & 0.217 & 0.77 \\
\hline 2 & B2-5 & 11.4 & 628 & 5 & 4.49 & 0.217 & 0.77 \\
\hline 3 & B3-1 & 7.83 & 650 & 4 & 4.1 & 0.25 & 0.77 \\
\hline 3 & B3-2 & 7.78 & 650 & 2 & 3.33 & 0.25 & 0.77 \\
\hline 3 & B3-3 & 5.61 & 650 & 3 & 4.08 & 0.25 & 0.77 \\
\hline 3 & B3-4 & 8.72 & 650 & 4 & 3.39 & 0.25 & 0.77 \\
\hline 3 & B3-5A & 6.79 & 640 & 4 & 3.33 & 0.25 & 0.77 \\
\hline 3 & B3-5B & 7.27 & 636 & 4 & 3.36 & 0.25 & 0.77 \\
\hline 4 & B4-1 & 6.87 & 635 & 4 & 3.5 & 0.10 & 3.0 \\
\hline 4 & B4-2 & 5.20 & 650 & 4 & 3.36 & 0.10 & 3.0 \\
\hline D5 & D5-A & 8.13 & 617 & 4 & 2.09 & 0.083 & 1.28 \\
\hline D5 & D5-B & 7.49 & 650 & 4 & 2.34 & 0.083 & 1.28 \\
\hline D30 & D30-A & 5.33 & 650 & 4 & 2.01 & 0.5 & 1.28 \\
\hline D30 & D30-B & 8.98 & 636 & 4 & 2.63 & 0.5 & 1.28 \\
\hline D15 & D15-A & 7.15 & 650 & 4 & 2.56 & 0.25 & 1.28 \\
\hline D15 & D15-B & 9.71 & 635 & 4 & 2.64 & 0.25 & 1.28 \\
\hline
\end{tabular}

The JMP statistical software developed a model and a corresponding fit of actual SSA results versus SSA values predicted by the model. For Case 1, the RSquare value in the Summary of Fit, shown in Table 3-14, indicates that some dependence of SSA is captured by the various effects (e.g., calcination temp.). Then, the Parameter Estimate, shown in Table 3-15, provides t-statistic values, which indicate that Batch Size (g) is a significant or non-zero effect and has a more significant effect than Calcination Temp. $\left({ }^{\circ} \mathrm{C}\right)$ and Calcination Time (h), which may be interacting with Batch Size. Also, Digestion Time (h) is not a significant effect. These results are indicated in Table 3-15 where the probability that the parameter estimate is zero (prob $>|t|)$ is about 2\% for the Batch Size, 9\% for the Calcination Temp., 12\% for the Calc. Time and 43\% for the Digestion Time. The Summary of Fit, shown in Table 3-14, indicates that the SSA is not a simple linear function of the calcination temperature, time, and batch size by the adjusted $\mathrm{R}^{2}$ of only 0.39. The prior literature review ${ }^{6}$ of $\mathrm{PuO}_{2} \mathrm{SSA}$ data indicated that calcination temperature and time were primary effects on SSA and that the dependence was not linear. 
Table 3-14. Statistical Summary of Fit - Case 1: All Data, 4 Parameters

\begin{tabular}{|l|r|}
\hline RSquare & 0.5091 \\
\hline RSquare Adj & 0.3936 \\
\hline Root Mean Square Error & 2.1833 \\
\hline Mean of Response & 9.076 \\
\hline Observations (or Sum Wgts) & 22 \\
\hline
\end{tabular}

Table 3-15. Statistical Parameter Estimate- Case 1: All Data, 4 Parameters

\begin{tabular}{||l|r|r|r|r||}
\hline Term & Estimate & \multicolumn{1}{|c|}{ Std Error } & \multicolumn{1}{c|}{ t Ratio } & \multicolumn{1}{c|}{ Prob $>|\mathrm{t}|$} \\
\hline Intercept & 36.81 & 16.98 & 2.17 & 0.0446 \\
\hline Calc. Temp. $\left[{ }^{\circ} \mathrm{C}\right]$ & -0.0464 & 0.0257 & -1.81 & 0.0887 \\
\hline Calc. Time $[\mathrm{h}]$ & -1.010 & 0.6231 & -1.62 & 0.1233 \\
\hline Batch Size $[\mathrm{g}]$ & 1.391 & 0.5561 & 2.50 & 0.0229 \\
\hline Digestion Time $[\mathrm{h}]$ & 3.749 & 4.678 & 0.80 & 0.4339 \\
\hline
\end{tabular}

For Case 2, the statistical results showed that both Calcination Temperature and Batch Size have a significant effect on the SSA but that the other parameters do not. Since the Case 2 results which excluded Batch 1 data had a better fit, those results are reported in Tables 3-16 and 3-17. From Table 3-17, the probability that the parameter estimate is zero (prob $>|t|)$ is about $0.2 \%$ for the Calcination Temp., 4\% for the Batch Size, 20\% for the Feed Acidity, and significantly higher (less likely to have an effect) for Digestion Time and Calcination Time.

Table 3-16. Statistical Summary of Fit - Case 2: Omit Batch 1 Data, 5 Parameters

\begin{tabular}{||l|r|}
\hline \hline RSquare* & 0.7844 \\
\hline RSquare Adj & 0.6946 \\
\hline Root Mean Square Error & 1.4923 \\
\hline Mean of Response & 8.5811 \\
\hline Observations (or Sum Wgts) & 18 \\
\hline
\end{tabular}

*RSquare indicates that excluding Batch 1 data gives a better

fit to SSA than including Batch 1, and a better fit than Case 1.

Table 3-17. Statistical Parameter Estimate-Case 2: Omit Batch 1 Data, 5 Parameters

\begin{tabular}{||l|r|r|r|r||}
\hline Term & \multicolumn{1}{|c|}{ Estimate } & \multicolumn{1}{|c|}{ Std Error } & \multicolumn{1}{c|}{ Probio $>|\mathrm{t}|$} \\
\hline Intercept & 85.17 & 20.0565 & 4.25 & 0.0011 \\
\hline Calc. Temp. $\left[{ }^{\circ} \mathrm{C}\right]$ & -0.1245 & 0.03078 & -4.05 & 0.0016 \\
\hline Calc. Time $[\mathrm{h}]$ & 0.00530 & 0.5147 & 0.01 & 0.9920 \\
\hline Batch Size $[\mathrm{g}]$ & 1.0267 & 0.4339 & 2.37 & 0.0356 \\
\hline Digestion Time $[\mathrm{h}]$ & 1.281 & 3.553 & 0.36 & 0.7248 \\
\hline Feed Acidity $[\mathrm{M}]$ & -0.8115 & 0.6013 & -1.35 & 0.2021 \\
\hline
\end{tabular}

Excluding Batch 1 data indicates that Calc. Temp. $\left[{ }^{\circ} \mathrm{C}\right]$ and Batch Size [g] are significant or non-zero effects and Calc. Time [h], Digestion Time [h], and Feed Acidity [M] are not significant effects.

Including Batch 1 data yielded the same results as to which parameters are significant effects on SSA. 
Though the statistical analyses showed that Batch Size had a significant effect on SSA in this study, the actual range of Batch Sizes tested, 2.01 - $5.65 \mathrm{~g} \mathrm{PuO}_{2}$, seems too narrow for a Batch Size evaluation. A study planned to follow this study will have two $\mathrm{PuO}_{2}$ batch sizes of $\sim 40 \mathrm{~g}$, which may help in evaluating this factor. In addition, historical experience with neptunium oxide $\left(\mathrm{NpO}_{2}\right)$ production in HB-line showed similar SSA values between SRNL-produced $\mathrm{NpO}_{2}$ on the 25-g scale and $\mathrm{HB}-\mathrm{Line} \mathrm{NpO}_{2}$ produced on the 1-kg scale, ${ }^{2}$ where calcination temperatures and times were also similar.

\subsection{Conclusions}

An anion exchange column experiment produced $1.4 \mathrm{~L}$ of a purified $52.6 \mathrm{~g} / \mathrm{L}$ Pu solution. Over the next nine weeks, seven $\mathrm{Pu}(\mathrm{IV})$ oxalate precipitations were performed using the same stock $\mathrm{Pu}$ solution, with precipitator feed acidities ranging from $0.77 \mathrm{M}$ to $3.0 \mathrm{M}$ nitric acid and digestion times ranging from 5 to 30 minutes. Analysis of precipitator filtrate solutions showed Pu losses below $1 \%$ for all precipitations. The four larger precipitation batches matched the target oxalic acid addition time of 44 minutes within 4 minutes. For the three smaller precipitation batches that focused on evaluation of digestion time, the oxalic acid addition step ranged from 25-34 minutes because of pump limitations in the low flow range.

Following the precipitations, 22 calcinations were performed in the range of $610-690{ }^{\circ} \mathrm{C}$, with the largest number of samples calcined at 650 or $635^{\circ} \mathrm{C}$. Characterization of the resulting $\mathrm{PuO}_{2}$ batches showed specific surface areas in the range of 5-14 m²/g, with 16 of the 22 samples in the range of $5-10 \mathrm{~m}^{2} / \mathrm{g}$. For samples analyzed with typical handling (exposed to ambient air for 1545 minutes with relative humidities of $20-55 \%$ ), the moisture content as measured by MS ranged from 0.15 to $0.45 \mathrm{wt} \%$ and the total mass loss at $1000{ }^{\circ} \mathrm{C}$, as measured by TGA, ranged from 0.21 to $0.58 \mathrm{wt} \%$. For the samples calcined between 635 and $650{ }^{\circ} \mathrm{C}$, the moisture content without extended exposure ranged from 0.20 to $0.38 \mathrm{wt} \%$, and the TGA mass loss ranged from 0.26 to $0.46 \mathrm{wt} \%$. Of these latter samples, the samples calcined at $650{ }^{\circ} \mathrm{C}$ generally had lower specific surface areas and lower moisture contents than the samples calcined at $635{ }^{\circ} \mathrm{C}$, which matches expectations from the literature.

Taken together, the TGA-MS results for samples handled at nominally $20-50 \% \mathrm{RH}$, without extended exposure, indicate that the $\mathrm{Pu}(\mathrm{IV})$ oxalate precipitation process followed by calcination at $635-650{ }^{\circ} \mathrm{C}$ appears capable of producing $\mathrm{PuO}_{2}$ with moisture content $<0.5 \mathrm{wt} \%$ as required by the 3013 Standard.

Exposures of $\mathrm{PuO}_{2}$ samples to ambient air for 3 or more hours generally showed modest mass gains that were primarily gains in moisture content. These results point to the need for a better understanding of the moisture absorption of $\mathrm{PuO}_{2}$ and serve as a warning that extended exposure times, particularly above the $50 \% \mathrm{RH}$ level observed in this study will make the production of $\mathrm{PuO}_{2}$ with less than $0.5 \mathrm{wt} \%$ moisture more challenging. Samples analyzed in this study generally contained approximately 2 monolayer equivalents of moisture.

In this study, the bulk of the moisture released from samples by $300{ }^{\circ} \mathrm{C}$, as did a significant portion of the $\mathrm{CO}_{2}$. Samples in this study consistently released a minor amount of NO in the $\sim 40-$ $300{ }^{\circ} \mathrm{C}$ range, but no samples released $\mathrm{CO}$ or $\mathrm{SO}_{2}$. TGA-MS results also showed that MS moisture content accounted for $80 \pm 8 \%$ of the total mass loss at $1000{ }^{\circ} \mathrm{C}$ measured by the TGA. 
The $\mathrm{PuO}_{2}$ samples produced had particles sizes that typically ranged from $0.2-88 \mu \mathrm{m}$, with the mean particle size ranging from $6.4-9.3 \mu \mathrm{m}$. The carbon content of ten different calcination batches ranged from 190-480 $\mu \mathrm{g}$ C/g Pu, with an average value of $290 \mu \mathrm{g} \mathrm{C/g} \mathrm{Pu.}$

A statistical review of the calcination conditions and resulting SSA values showed that in both cases tested, calcination temperature had a significant effect on SSA, as expected from literature data. The statistical review also showed that batch size had a significant effect on SSA, but the narrow range of batch sizes tested is a compelling reason to set aside that result until tests with larger batch sizes are completed. When feed acidity was not included as a variable, calcination time had a significant effect on SSA. However, including feed acidity as a variable showed that neither feed acidity nor calcination time had a significant effect on SSA in this study. Also, for both cases the statistical review also indicated that digestion time did not have a significant effect on SSA.

\subsection{Recommendations}

Complete the two larger ( $\sim 40 \mathrm{~g}$ ) batch syntheses of $\mathrm{PuO}_{2}$ as planned to investigate the impacts on properties. Examine moisture sorption behavior of that material under a broader range of relative humidity values, to include humidities representative of the HB-Line facility. In addition, SRNL recommends that the range of acceptable precipitator acidities be re-considered, as acidities below 1.5 $\mathrm{M}$ in this study did not show significant Pu losses, and showed similar SSA values at the same calcination conditions as materials precipitated at higher acidities. 
SRNL-STI-2012-00338

Revision 0

\subsection{References}

${ }^{1}$ Christopher, J.W., Task Technical Request, "Flow Sheet Verification for HB-Line Phase II Plutonium Oxide Production PPT/FLT/Calcination Operations and 3013 Equivalency”, NMMDHTS-2011-3178, November 22, 2011.

2 Crowder, M.L., and J.M. Duffey, “Task Technical and Quality Assurance Plan for Precipitation and Calcination of Plutonium(IV) Oxalate to Form Plutonium Oxide and Subsequent Gas Generation Studies to Support the MOX Feed Mission”, SRNL-RP-2011-01657, Rev. 0, January 15, 2011.

3 Smith, R.H., "HB-Line Pu-239 Production Flow Sheet Strategy (U)”, SRNS-E1100-201100025, October 12, 2011.

4 Stabilization, Packaging, and Storage of Plutonium-bearing Materials. 2004. DOE-STD3013-2004. U.S. Department of Energy: Washington, D.C.

5 Bluhm, E.A., et al, "Plutonium Oxide Polishing for MOX Fuel Production”, Separation Science and Technology, 40:281-296, 2005.

${ }^{6}$ Daniel, W.E., "Literature Review of $\mathrm{PuO}_{2}$ Calcination Time and Temperature Data for Specific Surface Area”, SRNL-TR-2011-00334, Rev. 0, March 6, 2012.

7 Rudisill, T.S., and R.A. Pierce, "Dissolution of Pu Metal in 8-10 M Nitric Acid” SRNL-STI2012-00043, Rev. 0, February 2012.

${ }^{8}$ Jones, M.A., D.P. DiPrete, B.J. Wiedenman, “Application of Column Extraction Method for Impurities Analysis on HB-Line Plutonium Oxide in Support of MOX Feed Product Specifications”, SRNL-STI-2012-00148, Rev. 0, March 2012.

9 Bronikowski, M.G., J.M. Duffey, and R.R. Livingston, "Lab Scale Production of $\mathrm{NpO}_{2}$ ", WSRC-TR-2003-00392, August 2003.

10 Duffey, J.M., B.C. Hill, and R.R. Livingston, "Capability for Moisture Removal from Neptunium Oxide by the HB-Line 9975 Inerting Process”, WSRC-TR-2004-00602, February 2005.

${ }^{11}$ Aluminum Construction Manual, $3^{\text {rd }}$ Ed., Section 3 "Engineering Data for Aluminum Structures”, p. 6, The Aluminum Association, New York, January 1975.

12 “Typical properties of aluminum wrought alloys”, Machine Design, Section 2 Nonferrous Metals, Penton Publishing, April 17, 1986.

${ }^{13}$ Crowder, M L., “Actinide Processing III”, Laboratory Notebook SRNL-NB-2012-00010.

14 Haschke, J. M. and T.E. Ricketts, “Adsorption of water on plutonium dioxide”. Journal of Alloys and Compounds 1997, 252, 148-156. 
SRNL-STI-2012-00338

Revision 0

Appendix A

A-1 
Table A-1. Anion Exchange Results for Pu and Am.

\begin{tabular}{|c|c|c|c|c|c|c|}
\hline Sample & $\begin{array}{c}\text { Volume } \\
\text { (mL) }\end{array}$ & $\begin{array}{c}\text { Gamma } \\
\text { PHA } \\
\text { Pu239 } \\
(\mathrm{dpm} / \mathrm{mL}) \\
\end{array}$ & $\begin{array}{c}\text { Pu239 } \\
\text { Gamma } \\
\text { PHA } \\
\text { (grams) }\end{array}$ & $\begin{array}{c}\text { Total WG } \\
\text { Pu } \\
\text { (grams) }\end{array}$ & $\begin{array}{c}\text { Gamma } \\
\text { PHA } \\
\text { Am241 } \\
(\mathrm{dpm} / \mathrm{mL})\end{array}$ & $\begin{array}{c}\text { Am241 } \\
\text { Gamma } \\
\text { PHA } \\
\text { (grams) }\end{array}$ \\
\hline $\begin{array}{l}3013 \mathrm{DE} \\
\text { Feed }\end{array}$ & 4400 & $1.24 \mathrm{E}+09$ & 39.6 & 42.1 & $2.46 \mathrm{E}+08$ & $1.42 \mathrm{E}-01$ \\
\hline Pu-B Feed & 1550 & $6.33 \mathrm{E}+08$ & 7.11 & 7.57 & $1.57 \mathrm{E}+08$ & 3.67E-02 \\
\hline Pu-Gd Feed & 1780 & $5.86 \mathrm{E}+08$ & 7.56 & 8.05 & $1.50 \mathrm{E}+08$ & $3.05 \mathrm{E}-02$ \\
\hline $\begin{array}{l}\text { Pu-Gd/B } \\
\text { Feeds }\end{array}$ & 2590 & \multicolumn{2}{|c|}{ Analyzed previously } & $\sim 17.1$ & & \\
\hline & & \multicolumn{2}{|c|}{ Total Pu Fed } & $\sim 74.8$ & & \\
\hline & & & & & & \\
\hline 3013DE Eff & 000 & $<7.60 \mathrm{E}+05$ & $<2.21 \mathrm{E}-02$ & $<2.35 E-02$ & $5.34 \mathrm{E}+07$ & $2.80 \mathrm{E}-01$ \\
\hline Am Wash & 1600 & $<6.89 \mathrm{E}+06$ & $<8.00 \mathrm{E}-02$ & $<8.52 \mathrm{E}-02$ & $2.29 \mathrm{E}+08$ & $4.81 \mathrm{E}-02$ \\
\hline B Feed Eff & 3500 & $<3.34 \mathrm{E}+06$ & $<8.48 \mathrm{E}-02$ & $<9.03 E-02$ & $1.41 \mathrm{E}+08$ & $6.48 \mathrm{E}-02$ \\
\hline Gd Feed Eff & 2000 & $<3.90 \mathrm{E}+06$ & $<5.66 \mathrm{E}-02$ & $<6.03 \mathrm{E}-02$ & $1.35 \mathrm{E}+08$ & $3.55 \mathrm{E}-02$ \\
\hline $\begin{array}{l}\text { Gd } \\
\text { Feed/Wash } 1\end{array}$ & 000 & $<4.00 \mathrm{E}+06$ & $<8.70 \mathrm{E}-02$ & $<9.27 \mathrm{E}-02$ & $2 E+08$ & $5.99 \mathrm{E}-02$ \\
\hline Wash 2 & 2000 & $3.39 \mathrm{E}+06$ & $4.92 \mathrm{E}-02$ & $5.24 \mathrm{E}-02$ & $4.19 \mathrm{E}+07$ & $1.10 \mathrm{E}-02$ \\
\hline Wash 3 & 2000 & $1.97 \mathrm{E}+06$ & $2.86 \mathrm{E}-02$ & $3.05 \mathrm{E}-02$ & $1.33 \mathrm{E}+07$ & $3.49 \mathrm{E}-03$ \\
\hline Wash 4 & 1750 & $<1.55 \mathrm{E}+06$ & $<1.97 \mathrm{E}-02$ & $<2.10 \mathrm{E}-02$ & $3.13 \mathrm{E}+06$ & $7.19 \mathrm{E}-04$ \\
\hline Heads & 1265 & $4.51 \mathrm{E}+06$ & $4.14 \mathrm{E}-02$ & $4.41 \mathrm{E}-02$ & $2.75 \mathrm{E}+06$ & $4.57 \mathrm{E}-04$ \\
\hline Hearts & 1400 & $6.82 \mathrm{E}+09$ & $6.93 \mathrm{E}+01$ & $7.38 \mathrm{E}+01$ & $1.88 \mathrm{E}+07$ & $3.46 \mathrm{E}-03$ \\
\hline Tails 1 & 1000 & $6.78 \mathrm{E}+07$ & $4.92 \mathrm{E}-01$ & $5.24 \mathrm{E}-01$ & $8.09 \mathrm{E}+04$ & $1.06 \mathrm{E}-05$ \\
\hline Tails 2 & 2000 & $1.67 \mathrm{E}+07$ & $2.42 \mathrm{E}-01$ & $2.58 \mathrm{E}-01$ & $7.24 \mathrm{E}+04$ & $1.90 \mathrm{E}-05$ \\
\hline
\end{tabular}

Table A-2. Impurity Content in Anion Exchange Feed by ICPES

\begin{tabular}{|c|c|c|c|c||}
\hline Element & $\begin{array}{c}\text { 3013 DE Feed } \\
\mathbf{m g} / \mathbf{L}\end{array}$ & & Element & $\begin{array}{c}\text { 3013 DE Feed } \\
\mathbf{~ m g / L}\end{array}$ \\
\hline $\mathrm{Al}$ & 681 & & $\mathrm{Li}$ & 0.675 \\
\hline $\mathrm{B}$ & 3.05 & & $\mathrm{Mg}$ & 103 \\
\hline $\mathrm{Be}$ & 4.35 & & $\mathrm{Mn}$ & 2.97 \\
\hline $\mathrm{Ca}$ & 68.7 & & $\mathrm{Mo}$ & 6.89 \\
\hline $\mathrm{Cd}$ & 0.811 & & $\mathrm{Na}$ & 27100 \\
\hline $\mathrm{Ce}$ & $<0.97$ & & $\mathrm{Ni}$ & 214 \\
\hline $\mathrm{Co}$ & $<0.85$ & & $\mathrm{~Pb}$ & $<7.16$ \\
\hline $\mathrm{Cr}$ & 103 & & $\mathrm{~S}$ & $<12$ \\
\hline $\mathrm{Cu}$ & 30 & & $\mathrm{Si}$ & 13.3 \\
\hline $\mathrm{Fe}$ & 82.5 & & $\mathrm{Ti}$ & 1.95 \\
\hline $\mathrm{Gd}$ & $<0.78$ & & $\mathrm{~V}$ & $<0.47$ \\
\hline $\mathrm{K}$ & 20.8 & & $\mathrm{Zn}$ & 1.9 \\
\hline
\end{tabular}


TGA-MS: FY2012 AFS2 (D30-A)

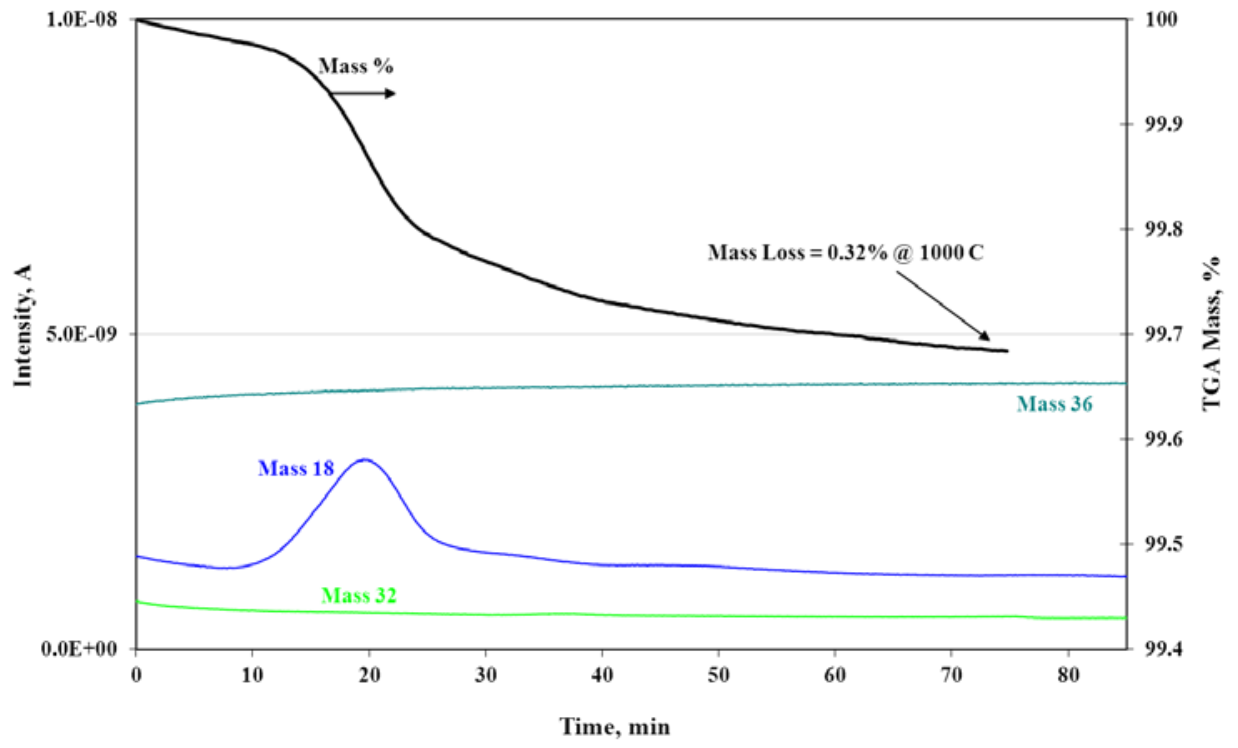

Figure A-1. MS Signals (linear scale) from TGA-MS Analysis of Sample D30-A.

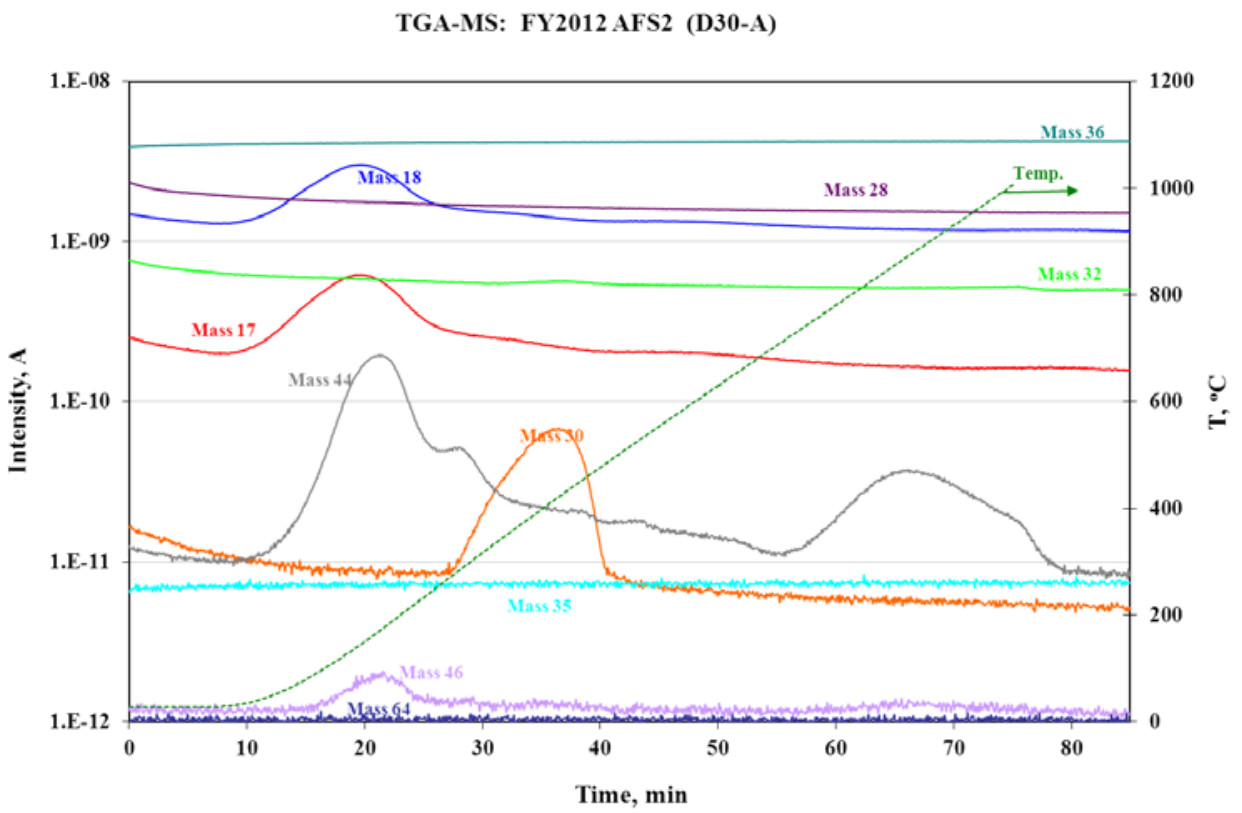

Figure A-2. MS Signals (logarithmic scale) from TGA-MS Analysis of Sample D30-A. 
Table A-3. Uncertainties in MS Moisture Contents

\begin{tabular}{|c|c|c|c|}
\hline \multirow{2}{*}{ Batch ID } & \multirow{2}{*}{$\begin{array}{c}\text { MS } \\
\text { Moisture } \\
\text { Content, } \\
\text { wt \% }\end{array}$} & \multicolumn{2}{|c|}{$\begin{array}{c}\text { 95\% Confidence } \\
\text { Interval } \\
\end{array}$} \\
\hline & & $\begin{array}{l}\text { Lower } \\
\text { Bound } \\
\end{array}$ & $\begin{array}{l}\text { Upper } \\
\text { Bound }\end{array}$ \\
\hline B1-2 & 0.42 & 0.40 & 0.44 \\
\hline В1-3a & 0.22 & 0.21 & 0.23 \\
\hline B1-3b & 0.40 & 0.39 & 0.43 \\
\hline B1-4 & 0.15 & 0.14 & 0.15 \\
\hline B1-5 & 0.18 & 0.17 & 0.19 \\
\hline B2-2a ${ }^{\dagger}$ & 0.45 & 0.35 & 0.55 \\
\hline $\mathrm{B}^{2}-2 \mathrm{~b}^{\dagger}$ & 0.58 & 0.51 & 0.65 \\
\hline 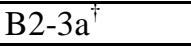 & 0.44 & 0.37 & 0.51 \\
\hline $\mathrm{B}^{2}-3 \mathrm{~b}^{\dagger}$ & 0.66 & 0.59 & 0.73 \\
\hline $\mathrm{B} 2-4^{\dagger}$ & 0.26 & 0.22 & 0.30 \\
\hline $\mathrm{B} 2-5^{\dagger}$ & 0.49 & 0.44 & 0.54 \\
\hline B3-1a & 0.32 & 0.31 & 0.34 \\
\hline B3-1b & 0.35 & 0.33 & 0.37 \\
\hline B3-2a & 0.38 & 0.37 & 0.40 \\
\hline B3-2b & 0.42 & 0.40 & 0.45 \\
\hline B3-3a & 0.30 & 0.29 & 0.32 \\
\hline B3-3b & 0.35 & 0.33 & 0.37 \\
\hline B3-4a & 0.37 & 0.35 & 0.39 \\
\hline B3-4b & 0.36 & 0.34 & 0.38 \\
\hline B3-5Aa & 0.27 & 0.26 & 0.29 \\
\hline B3-5Ab & 0.26 & 0.25 & 0.28 \\
\hline B3-5Ba & 0.26 & 0.24 & 0.27 \\
\hline B3-5Bb & 0.31 & 0.30 & 0.33 \\
\hline B4-1a & 0.26 & 0.25 & 0.27 \\
\hline B4-1b & 0.34 & 0.32 & 0.36 \\
\hline B4-2a & 0.20 & 0.19 & 0.21 \\
\hline B4-2b & 0.21 & 0.20 & 0.22 \\
\hline B4-2c & 0.22 & 0.21 & 0.23 \\
\hline D5-A & 0.38 & 0.37 & 0.39 \\
\hline D5-B & 0.31 & 0.30 & 0.32 \\
\hline D5-Bb & 0.30 & 0.30 & 0.31 \\
\hline D30-A & 0.23 & 0.23 & 0.24 \\
\hline D30-B & 0.35 & 0.35 & 0.36 \\
\hline D30-Bb & 0.43 & 0.42 & 0.44 \\
\hline D15-A & 0.34 & 0.33 & 0.34 \\
\hline D15-Ab & 0.30 & 0.29 & 0.31 \\
\hline D15-B & 0.33 & 0.33 & 0.34 \\
\hline D15-Bb & 0.40 & 0.39 & 0.41 \\
\hline
\end{tabular}

${ }^{\dagger}$ Range in 95\% confidence limits greater than $\pm 10 \%$ for these values because one large sample size (3.7 g) required a large gypsum standard amount tested in a large crucible that caused higher uncertainty. 
Table A-4. Specific Surface Area Measurements with Uncertainties

\begin{tabular}{|c|c|c|c|}
\hline \multirow{2}{*}{ Batch ID } & \multirow{2}{*}{$\begin{array}{l}\text { SSA, } \\
\mathrm{m}^{2} / \mathrm{g}\end{array}$} & \multicolumn{2}{|c|}{$\begin{array}{c}\text { 95\% Confidence } \\
\text { Interval }\end{array}$} \\
\hline & & $\begin{array}{l}\text { Lower } \\
\text { Bound }\end{array}$ & $\begin{array}{l}\text { Upper } \\
\text { Bound }\end{array}$ \\
\hline B1-2 & 13.5 & 13.4 & 13.7 \\
\hline B1-3 & 13.2 & 13.1 & 13.4 \\
\hline B1-4 & 9.42 & 9.27 & 9.57 \\
\hline B1-5 & 9.09 & 8.93 & 9.24 \\
\hline B2-2 & 14.1 & 13.9 & 14.3 \\
\hline B2-3 & 13.7 & 13.5 & 13.9 \\
\hline B2-4 & 12.4 & 12.2 & 12.6 \\
\hline B2-5 & 11.4 & 11.2 & 11.5 \\
\hline B3-1 & 7.83 & 7.64 & 8.03 \\
\hline B3-2 & 7.78 & 7.58 & 7.97 \\
\hline B3-3 & 5.61 & 5.40 & 5.82 \\
\hline B3-4 & 8.72 & 8.53 & 8.92 \\
\hline B3-5A & 6.79 & 6.60 & 6.97 \\
\hline B3-5B & 7.27 & 7.07 & 7.47 \\
\hline B4-1 & 6.87 & 6.71 & 7.04 \\
\hline B4-2 & 5.20 & 5.00 & 5.41 \\
\hline D5-A & 8.13 & 7.95 & 8.30 \\
\hline D5-B & 7.49 & 7.30 & 7.68 \\
\hline D30-A & 5.33 & 5.11 & 5.56 \\
\hline D30-B & 8.98 & 8.78 & 9.19 \\
\hline D15-A & 7.15 & 6.96 & 7.34 \\
\hline D15-B & 9.71 & 9.51 & 9.92 \\
\hline
\end{tabular}


SRNL-STI-2012-00338

Revision 0

Appendix B 
SRNL-STI-2012-00338

Revision 0

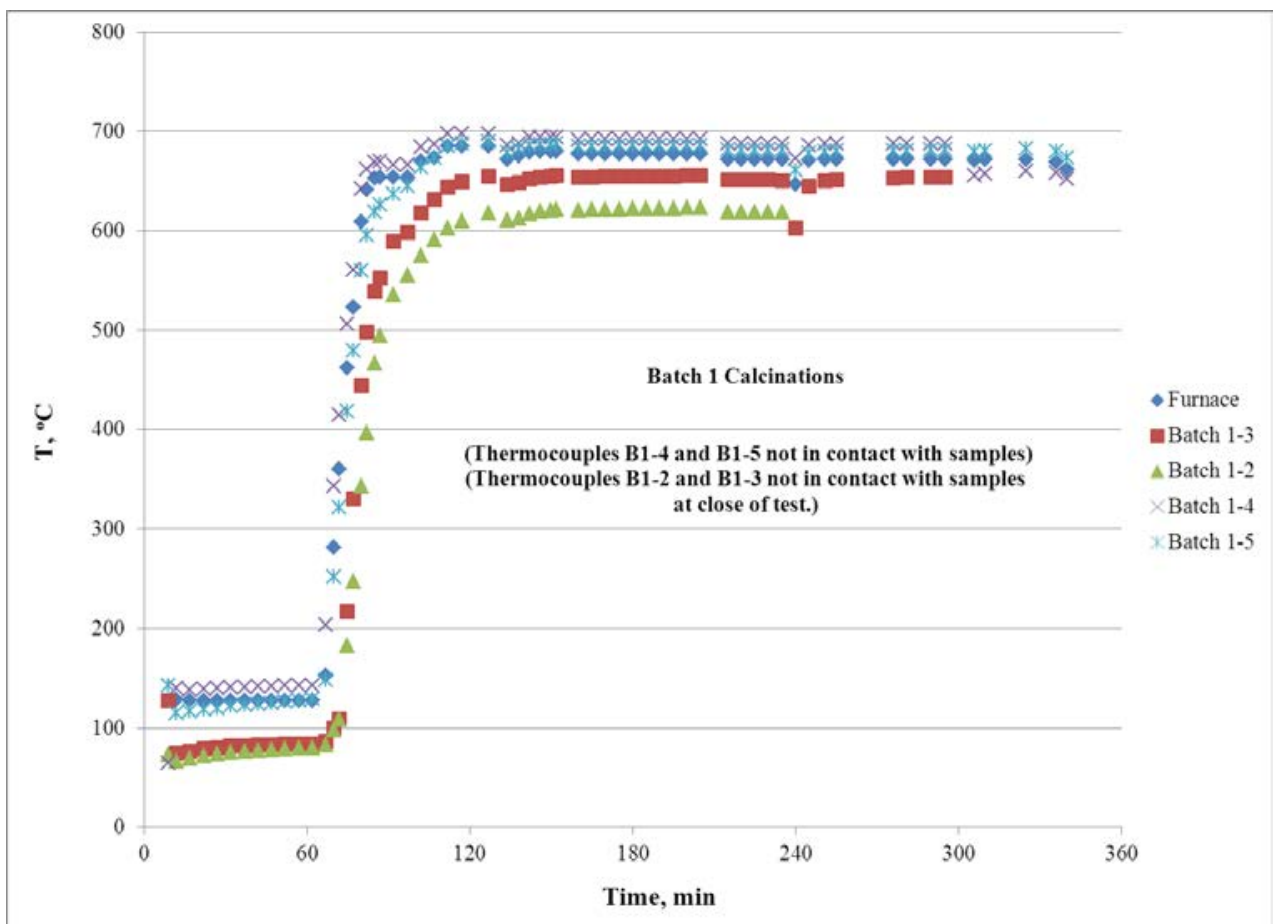

Figure B-1. Temperature Profiles for Batch 1 Calcinations

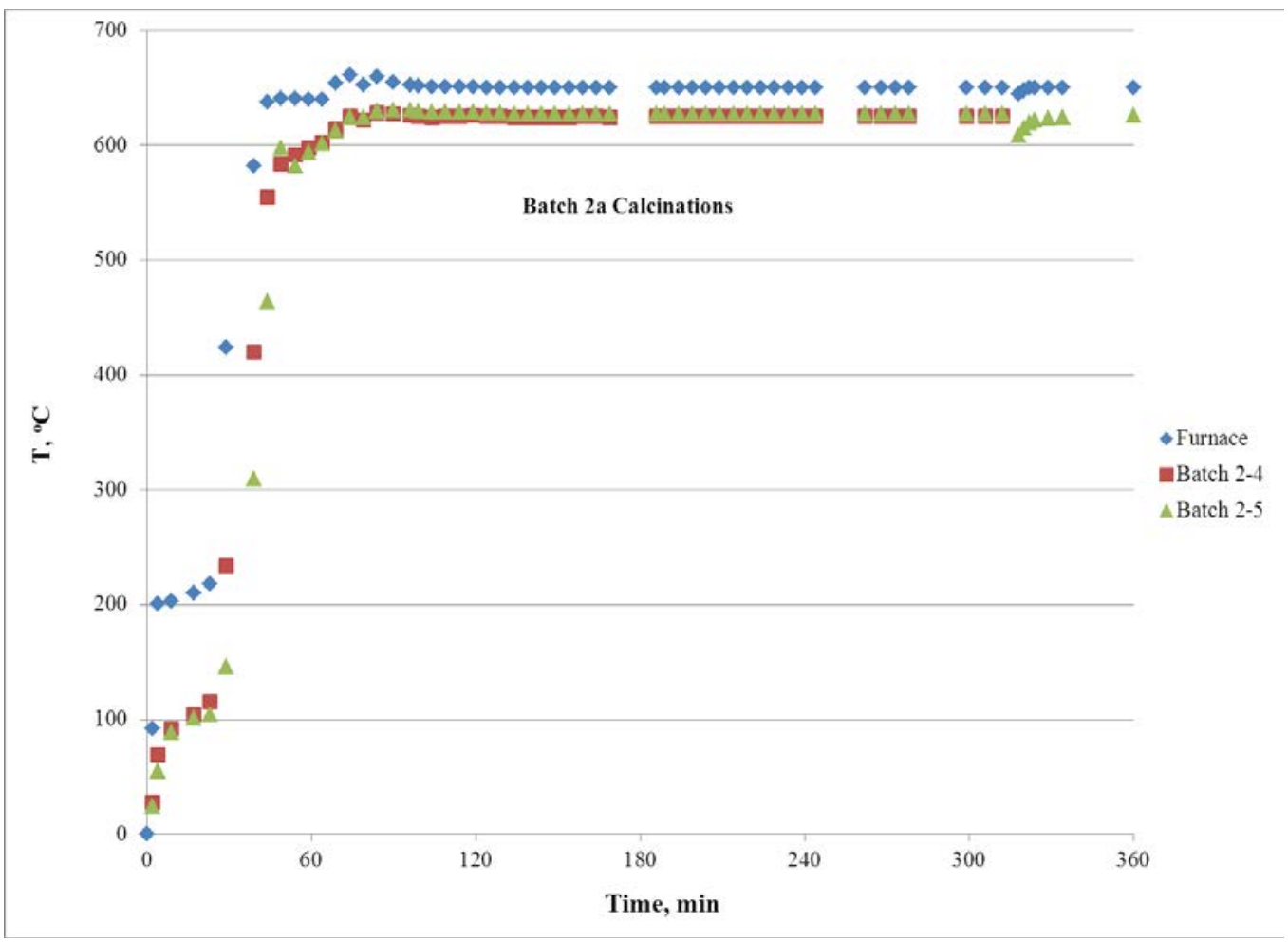

Figure B-2. Temperature Profiles for Batch 2a Calcinations 
SRNL-STI-2012-00338

Revision 0

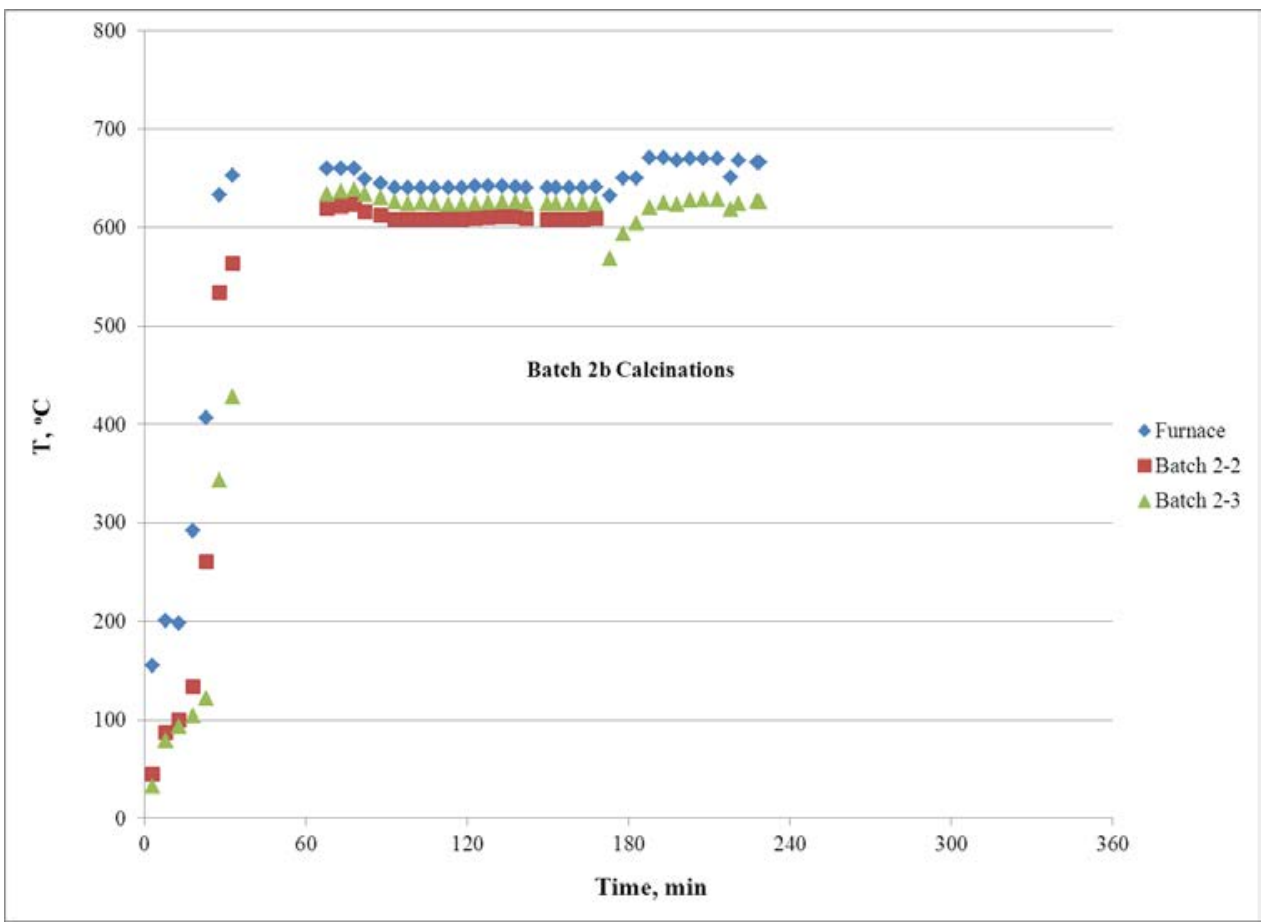

Figure B-3. Temperature Profiles for Batch 2b Calcinations

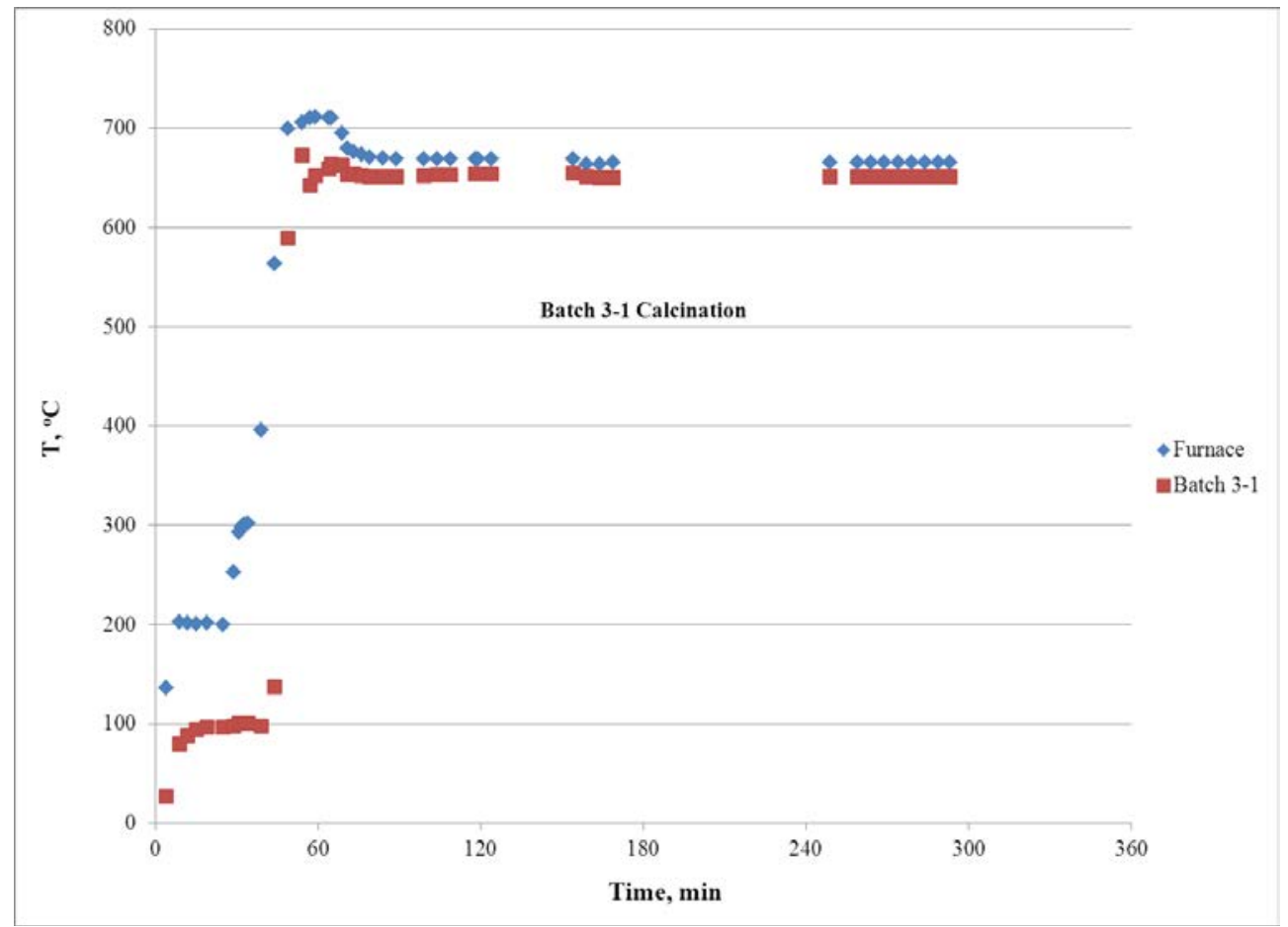

Figure B-4. Temperature Profile for Batch 3-1 Calcination 
SRNL-STI-2012-00338

Revision 0

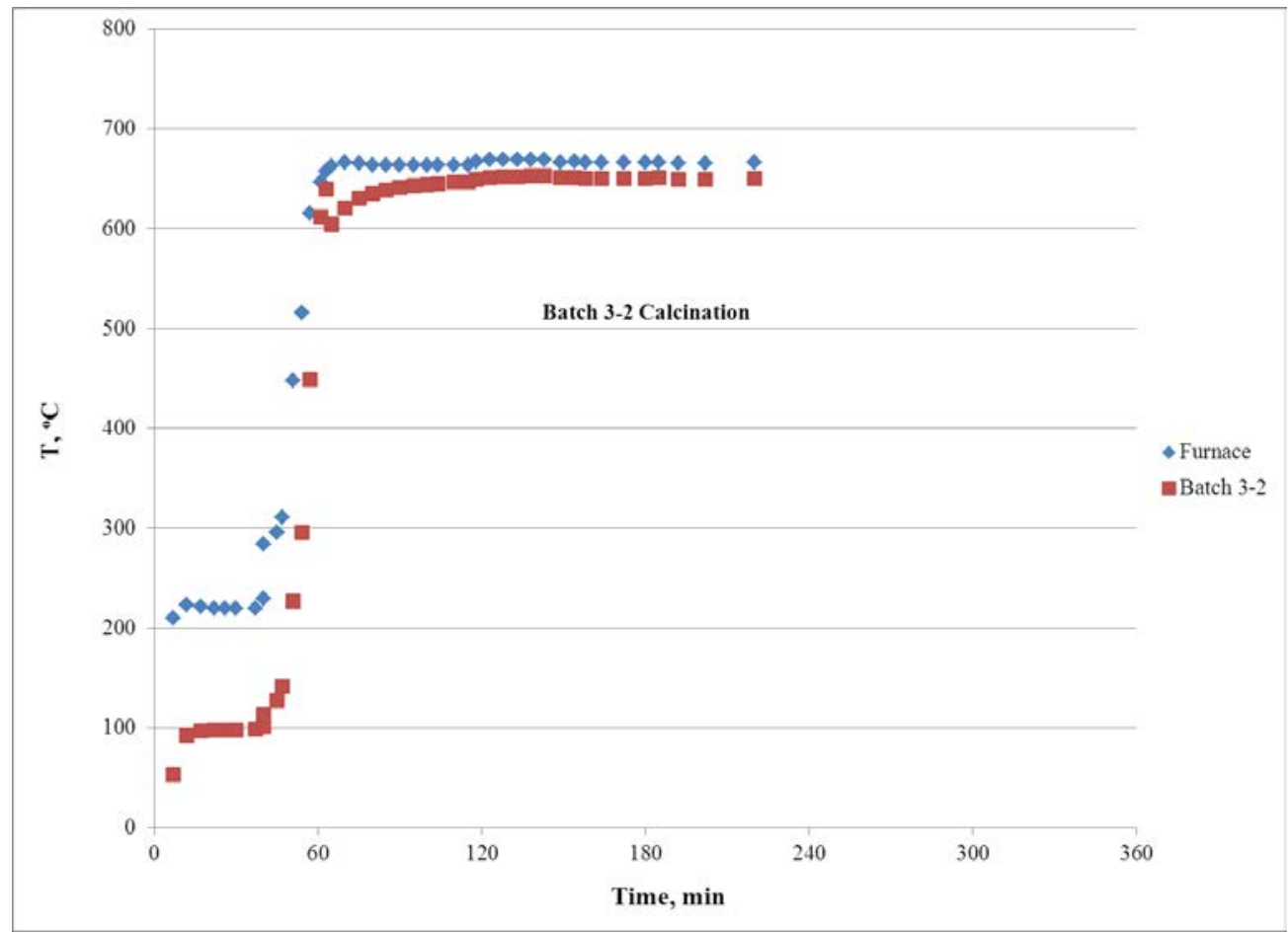

Figure B-5. Temperature Profile for Batch 3-2 Calcination

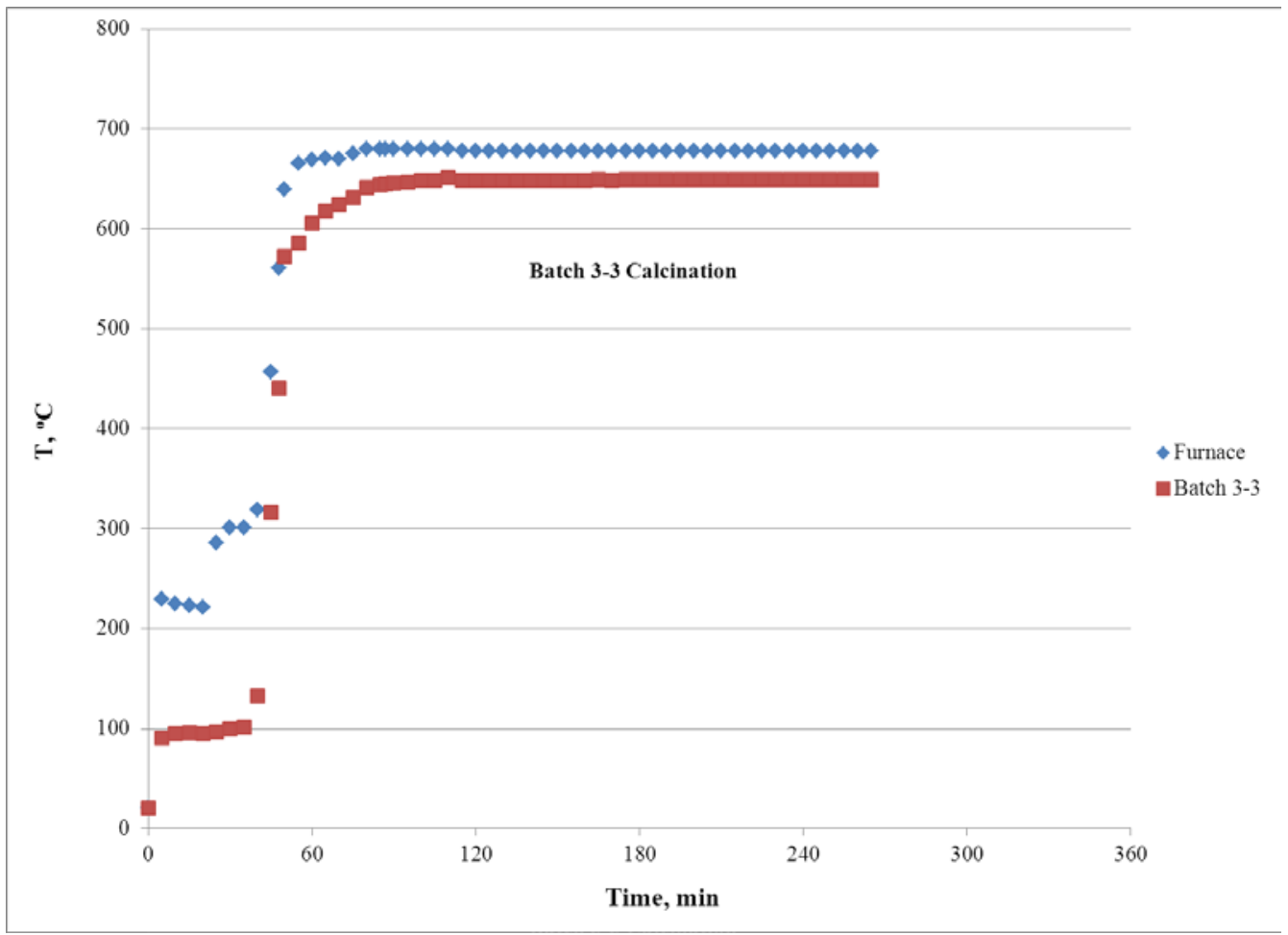

Figure B-6. Temperature Profile for Batch 3-3 Calcination 
SRNL-STI-2012-00338

Revision 0

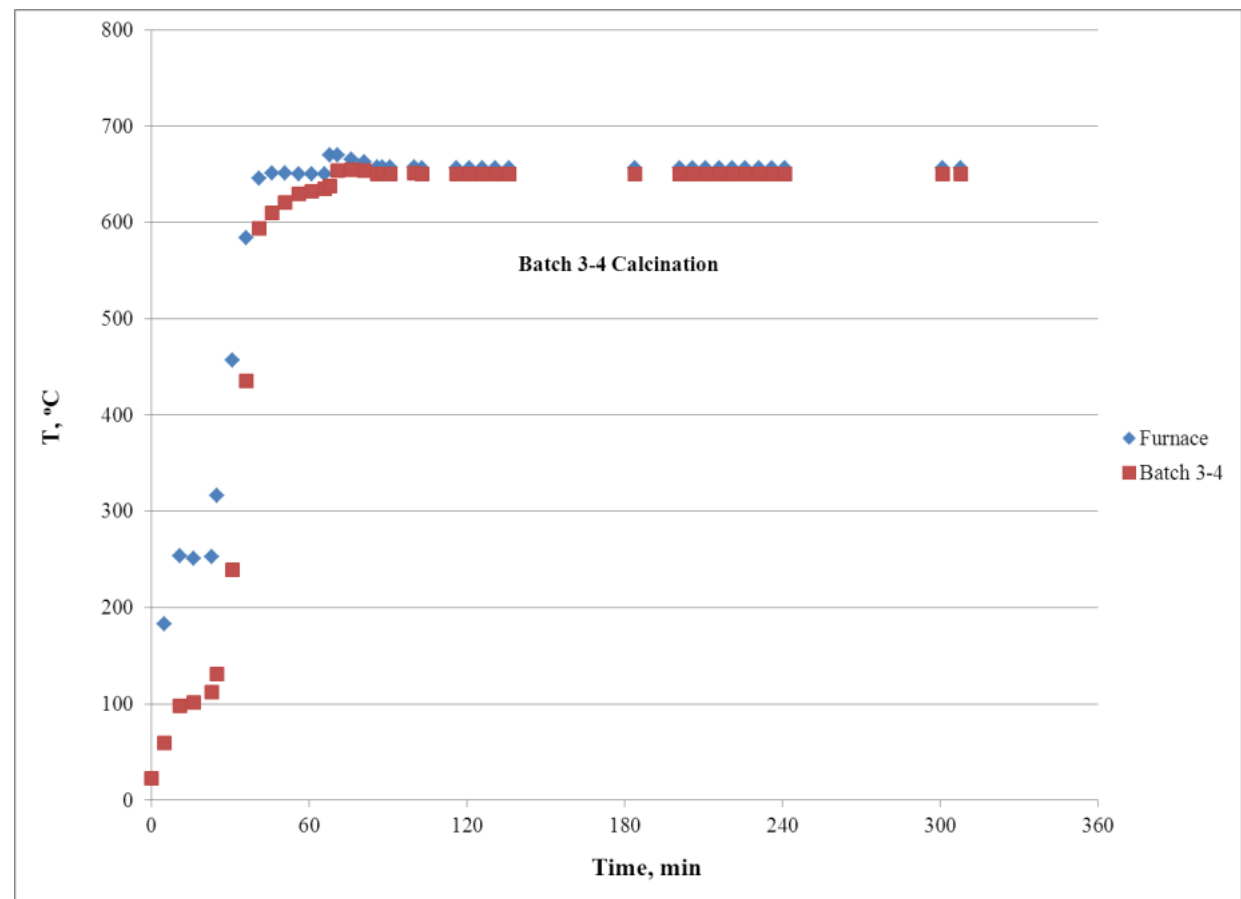

Figure B-7. Temperature Profile for Batch 3-4 Calcination

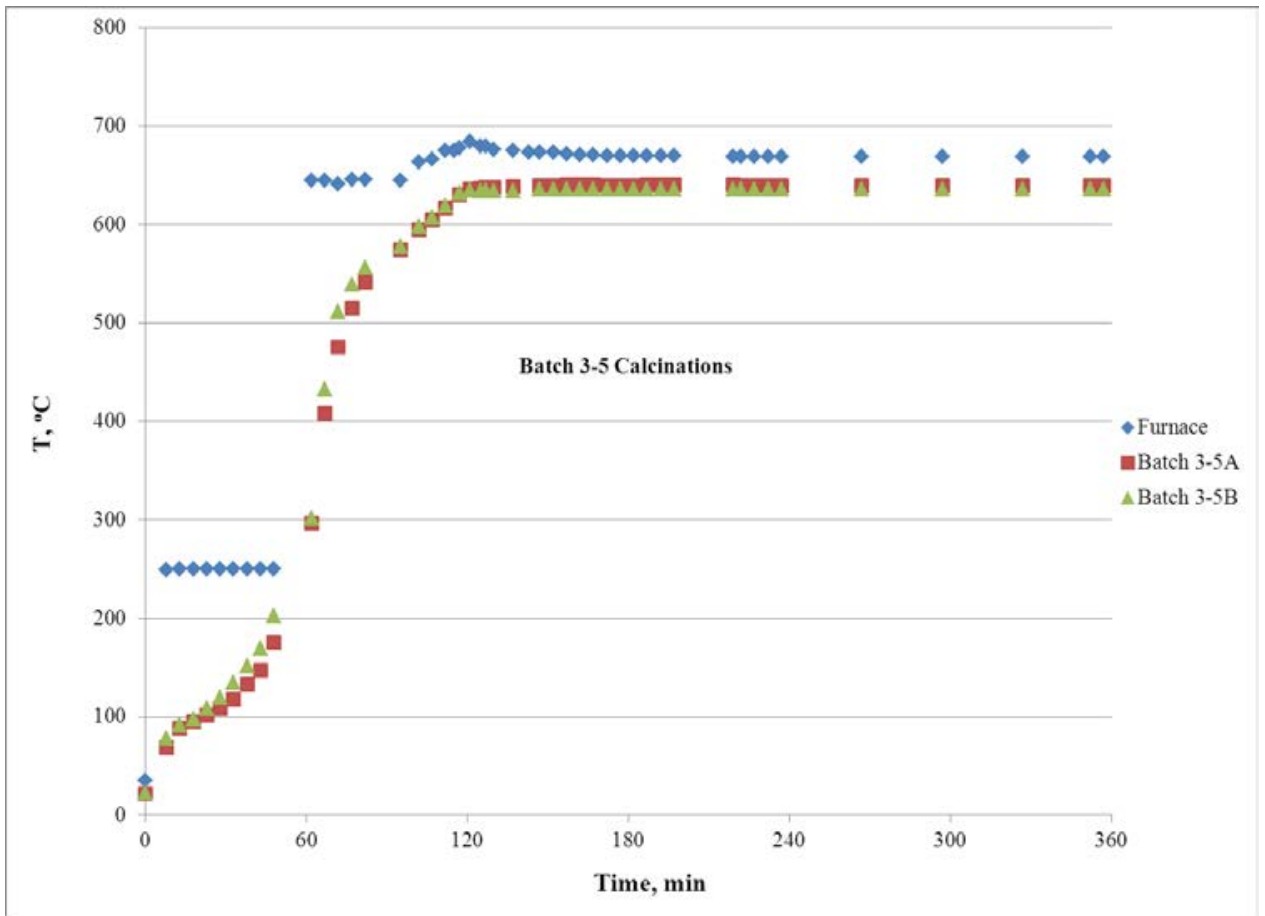

Figure B-8. Temperature Profiles for Batch 3-5 Calcinations 
SRNL-STI-2012-00338

Revision 0

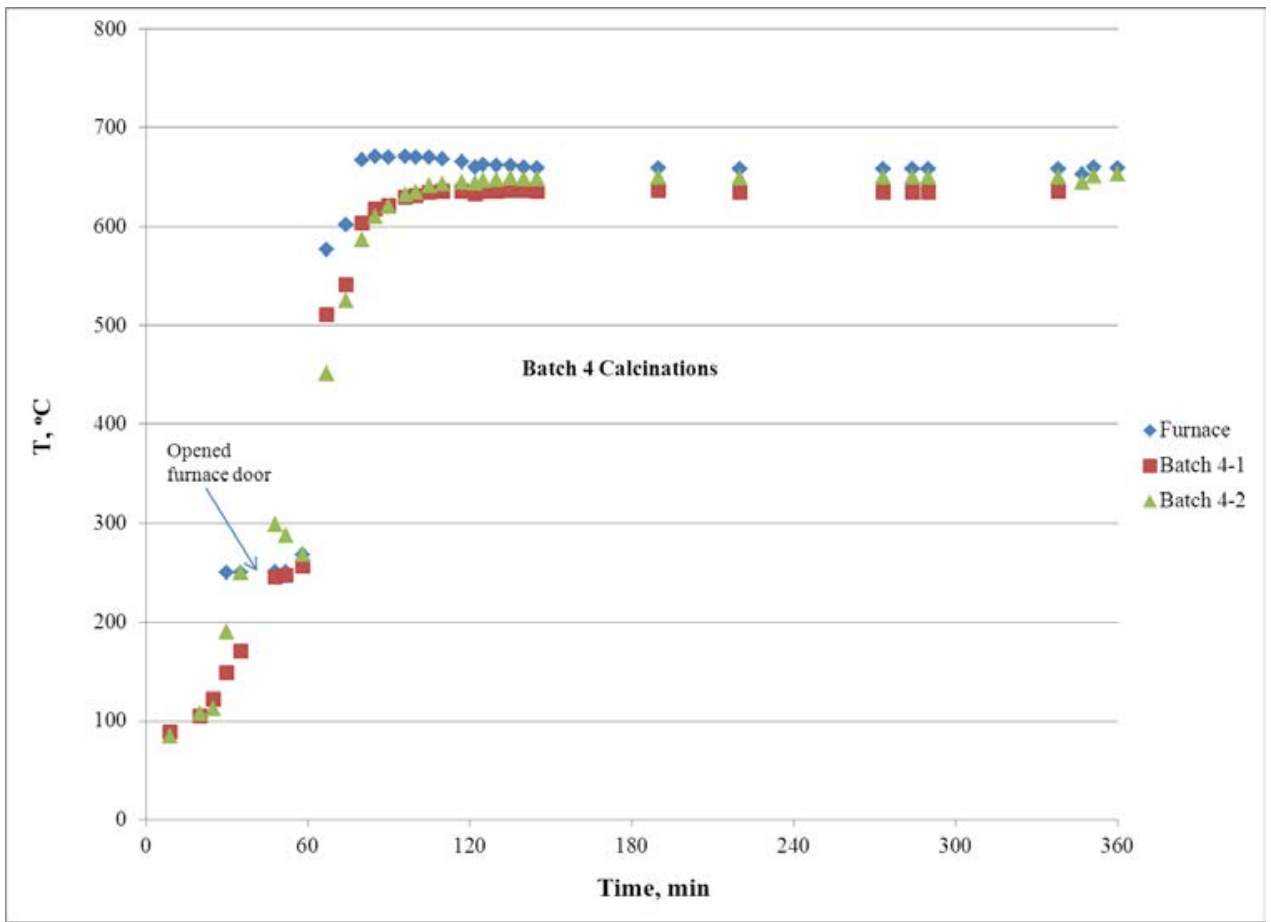

Figure B-9. Temperature Profiles for Batch 4 Calcinations

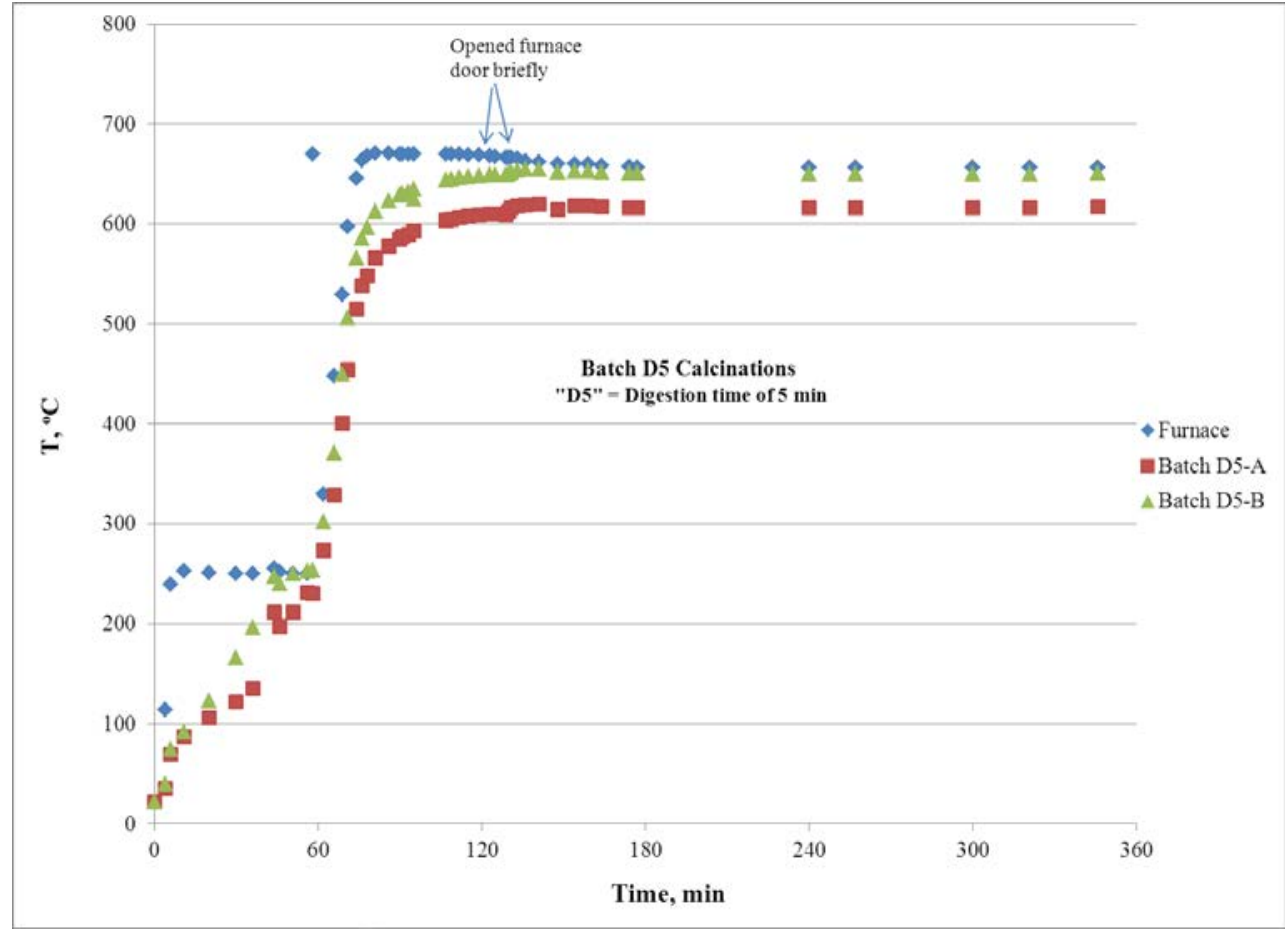

Figure B-10. Temperature Profiles for Batch D5 Calcinations 


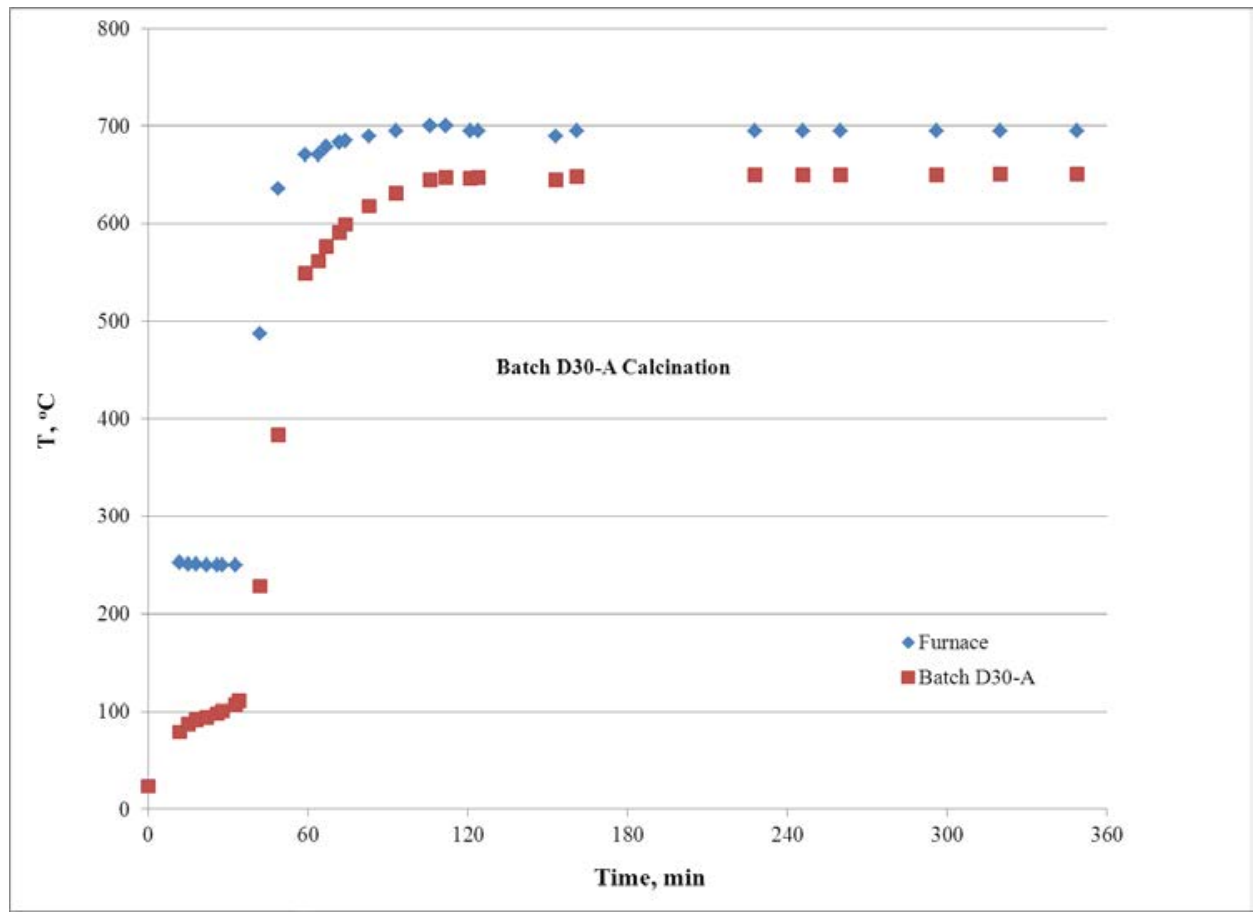

Figure B-11. Temperature Profile for Batch D30-A Calcination

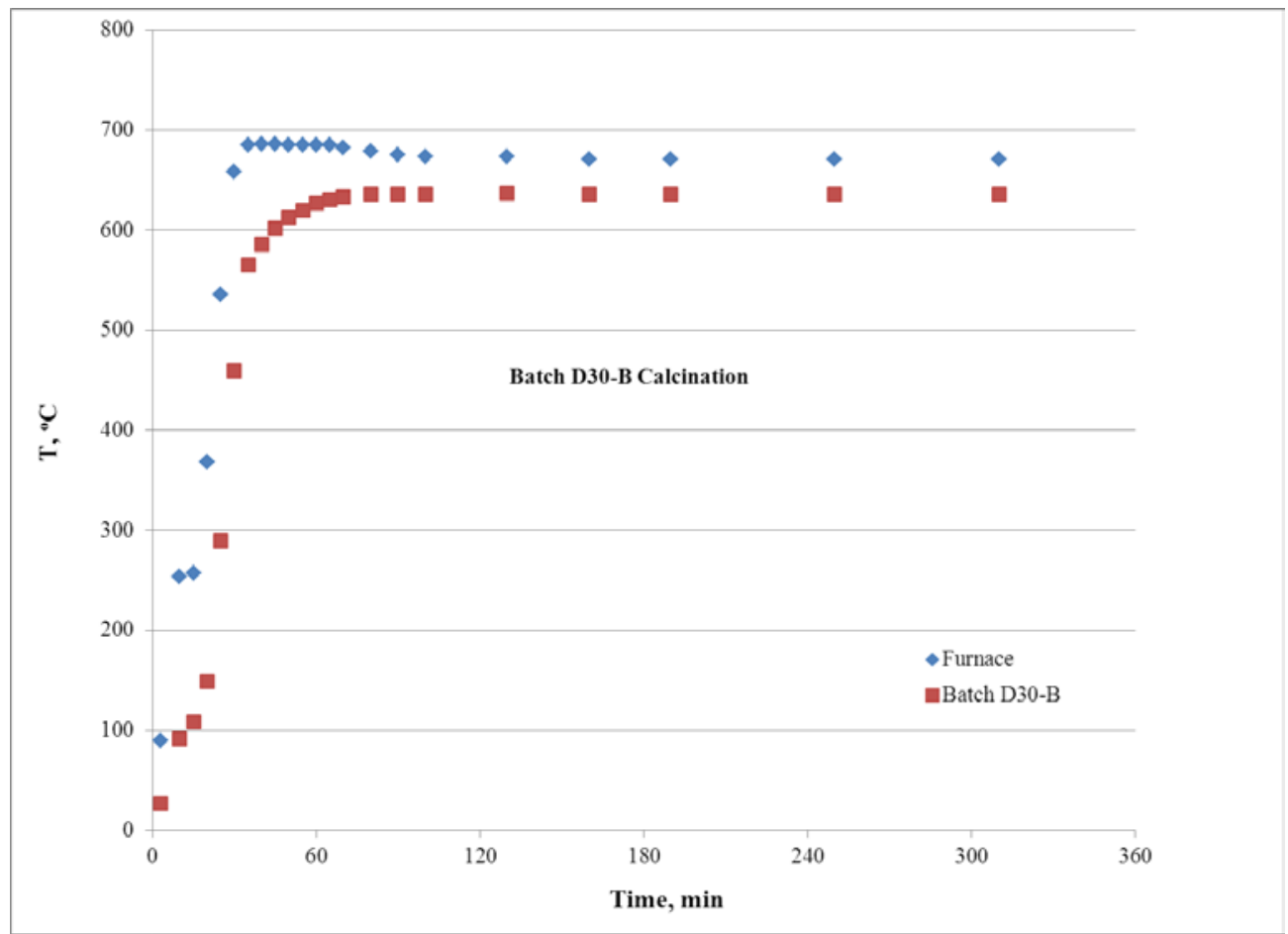

Figure B-12. Temperature Profile for Batch D30-B Calcination 


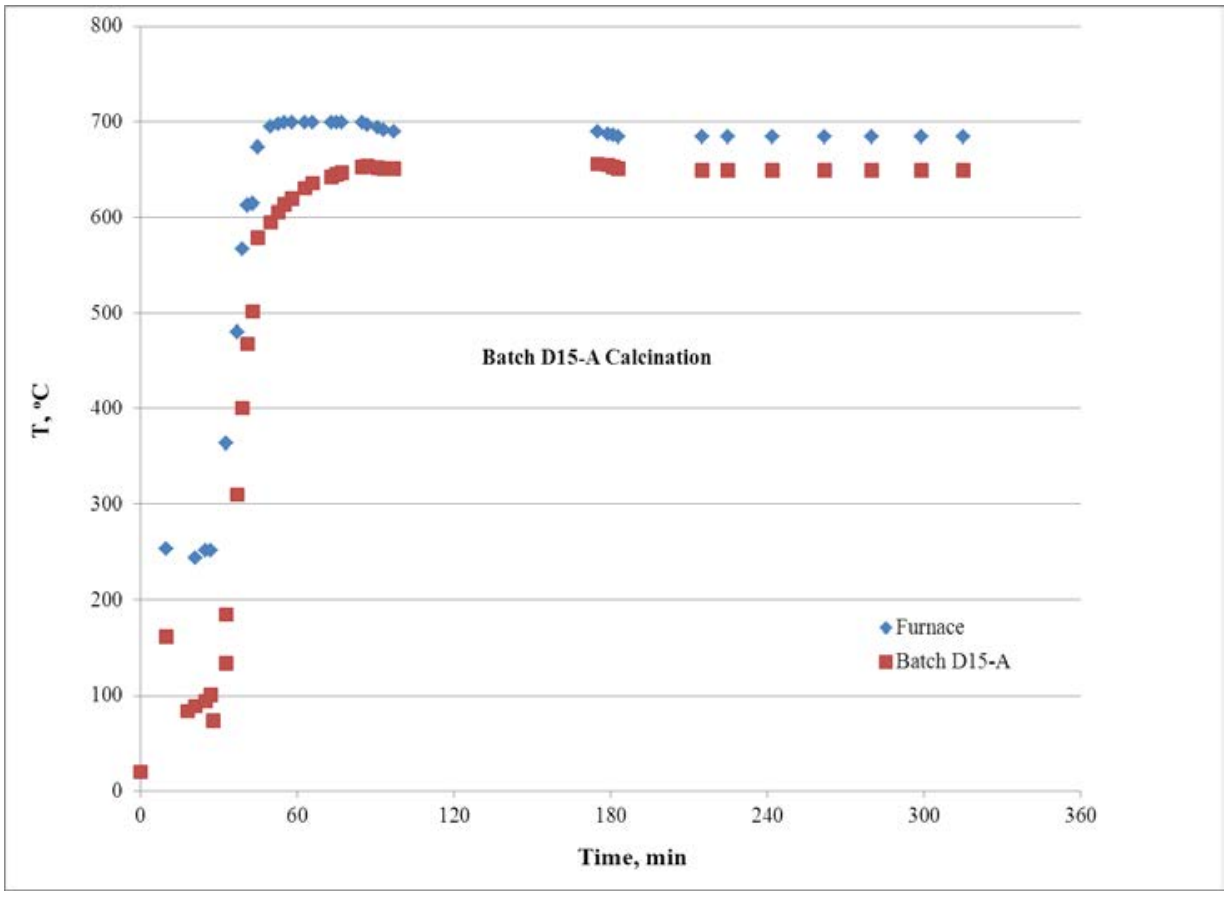

Figure B-13. Temperature Profile for Batch D15-A Calcination

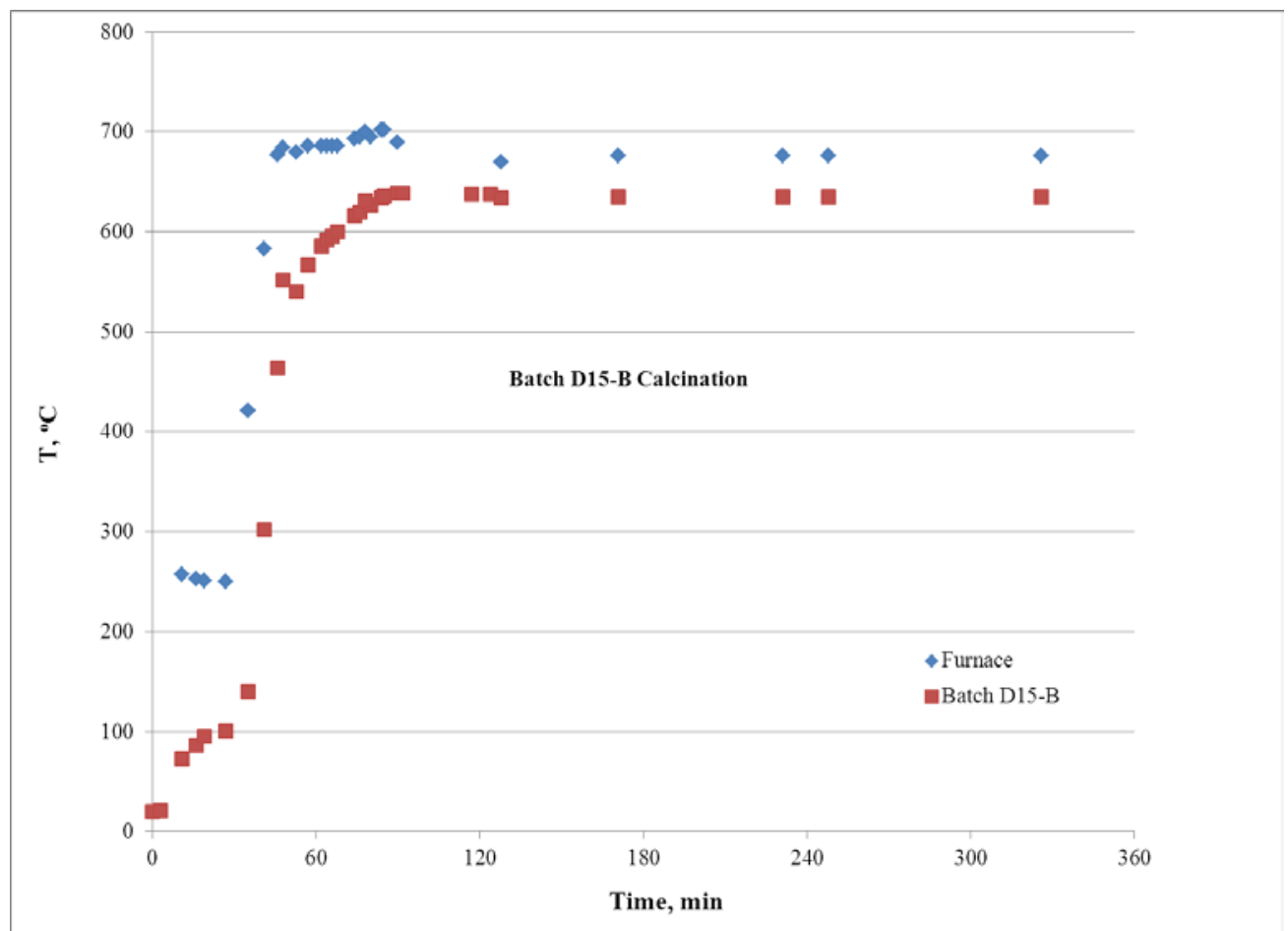

Figure B-14. Temperature Profile for Batch D15-B Calcination 
SRNL-STI-2012-00338

Revision 0

Appendix C 


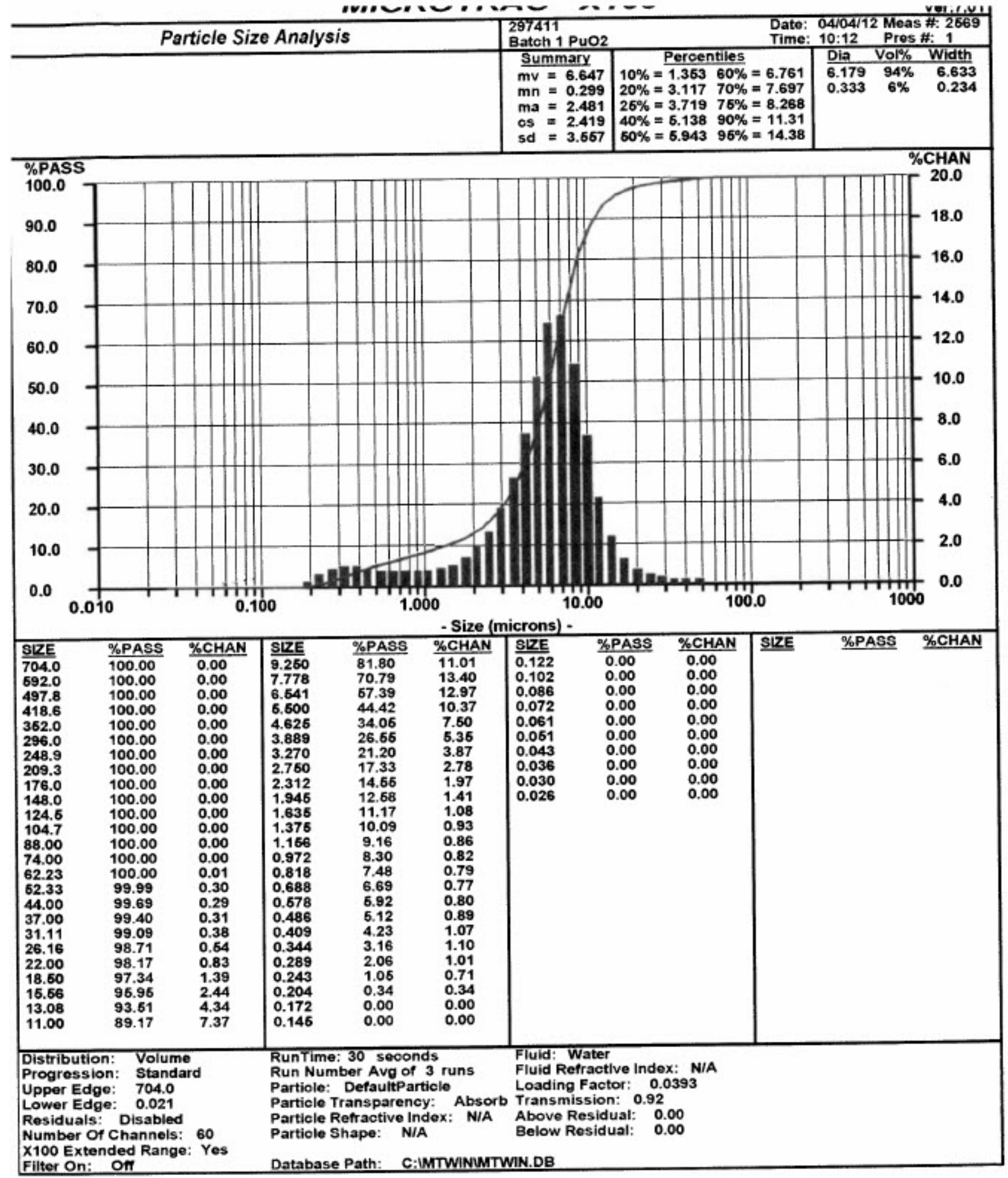

Figure C-1. Particle Size Analysis for Batch $1 \mathrm{PuO}_{2}$ 


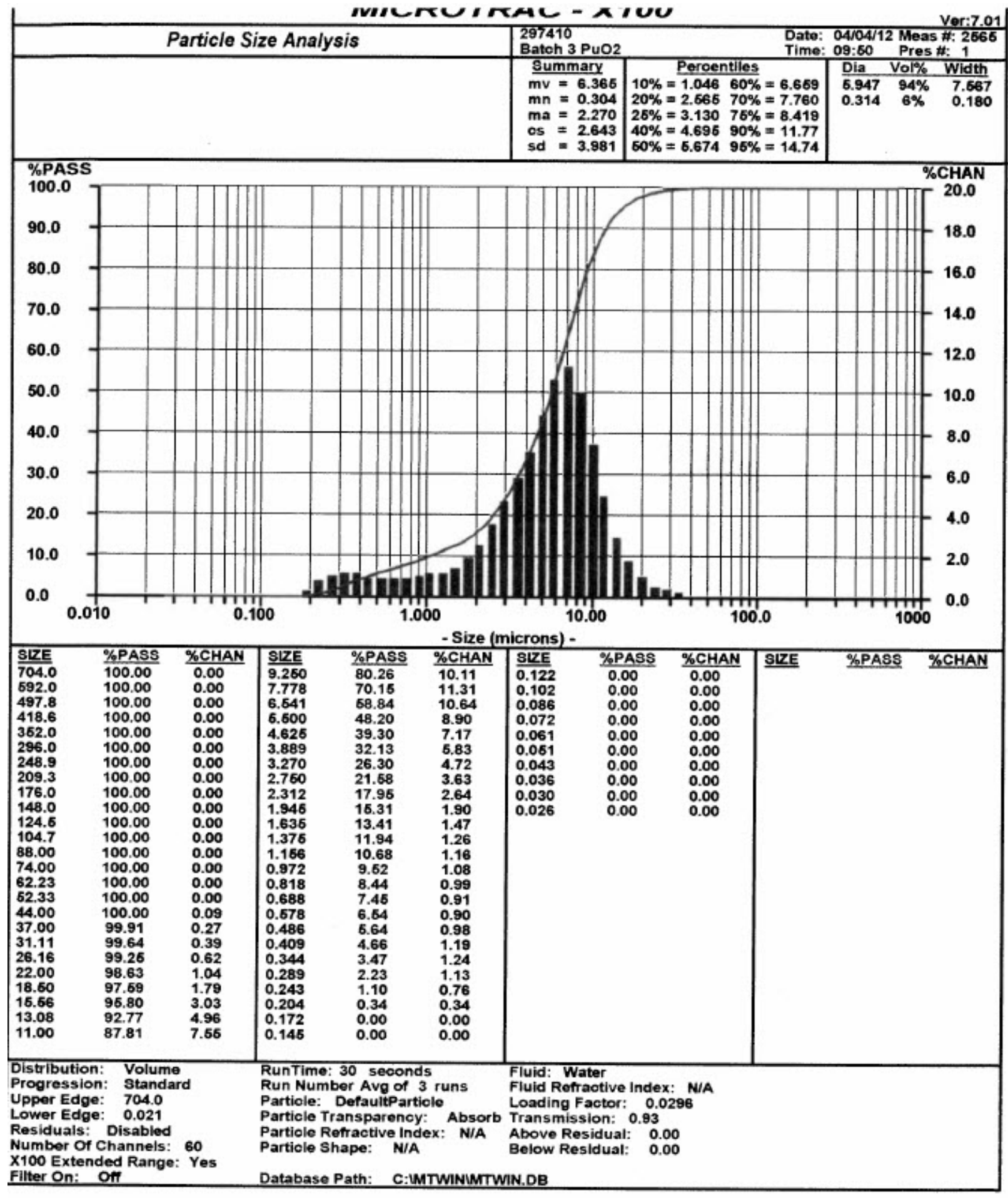

Figure C-2. Particle Size Analysis for Batch $3 \mathrm{PuO}_{2}$ 


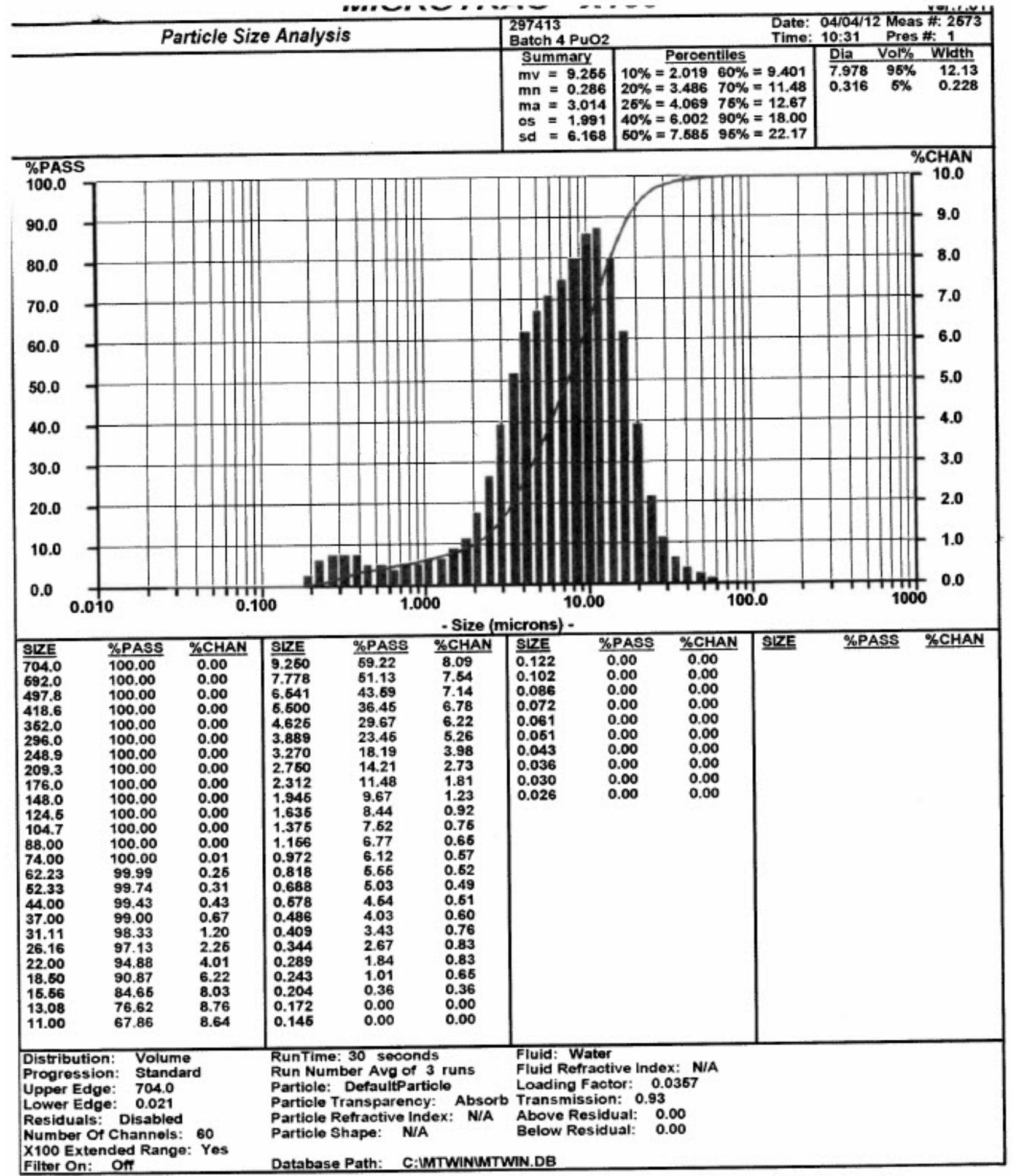

Figure C-3. Particle Size Analysis for Batch $4 \mathrm{PuO}_{2}$ 


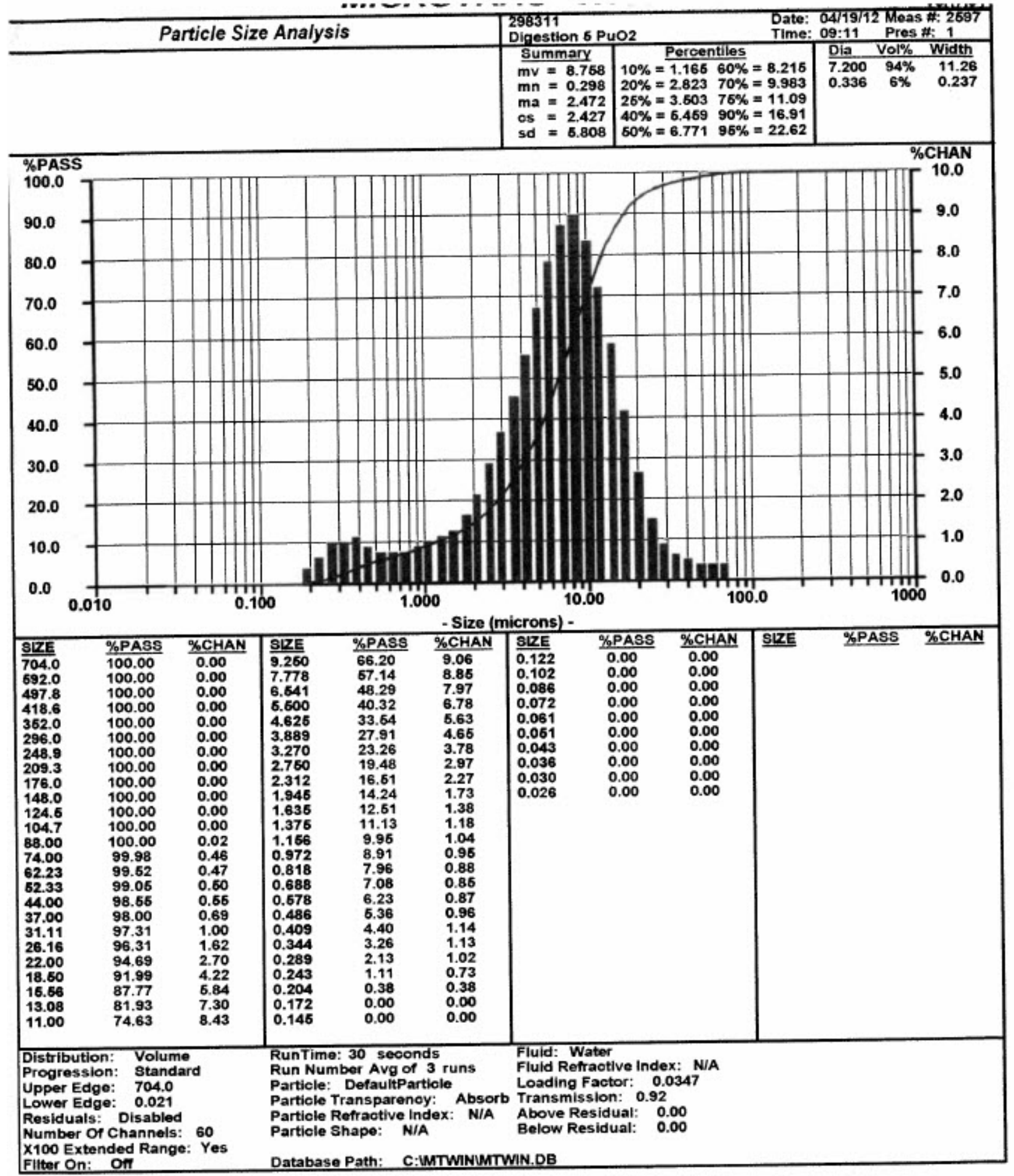

Figure C-4. Particle Size Analysis for Batch D5-A $\mathrm{PuO}_{2}$ 


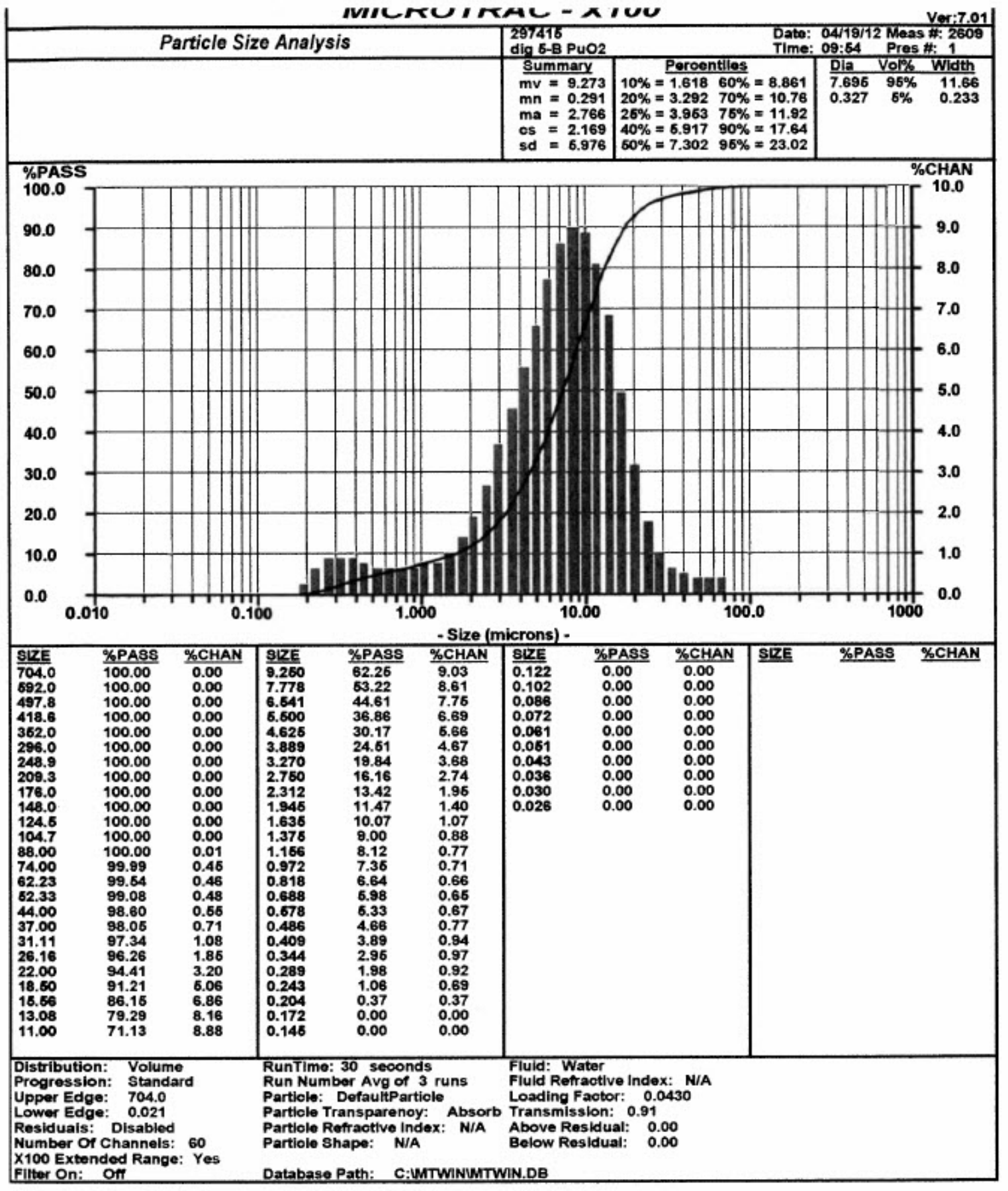

Figure C-5. Particle Size Analysis for Batch D5-B $\mathbf{P u O}_{2}$ 


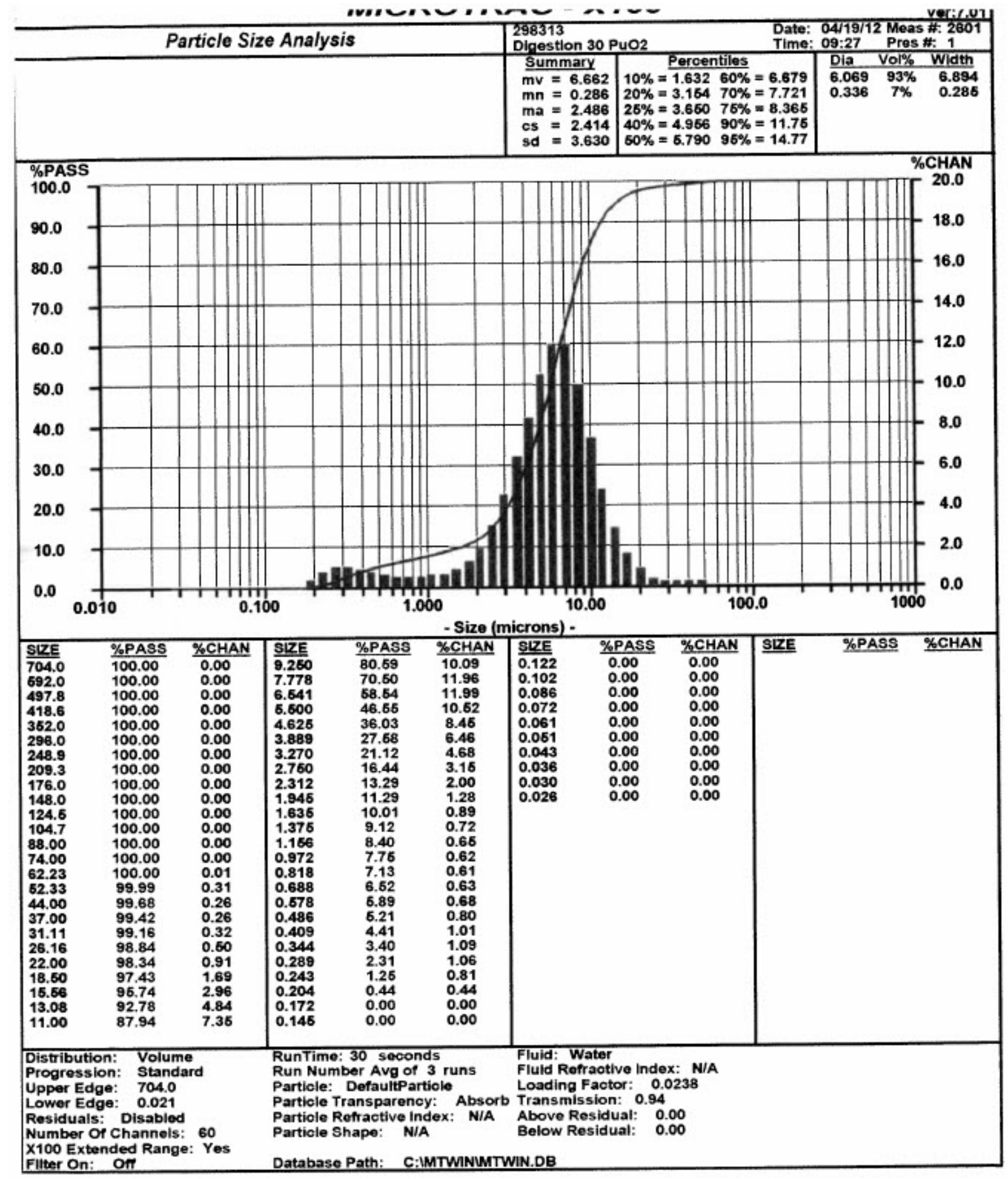

Figure C-6. Particle Size Analysis for Batch D30 $\mathrm{PuO}_{2}$ 


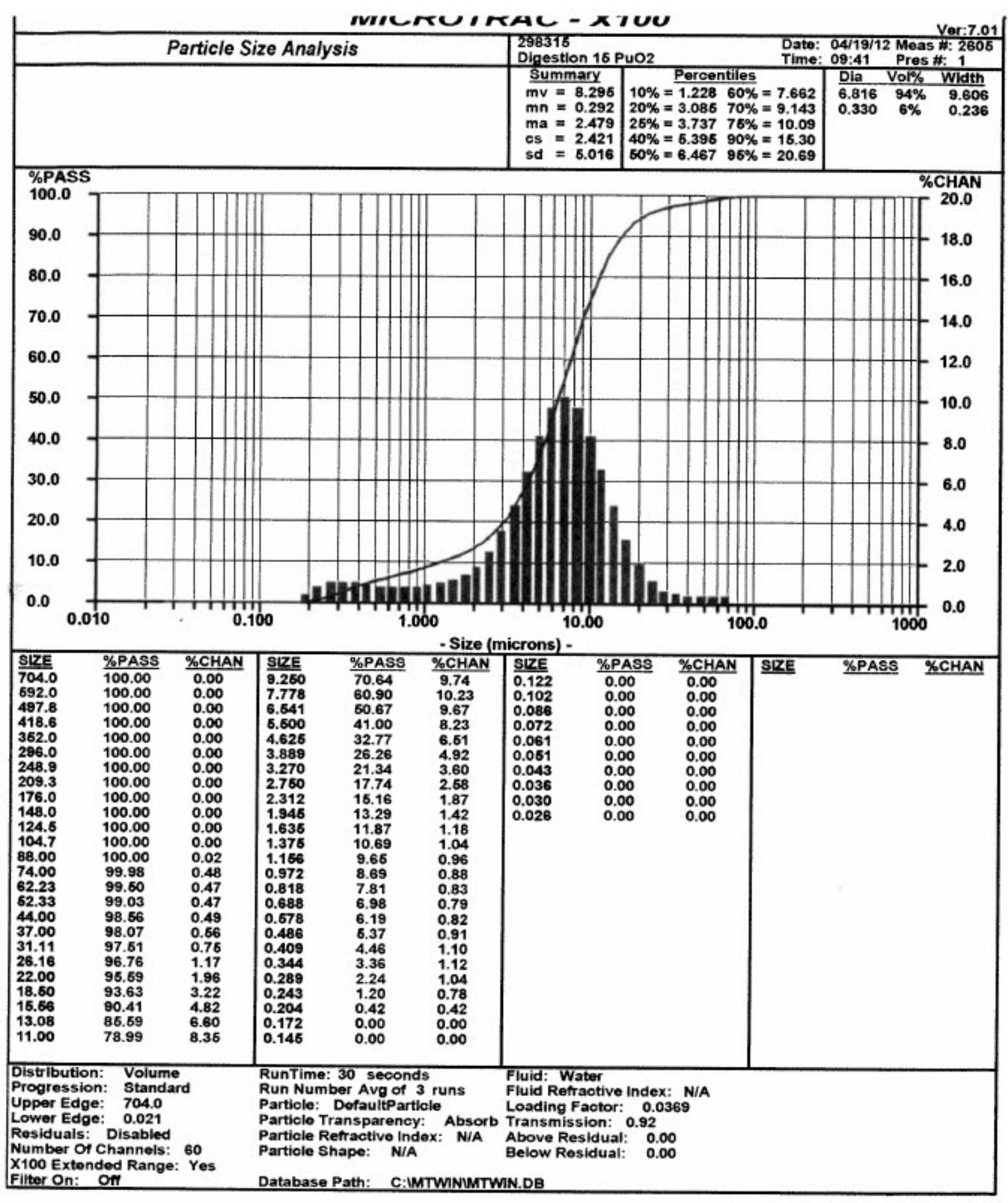

Figure C-7. Particle Size Analysis for Batch D15 $\mathrm{PuO}_{2}$ 


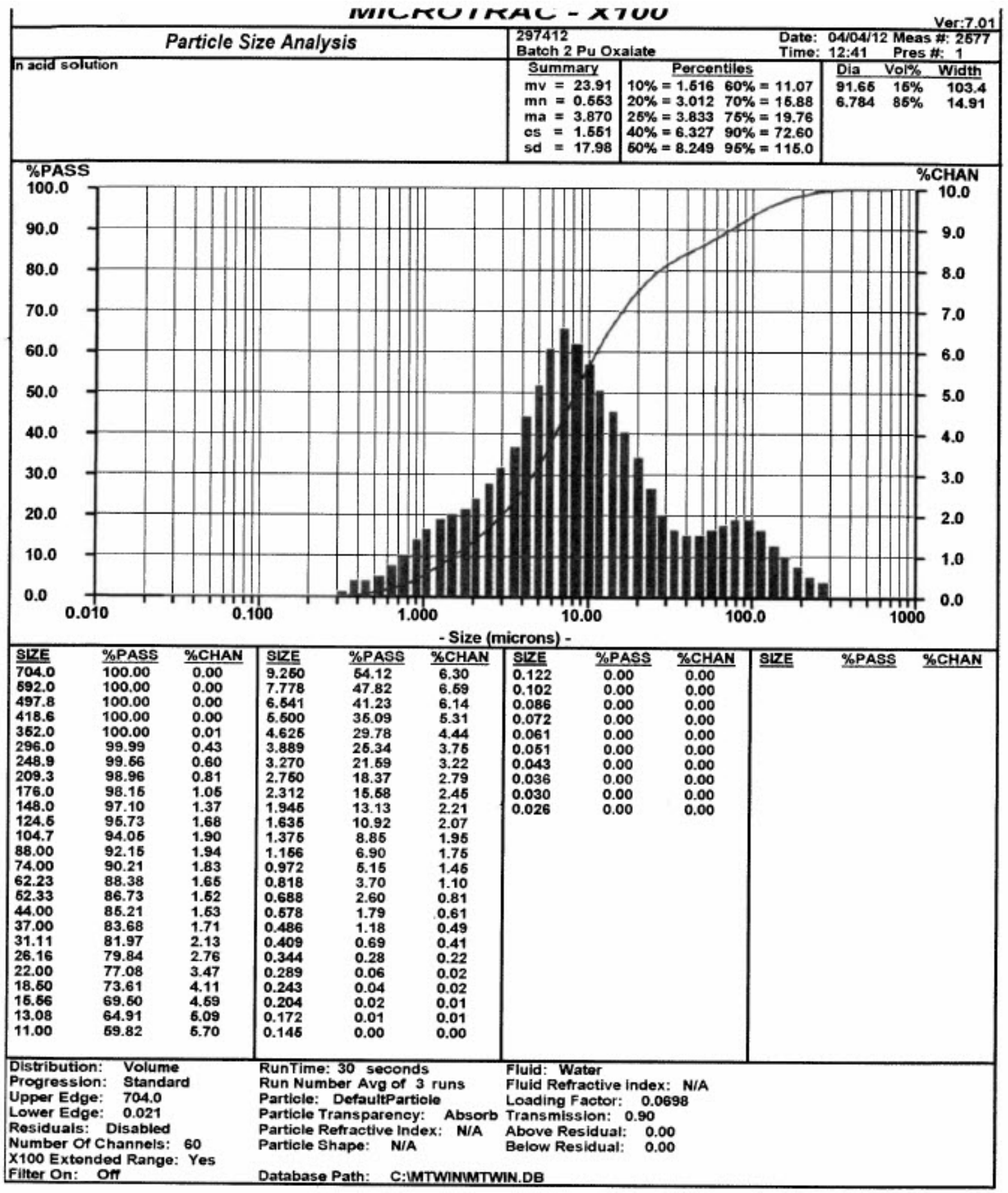

Figure C-8. Particle Size Analysis for Batch 2 Pu Oxalate 


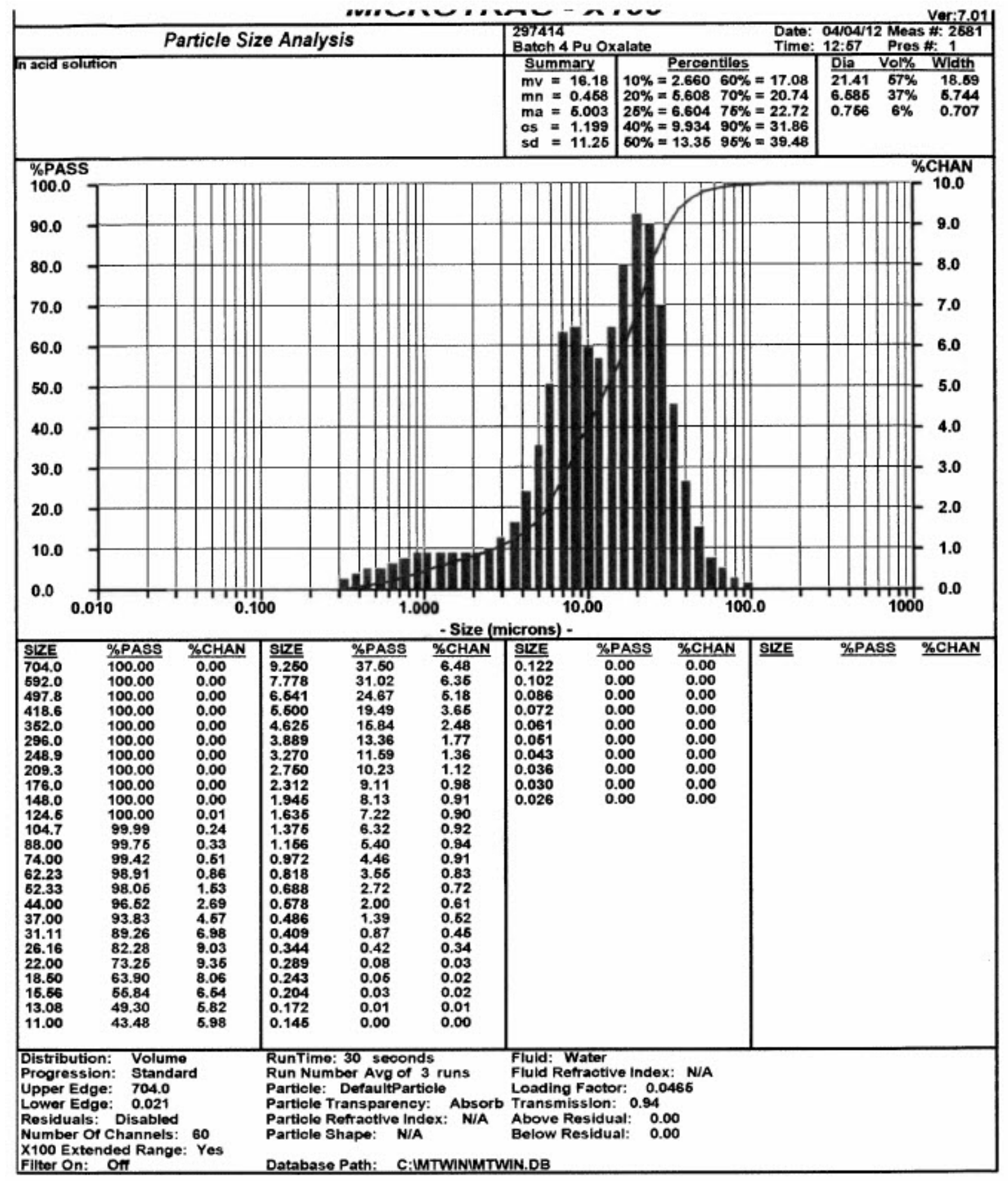

Figure C-9. Particle Size Analysis for Batch 4 Pu Oxalate 


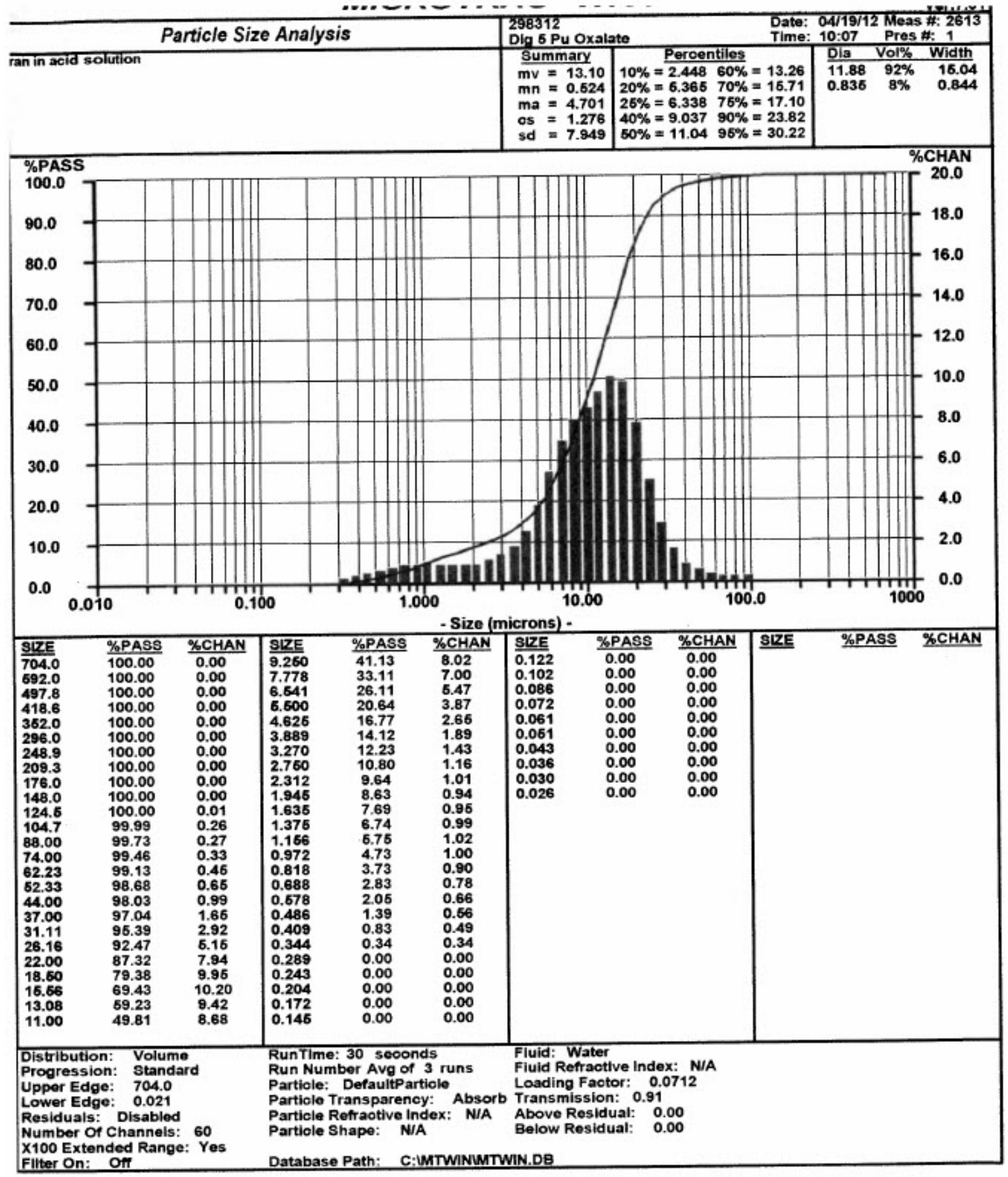

Figure C-10. Particle Size Analysis for Batch D5 Pu Oxalate 


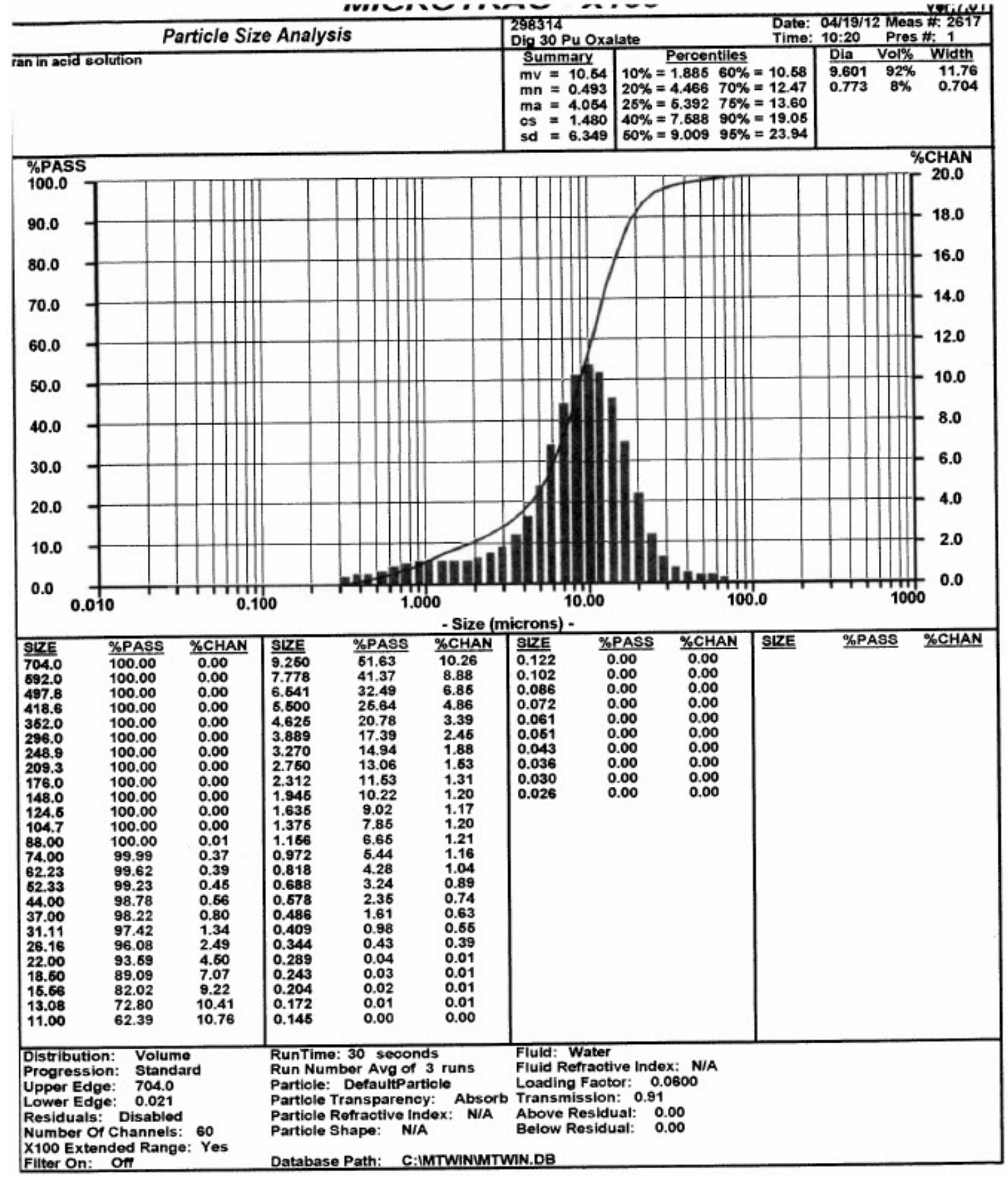

Figure C-11. Particle Size Analysis for Batch D30 Pu Oxalate 


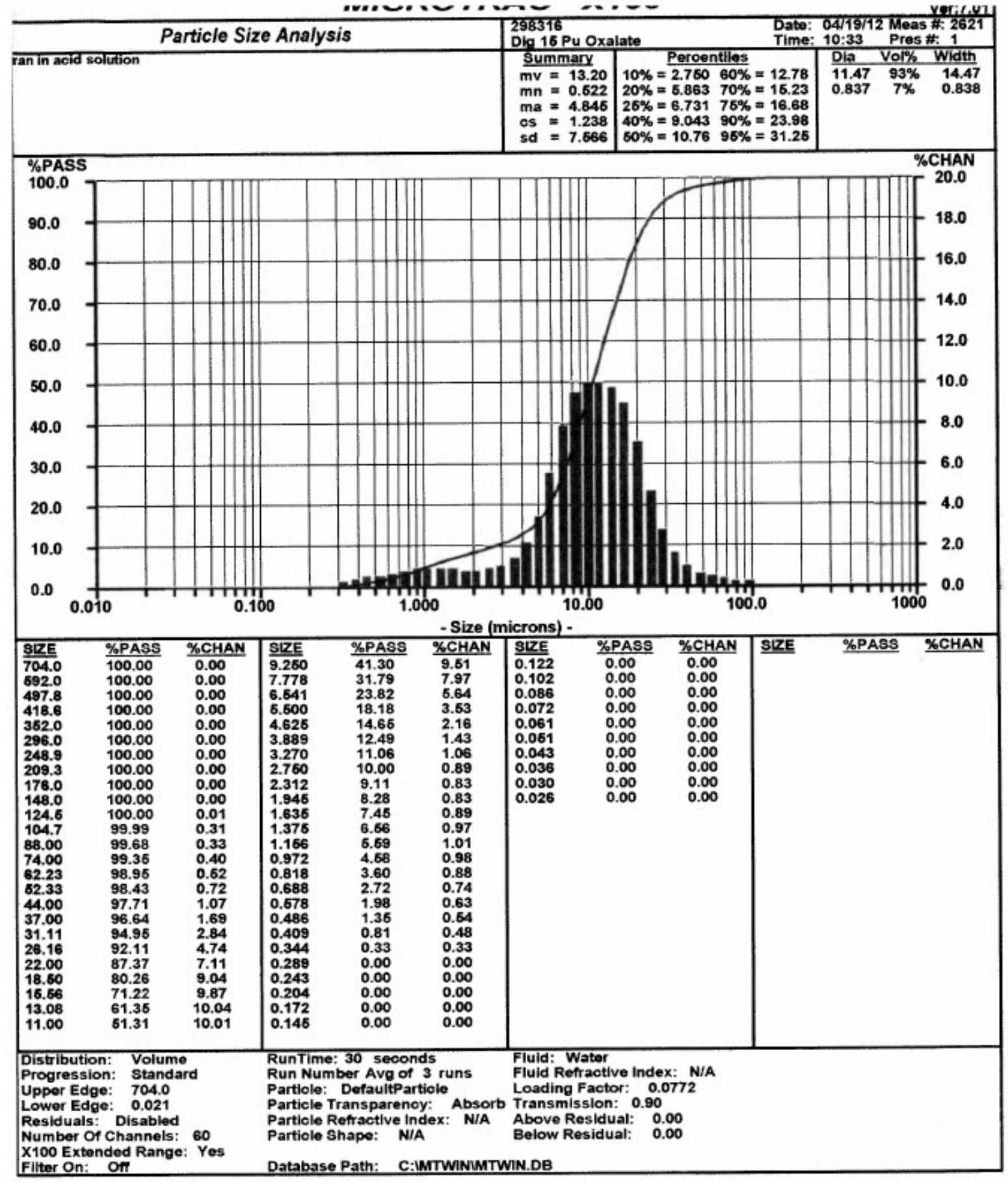

Figure C-12. Particle Size Analysis for Batch D15 Pu Oxalate 


\section{Distribution:}

S. D. Fink, 773-A

K. M. Fox, 999-W

B. J. Giddings, 786-5A

C. C. Herman, 999-W

S. L. Marra, 773-A

F. M. Pennebaker, 773-42A

W. R. Wilmarth, 773-A

E. A. Kyser, 773-A

T. S. Rudisill, 773-A

R. A. Pierce, 773-A

J. H. Scogin, 773-A

M. C. Thompson, 773-A

W. E. Daniel, 999-W

W. D. King, 773-42A

C. A. Nash, 773-42A

M. L. Crowder, 773-A

K. M. L. Taylor-Pashow, 773-A

Records Administration (EDWS)
W. E. Harris, 704-2H

J. B. Schaade, 704-2H

G. J. Zachman, 225-7H

P. B. Andrews, 704-2H

S. J. Howell, 221-H

W. G. Dyer, 704-2H

M. J. Swain, 703-H

M. J. Lewczyk, 221-H

J. L. O’Conner, 704-2H

S. L. Hudlow, 221-H

W. H. Clifton, 704-2H

K. P. Burrows, 704-2H

K. J. Gallahue, 221-H

J. E. Therrell, 704-2H

J. W. Christopher, 704-2H

R. H. Smith, 704-2H

R. R. Livingston, 730-2B

D. Stimac, 730-2B

S. A. Thomas, 703-46A

C. Wilson, 773-A 